\title{
Spectroscopy of southern Galactic disk planetary nebulae
}

\section{Notes on chemical composition and emission-line stars ${ }^{\star}, \star$}

\begin{abstract}
S. K. Górny
N. Copernicus Astronomical Center, Rabiańska 8, 87-100 Toruń, Poland

e-mail: skg@ncac.torun.pl

Received 5 June 2013 / Accepted 1 June 2014

ABSTRACT

Aims. We present low resolution spectroscopic observations for a sample of 53 planetary nebulae (PNe) located in the southern sky between Vela and Norma constellations and pertaining to the Galactic disk with expected Galactocentric distance range of 5 to $10 \mathrm{kpc}$.

Methods. We derive nebular chemical composition and plasma parameters with the classical empirical method. For most of the observed objects, this has been done for the first time. We compare our results to published data for PNe of the Galactic bulge and $\mathrm{PNe}$ in the inner-disk region with expected typical Galactocentric distance of about $3 \mathrm{kpc}$. We use the spectra to search for emissionline central stars in the observed sample.

Results. The distributions of the chemical abundances of the observed disk sample are generally indistinguishable from Galactic bulge and inner-disk PNe populations. The exceptions are possible differences in the $\mathrm{He} / \mathrm{H}$ distribution, as compared to bulge PNe and $\mathrm{Ne} / \mathrm{Ar}$, as compared to the inner-disk PNe sample. The derived $\mathrm{O} / \mathrm{H}$ ratios for the observed disk PNe fit to the concept of flattening of the chemical gradient in the inner parts of the Milky Way. Investigating the spectra, we found six new emission-line central stars comprising examples of all known types: WEL, VL, and [WR]. We confirm that these types represent three evolutionary unconnected forms of enhanced mass-loss in the central stars of PNe. We note on the problem of high ionisation PNe with nebular C IV emission that can mimic the presence of WEL central stars in 1D spectra.
\end{abstract}

Key words. planetary nebulae: general - Galaxy: abundances - stars: Wolf-Rayet

\section{Introduction}

Planetary nebulae (PNe) are a very short evolutionary phase in the life of low- and intermediate-mass stars $\left(0.8-8 M_{\odot}\right)$ that occur after they leave the asymptotic giant branch (AGB) and before they end their lives as white dwarfs (Iben 1995). During the AGB and in particular, at the tip of this phase of evolution, stars experience strong winds that efficiently enrich the surrounding interstellar medium with huge amounts of gas, dust, and molecules from the outer layers of the star (e.g., Herwig 2005). When mass loss stops, these stars leave the AGB and rapidly increase their effective temperatures preserving a roughly constant luminosity. When the ionisation of the ejected gas by the central star becomes possible, a new PN emerges composed of the matter formerly expelled from the progenitor.

A better knowledge of the PNe phase is necessary for understanding the final fate of stars like the Sun but also to study the formation and the chemical evolution of the Milky Way and other galaxies. The PNe have several properties that make them very good tools in this respect. They are good indicators of the chemical composition of the interstellar matter from which the progenitor stars were born (see, e.g., Chiappini et al. 2009). Due to the wide mass range of their progenitors, the PNe that we now observe have been created by stars that formed at very

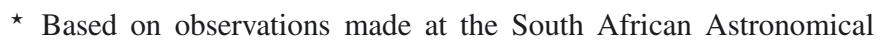
Observatory.

$\star \star$ Appendices are available in electronic form at http://www. aanda.org different epochs. In addition, their narrow emission-line nature makes them observable at very large distances.

Thanks to a considerable effort, hundreds of new PNe have been discovered in the Milky Way in the last two decades (for a review see Parker \& Frew 2011). However, published analysis based on the observed PNe properties still frequently use limited and biased samples. The first observing bias is the natural condition that the most easily accessible objects (brightest or simply near-by) are first to be observed and analysed. Even if a substantial number of such data is collected, it does not necessarily mean they properly represent the PNe population across the Galaxy.

The problem that observational selection effects have to be properly taken into account has been underlined many times in the past (e.g., Stasińska \& Tylenda 1994). Nevertheless, they can remain one of the major concerns, while investigating the abundance gradients in the Milky Way. By analysing the samples collected by different authors, it can be noted that they are often dominated by the relatively close objects.

In some cases, selection effects may appear unexpectedly. For example, Górny et al. (2009) reported that Wolf-Rayet (WR) type central stars are probably related to the intrinsically brightest $\mathrm{PNe}$ in a given population. The reason for this is unknown. It is important here that this property remained unnoticed until a dedicated, sufficiently deep search of new [WR] objects was undertaken that also incorporated the fainter Galactic bulge PNe.

For this reason, we think it is still necessary to collect new observational data to further minimise the presence and influence of selection effects in PNe related studies. In this paper, we present low resolution optical spectroscopic observations 


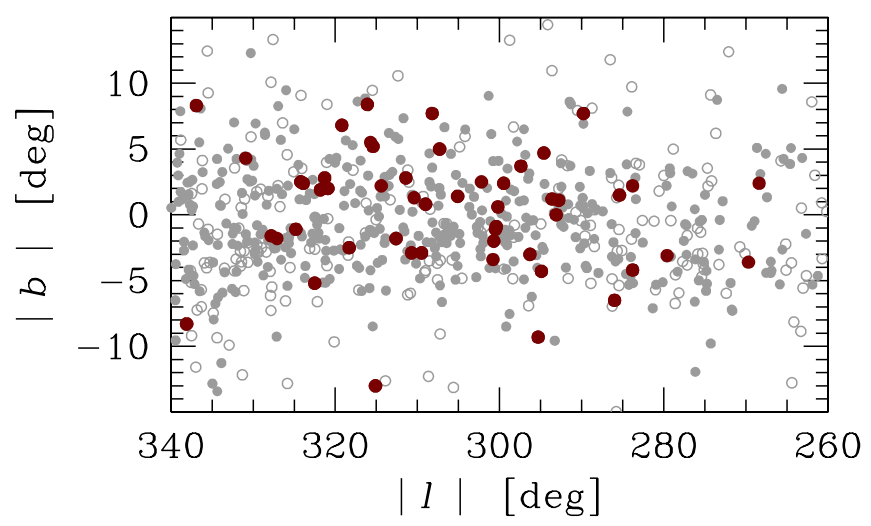

Fig. 1. Distribution of the observed PNe on the sky in Galactic coordinates, dark circles. Open grey circles mark other PNe catalogued by Acker et al. (1992) and filled grey circles PNe from Parker et al. (2006) and Miszalski et al. (2008).

of 53 PNe that are located in the southern sky between Vela and Norma constellations with an expected Galactocentric distance range of 5 to $10 \mathrm{kpc}$. The sample and observations are described in Sect. 2. The results of the search for new emission-line central stars is presented in Sect. 3. In Sect. 4, we derive the chemical composition of the observed $\mathrm{PNe}$ and compare them briefly with abundance distributions for Galactic bulge and inner-disk PNe populations. The main results of this work are summarised in Sect. 5.

\section{Low resolution optical spectra}

\subsection{Observations and data reduction}

We present observations of $53 \mathrm{PNe}$ that are located near the plane of the Milky Way disk with Galactic longitude from $l=260^{\circ}$ to $340^{\circ}$. Their on-sky distribution is presented in Fig. 1. Spectra of these objects were secured with the 1.9-m telescope of the South African Astronomical Observatory in April 2003, May 2004, June 2005, and May 2006 as an auxiliary program during observing runs dedicated to the search of new small PNe towards the Galactic bulge (Górny 2006) when that part of the sky was not accessible. No strict selection criteria were employed to choose the targets; however, objects not listed in large surveys like de Freitas Pacheco et al. (1991), de Freitas Pacheco et al. (1992), Kingsburgh \& Barlow (1994), Cuisinier et al. (1996), Milingo et al. (2002), Kwitter et al. (2003) were preferred and, therefore, we have only 13 sources in common with these authors. Some additional preference was given to $\mathrm{PNe}$ with an unknown type of the central star and without information on measured stellar flux. Three additional PNe with Spitzer spectra were observed in April 2011.

In Fig. 2 we present the distribution of total apparent nebular $\mathrm{H} \beta$ fluxes for our observed sample, as seen in the dark hatched bars. We compare them to the distribution for the PNe located in the same direction of the sky and presented in above mentioned papers or included in more recent papers, such as Cavichia et al. (2010), Henry et al. (2010), Milingo et al. (2010). For a reference, the remaining PNe of this region from Strasbourg-ESO Catalogue of Acker et al. (1992) are shown. As a result of our selection approach, the sample we observed is composed of fainter $\mathrm{PNe}$. Our targets were also smaller. The median diameter of PNe we observed was about 8 arcsec, whereas the PNe included in other papers had a median diameter of $10 \mathrm{arcsec}$, as compared to almost 16 arcsec for a general $\mathrm{PNe}$ population in that region (238 PNe from Acker et al. 1992).
In Table 1, the detailed log of observations is presented. The PNe are identified by their PNG identifier (Galactic coordinates) and usual names. The typical spectral coverage was 3500-7400 $\AA$ with an average resolution of 1000 which allows for detection of all important nebular lines without serious blending. The slit width was usually set to $1.8 \mathrm{arcsec}$, which is slightly larger than the typical seeing conditions at the site. The slit orientation was always E-W, and it was positioned directly on the central star if it could be identified or roughly at the geometrical centre of the nebula. The CCD was read with a $1 \times 2$ prebinning in the spatial direction, which is along the slit. The slit width and its orientation could in principle lead to some loss of the stellar light due to seeing variations and differential atmospheric refraction. The latter effect could have influence on relative line ratios for the smallest observed PNe. To avoid this, we tried to observe all objects at their minimum air-masses. Their values are given in Col. 5 of Table 1.

The integration time of the observations varied from 20 to $90 \mathrm{~min}$ and was divided into two or three sub-exposures. In many cases, additional shorter exposure lasting from $3 \mathrm{~min}$ to only $15 \mathrm{~s}$ were executed to ensure unsaturated detection of the strongest lines: $\mathrm{H} \alpha$, [O III] $\lambda 5007$, and/or [N II] $\lambda 6583$.

Each night, at least two different spectroscopic standard stars were observed (LTT 3218, LTT3864, LTT4364, LTT 7987, LTT 9239 CD -32 or Eg 274). Since no order blocking filters were used, some contamination to the red light of the standard stars is possible from the second order blue continuum. The spectrograph was, however, characterised by a general low sensitivity to blue light. We checked during tests in 2011 and 2012 with the same instrument and configuration for stars, LTT 3218 and $\mathrm{CD}-32$, that contamination was adding only up to $4 \%$ of additional light at $7600 \AA$. The effect was linear in wavelength (from about $6000 \AA$ upward) but would sometimes disappear depending on the sky conditions of a given night. We have therefore not corrected the measured lines for this effect. In practise, its influences for our PNe would be measurable only for [O II] $\lambda 7325$ doublet adding some additional uncertainty to its measurements ${ }^{1}$.

We used the long-slit package procedures of ESO-MIDAS ${ }^{2}$ to reduce and calibrate the spectra. These included bias subtraction, flat-field correction, atmospheric extinction correction, wavelength, and flux calibration and extraction of the 1-dimensional spectra. For the standard stars and most of the observed PNe, this was done in the usual manner by summing the appropriate rows of the sky subtracted frames. In the case of some PNe, in particular, those located close to the Galactic plane in crowded fields a multi-step method similar to the one described in Górny et al. (2009) had to be applied. In this method before extracting 1D spectra, all the background sources have to be removed. This includes not only sky continuum emission and telluric and interstellar lines but also stellar continua, including that of the PN central star. Intensities of the nebular lines were finally measured from the 1-dimensional spectra by employing the REWIA package ${ }^{3}$, assuming Gaussian profiles and performing multi-Gaussian fits when necessary.

\footnotetext{
1 We anyway correct $\lambda 7320 / 30$ lines to measurements of their blue counterpart [O II] $\lambda 3725$ - see in Sect. 4.

2 ESO-MIDAS is developed and maintained by the European Southern Observatory http://www. eso.org/sci/software/esomidas/

3 REWIA is a data processing program developed by Borkowski at Copernicus Astronomical Center http://www.ncac.torun.pl/ jubork/rewia/
} 
Table 1. Log of observations.

\begin{tabular}{|c|c|c|c|c|c|}
\hline$\overline{\mathrm{PNG}}$ & Name & Year & $\overline{E \text { Exp }}$ & $\overline{\bar{Z}}$ & $\overline{\text { Diam }}$ \\
\hline $268.4+02.4$ & PB 5 & 2004 & 3600 & 1.10 & 1.6 \\
\hline 269.7-03.6 & PB 3 & 2003 & 900 & 1.06 & 7.0 \\
\hline 279.6-03.1 & He 2-36 & 2004 & 1800 & 1.11 & 19.5 \\
\hline $283.8+02.2$ & Мy 60 & 2006 & 1800 & 1.17 & 8.0 \\
\hline 283.8-04.2 & He 2-39 & 2006 & 1800 & 1.19 & 12.3 \\
\hline $285.4+01.5$ & Pe 1-1 & 2004 & 2400 & 1.14 & 3.0 \\
\hline $286.0-06.5$ & He 2-41 & 2011 & 2400 & 1.24 & st. \\
\hline $289.8+07.7$ & He 2-63 & 2011 & 2400 & 1.09 & 2.9 \\
\hline $291.4+19.2$ & ESO $320-28$ & 2004 & 5400 & 1.02 & 28.8 \\
\hline $292.8+01.1$ & He 2-67 & 2003 & 1800 & 1.20 & 3.6 \\
\hline 293.1-00.0 & BMPJ1128-61 & 2005 & 2700 & 1.19 & 0.1 \\
\hline $293.6+01.2$ & He 2-70 & 2003 & 1500 & 1.13 & 21.7 \\
\hline $294.6+04.7$ & NGC 3918 & 2004 & 2400 & 1.11 & 17.9 \\
\hline 294.9-04.3 & He 2-68 & 2004 & 2400 & 1.25 & 2.5 \\
\hline 295.3-09.3 & He 2-62 & 2006 & 1200 & 1.29 & st. \\
\hline 296.3-03.0 & He 2-73 & 2005 & 2400 & 1.21 & 2.9 \\
\hline $297.4+03.7$ & He 2-78 & 2003 & 900 & 1.12 & 3.5 \\
\hline $299.0+18.4$ & K 1-23 & 2004 & 3600 & 1.03 & 60.2 \\
\hline $299.5+02.4$ & He 2-82 & 2003 & 1200 & 1.13 & 28.4 \\
\hline $300.2+00.6$ & He 2-83 & 2004 & 2400 & 1.15 & 4.6 \\
\hline $300.4-00.9$ & He 2-84 & 2004 & 1800 & 1.18 & 29.1 \\
\hline $300.5-01.1$ & He 2-85 & 2003 & 2700 & 1.18 & 8.5 \\
\hline $300.7-02.0$ & He 2-86 & 2004 & 2400 & 1.19 & 3.2 \\
\hline $300.8-03.4$ & ESO 095-12 & 2006 & 3600 & 1.21 & 18.0 \\
\hline $302.2+02.5$ & Wray $16-120$ & 2005 & 1200 & 1.14 & 12.0 \\
\hline $305.1+01.4$ & He 2-90 & 2003 & 1620 & 1.14 & 3.1 \\
\hline $307.3+05.0$ & Wray $16-128$ & 2004 & 3600 & 1.11 & 18.0 \\
\hline $308.2+07.7$ & MeWe 1-3 & 2004 & 5400 & 1.11 & 18.0 \\
\hline $309.0+00.8$ & He 2-96 & 2006 & 1050 & 1.15 & 2.8 \\
\hline $309.5-02.9$ & MaC 1-2 & 2011 & 3600 & 1.19 & st. \\
\hline $310.4+01.3$ & Vo 4 & 2003 & 1800 & 1.14 & 8.0 \\
\hline $310.7-02.9$ & He 2-103 & 2003 & 1680 & 1.19 & 21.5 \\
\hline $311.4+02.8$ & He 2-102 & 2004 & 2400 & 1.12 & 11.5 \\
\hline $312.6-01.8$ & He 2-107 & 2004 & 2400 & 1.17 & 9.4 \\
\hline $314.4+02.2$ & PM 1-81 & 2004 & 1800 & 1.12 & 4.7 \\
\hline $315.1-13.0$ & He 2-131 & 2004 & 1200 & 1.30 & 9.8 \\
\hline $315.4+05.2$ & He 2-109 & 2004 & 2400 & 1.09 & 9.1 \\
\hline $315.7+05.5$ & LoTr 8 & 2005 & 1200 & 1.09 & 26.7 \\
\hline $316.1+08.4$ & He 2-108 & 2004 & 2400 & 1.07 & 12.9 \\
\hline $318.3-02.5$ & He $2-116$ & 2004 & 2400 & 1.15 & 47.3 \\
\hline $319.2+06.8$ & He $2-112$ & 2004 & 3600 & 1.07 & 6.6 \\
\hline $320.9+02.0$ & He 2-117 & 2004 & 2400 & 1.10 & 4.9 \\
\hline $321.3+02.8$ & He $2-115$ & 2005 & 2400 & 1.09 & 2.9 \\
\hline $321.8+01.9$ & He $2-120$ & 2006 & 3600 & 1.10 & 30.9 \\
\hline $322.5-05.2$ & NGC 5979 & 2004 & 2400 & 1.14 & 19.6 \\
\hline $323.9+02.4$ & He $2-123$ & 2005 & 2400 & 1.11 & 6.7 \\
\hline $324.2+02.5$ & He $2-125$ & 2006 & 2700 & 1.14 & 3.3 \\
\hline $324.8-01.1$ & He 2-133 & 2004 & 1800 & 1.10 & 1.8 \\
\hline $327.1-01.8$ & He $2-140$ & 2005 & 2100 & 1.14 & 4.1 \\
\hline $327.8-01.6$ & He $2-143$ & 2004 & 2400 & 1.10 & 3.7 \\
\hline $330.9+04.3$ & Wray 16-189 & 2005 & 1800 & 1.04 & 15.0 \\
\hline $336.9+08.3$ & StWr 4-10 & 2006 & 2100 & 1.07 & st. \\
\hline $338.1-08.3$ & NGC 6326 & 2004 & 2400 & 1.06 & 16.8 \\
\hline
\end{tabular}

Notes. Columns: PN G numbers, usual names, year of the observation, exposure time in seconds; mean airmass during observation, and nebular diameter in arcsec.

The line intensities have been corrected for extinction by adopting the extinction law of Seaton (1979) to reproduce the theoretical case B of Balmer line ratios at the electron temperature and density derived for the object. The same iterative procedure, as the one described in Górny et al. (2009), was applied using the measured $\mathrm{H} \alpha / \mathrm{H} \beta$ ratio. As a result the procedure was usually not giving the theoretically expected ratios of $\mathrm{H} \gamma / \mathrm{H} \beta$

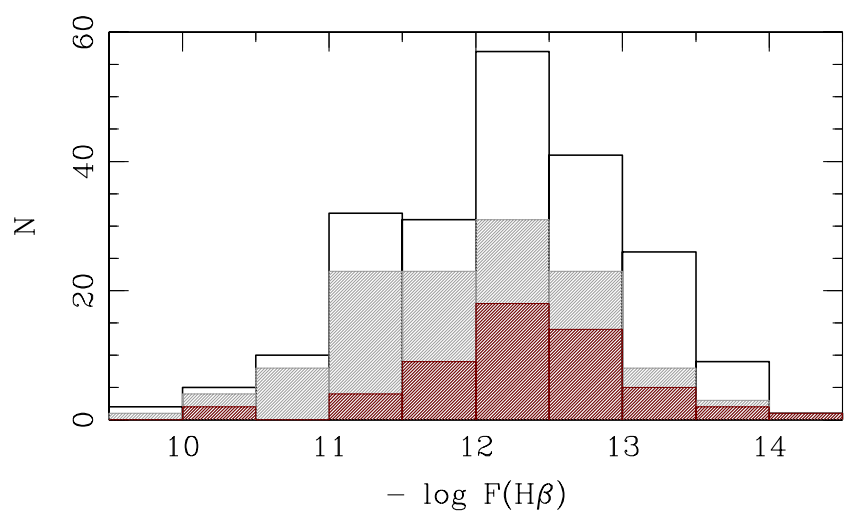

Fig. 2. Distribution of the nebular $F(\mathrm{H} \beta)$ fluxes for PNe observed in this work, dark hatched bars; PNe included in other large spectroscopic surveys (see text for the references) - grey hatched bars; and other PNe from Acker et al. (1992), as open bars.

and/or $\mathrm{H} \delta / \mathrm{H} \beta$. This can be due to deviations from the adopted extinction law for individual PNe or higher uncertainty of flux calibration in the blue part of the spectra. If the deviations in $\mathrm{H} \delta$ and/or $\mathrm{H} \gamma$ were systematical in one direction and larger than expected from purely observational uncertainties, we applied an additional correction procedure (Górny et al. 2009) to bring the $\mathrm{H} \gamma / \mathrm{H} \beta$ and $\mathrm{H} \delta / \mathrm{H} \beta$ ratios to their theoretically expected values. The correction factors typically amounted to $7 \%$ and $11 \%$ for $\mathrm{H} \gamma$ and $\mathrm{H} \delta$ lines, respectively. A proportional wavelength dependent correction was than applied to all the nearby lines, including the important [O III] $\lambda 4363$ and [O II] $\lambda 3727$ lines, to secure that they are properly reddening corrected.

In Table B.1 we present the measured and dereddened intensities of all important nebular lines on the scale of $\mathrm{H} \beta=100$ for the observed PNe. In cases when the additional correction described above was necessary, the lines are marked with " $\mathrm{c}$ " in Table B.1.

\subsection{Quality of the data}

Figure 4 presents intensity ratios of the [O III] doublet lines $\lambda 5007$ and $\lambda 4959$ for the observed objects. The mean value for this sample is marked with a dashed line in Fig. 4, and the 5\% deviations from it are marked with dotted lines. The $\lambda 5007$ to $\lambda 4959$ ratio should be practically constant for all PNe, therefore, the observed deviations can be regarded as the evidence of the quality of the registered spectra. Since the [O III] $\lambda 5007$ line is usually one of the brightest in the PN spectrum, it often saturates during long exposures. Therefore its measured value comes usually from an additional short exposure. It is of some difficulty to precisely relate the measured value to the other much fainter lines. In the ratio shown in Fig. 4, the larger source of error is indeed measurements of the $\lambda 4959$ line. This line is three times fainter than the $\lambda 5007$, but both lines had to be measured from the snapshot spectra. From the deviations of the intensity ratio plotted in Fig. 4, the accuracy of the $\lambda 4959$ line can be estimated to be typically better than $5 \%$ for most of cases.

Similar exercises can be performed for the [N II] doublet of $\lambda 6583$ and $\lambda 6548$ lines at wavelengths considerably further to the red. Their measured ratios are displayed in Fig. 5. Analogous conditions to the described above apply to this doublet but an additional disturbing factor can be the strong $\mathrm{H} \alpha$ line separating them. It can be seen in Fig. 5 that the majority of the observed ratios are well confined between the $5 \%$ deviations. There are, however, some outliers, in particular, for cases when 

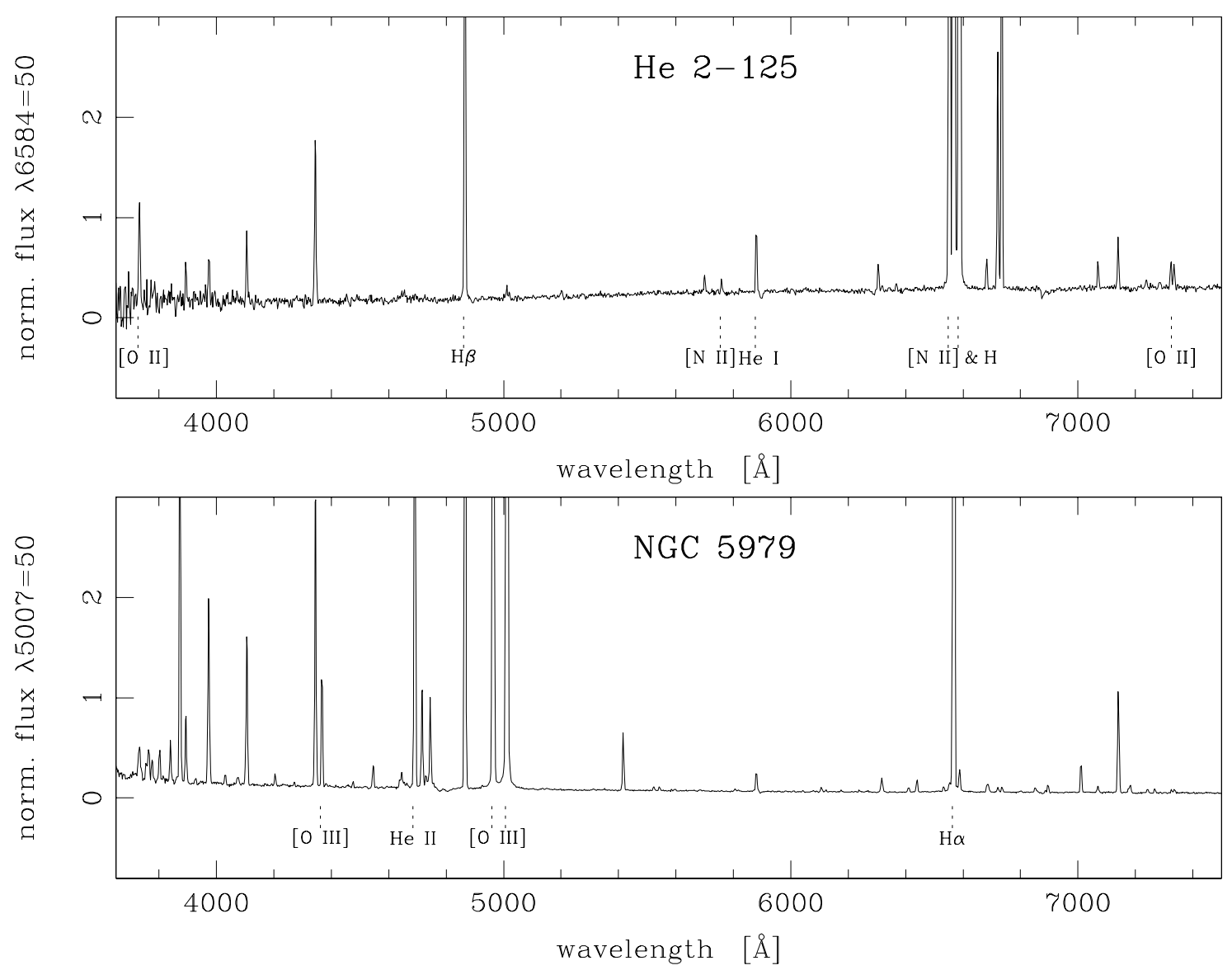

Fig. 3. Illustrative examples of the acquired spectra of low ionisation planetary nebula (top panel) and a high ionisation nebula (bottom panel) in our observing programme.

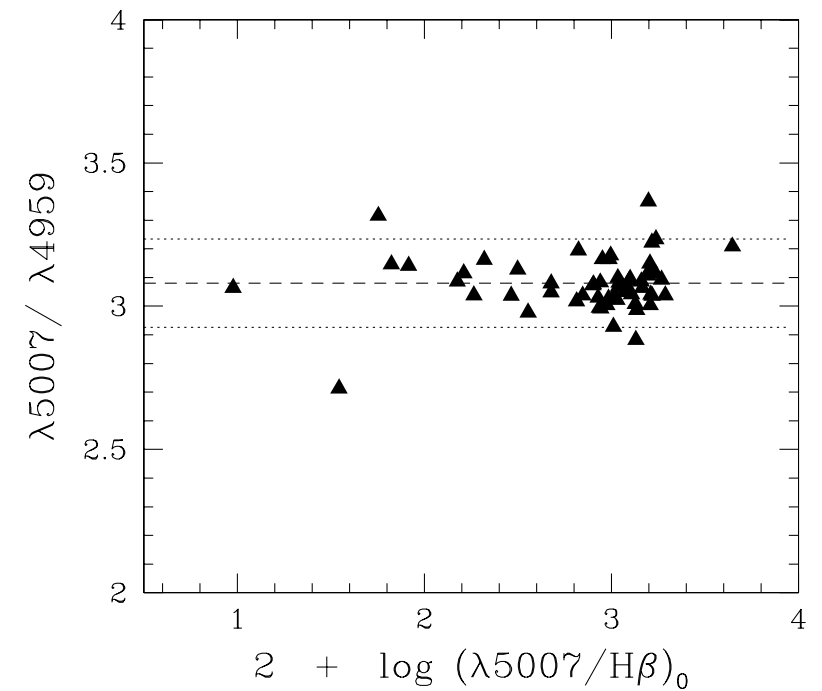

Fig. 4. Intensity ratio of the $[\mathrm{O} \mathrm{III}] \lambda 5007$ to $\lambda 4959$ lines as the function of the flux of [O III] $\lambda 5007$ (in units of $\mathrm{H} \beta$ ). The dashed line represents mean value for the presented observations, and the dotted lines are $5 \%$ deviations from it.

[N II] lines are fainter, and it can be noted that the intensity of the $\lambda 6548$ line is apparently overestimated. Indeed, this is possible when a stronger blending with nearby prominent $\mathrm{H} \alpha$ line takes place. However, this has to be a very minor effect on our results,

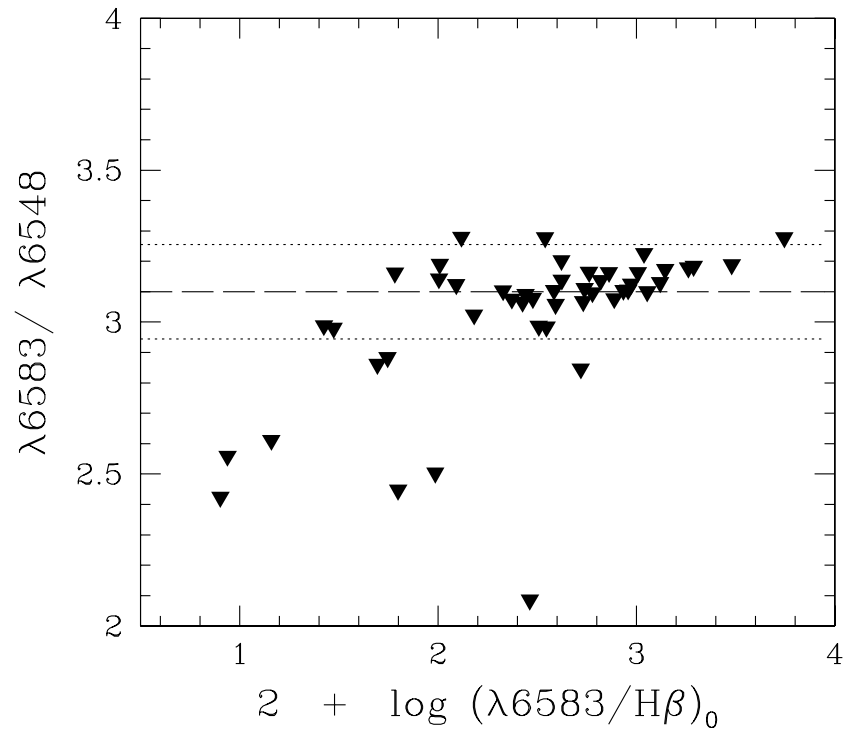

Fig. 5. Intensity ratio of the $[\mathrm{N}$ II] $\lambda 6583$ to $\lambda 6548$ lines as the function of the flux of [N II] $\lambda 6548$ (in units of $\mathrm{H} \beta$ ). The long dashed line represents median value for the presented observations, and the dotted lines are $5 \%$ deviations from it.

since [N II] $\lambda 6548$ line is not used for calculations of nitrogen abundances.

An independent test of the quality of observations can be reached through a comparison with other observers. However, 
since selecting the targets, we were trying to avoid objects already present in large spectroscopic surveys of the Galactic disk $\mathrm{PNe}$, the existing duplicates with other authors are not as numerous and distributed through several different references. We found instead that our list of targets has 11 objects in common with Dopita \& Hua (1997), who measured absolute fluxes of selected lines for a large sample of southern sky PNe. In Appendix A, we present and discuss the comparison of our measurements with those of Dopita \& Hua (1997).

As a result of all above mentioned evaluations, we conclude that the basic accuracy of all the line measurements from our spectra can be adopted as roughly $5 \%$. In cases marked with a colon in Table B.1, the uncertainty is estimated around $20 \%$, and in the rare cases of extremely weak lines or lines contaminated with sky features or field stars (marked with semicolon), this can be as high as $40 \%$.

\section{Search for PNe with emisssion-line stars}

\subsection{New and reclassified objects}

A large fraction of PNe exhibit emission-line central stars (CSs). As can be inferred from the work of Weidmann \& Gamen (2011b), they compose about one third of PNe with classified CSs. Two main types of emission-line central stars are widely recognised in the literature (Tylenda et al. 1993): the Wolf-Rayet type central stars ([WR]) and weak emission-line CSs (WELs). The spectra of the first group closely resemble those of the genuine massive population I Wolf-Rayet stars of the WC spectral subclass with strong and wide emissions of $\mathrm{C}$, $\mathrm{O}$, and He. The WELs seem to be a less homogeneous group with usually only narrow and much fainter C IV doublet $\lambda 5801 / 12$. Recently, the existence of a separate third group of $\mathrm{PNe}$ with emission-line central stars has been proposed by Górny et al. (2009), who investigated a large sample of PNe in the Galactic bulge and innerdisk region. This new class of CSs was named VL or very late type and was found in the low ionisation PNe with a stellar spectra represented by C III and C II emission lines, but, again narrow and less strong. In the classical scheme, they could be assigned to [WC 11] subtype. The sample of PNe analysed in the present work gave us the possibility to check if VL type of objects are also present among Galactic disk PNe.

We used our acquired data to search for new emission-line CSs. We checked our reduced 2D and integrated 1D spectra for the presence of characteristic emission-lines utilised for the spectral classification as listed in Górny et al. (2004) and the compound of $\mathrm{C}$ and $\mathrm{N}$ lines around $4650 \AA$, which is usually associated with the WELs type objects (Tylenda et al. 1993).

We have found three new WELs, two new [WR]-type, and one new VLPNe. The spectra of the new WELs PNe are presented in Fig. C.1 and of the new [WR] and VL type objects in Fig. C.2. In both figures, the expected locations of the characteristic emission lines are indicated with dotted lines, and if positively identified, they are marked with the ion name of their origin.

In addition, we also registered stellar emission lines in almost all cases when the previous emission-line classification already existed (Weidmann \& Gamen 2011b). The only exception was He 2-63, which is probably due to the short exposure time of our observation and the NGC 5979 that turned out not to be a true but a mimic of a WEL object (see below). We hereby confirmed the [WR]-type nature of two CSs but reclassified three other objects to be a VL-type PNe. In Fig. C.3, we present spectra of the reobserved and confirmed $\mathrm{PNe}$ with previously known emissionline CSs.

In Table B. 2 we present a complete list of new and previously known emission-line CSs that are present among PNe from our observing list. In the first column we give their usual names. In Col. 2, the full width at half maximum of the main stellar emission line is presented but only if it was exceeding the instrumental width. In practise, these measurements in Table B.2 are always referring to CIV $\lambda 5805$, since in the cases that the C III $\lambda 5695$ line was present, it was of the same width as the nebular lines. In Col. 3, we give our classifications of the central star. We tried to use the standard classification framework, as in Górny et al. (2004, 2009), which are based on ratios of intensities of the main emission features of the $\mathrm{C}$ and $\mathrm{O}$ ions. In practise, however, only single lines of C IV or C III were present in analysed spectra. In Col. 5, previous classification from the compilation of Weidmann \& Gamen (2011b) is given.

We were able to positively or tentatively recognise the presence of the stellar continuum of the central star in about $83 \%$ of our spectra. Although this is not a necessary condition for the prominent features of [WR]-type objects to be discovered nevertheless, in particular for the WELs, the stellar emissionlines should be detectable if the stellar continuum is observed. We, therefore, assume that the list of PNe with emission-line CSs presented in Table B.2 is probably complete in the same proportion.

\subsection{Notes on individual PNe}

Objects PB 5, My 60, and He 2-115, whose spectra are shown in Fig. C.1 present good examples of WELs PNe, as defined by Tylenda et al. (1993). The C IV lines at $\lambda 5801 / 12$ are visible as separate doublet components and are much fainter and narrower than in the case of [WR] PNe. Other lines often associated with WELs, such as $\lambda 7235$ and some elements of the $\lambda 4650$ aggregate, are also present. The same situation can be observed in the case of He 2-123, whose spectra is shown in Fig. C.3 and was already classified as WEL by Lee et al. (2007)

He 2-67 and He 2-117 are two PNe discovered in our spectra to posses classical broad emission structures of C IV at $\lambda 5805$. No other emission lines of C III or oxygen ions used in the classical classification scheme can be seen. For this reason, we use the FWHM of the CIV line as an additional classification parameter and following suggestions of Acker \& Neiner (2003), we tentatively classify He 2-67 as a [WC 4] and He 2-117 as a [WC 5-6] objects. In the latter case, we reject the possibility that the star is of an even earlier subclass, since no trace of C III $\lambda 5695$ line is seen in our spectra.

The object Pe 1-1 has been classified by Acker \& Neiner (2003) in their modified scheme as [WO 4]. Their spectrum was apparently of better quality than ours since it was acquired with the $3.6 \mathrm{~m}$ telescope, and they were able to measure both C IV $\lambda 5805$ feature and the O V $\lambda 5590$ line. The intensity of the latter is at about $1 / 10$ of $\lambda 5805$, according to Acker \& Neiner (2003) but could not be identified in our spectra. Using their measurements, we would classify that object in the pure classical scheme of [WC] classes as [WC 4-5]. It can be added that the measured FWHM of C IV line would also place it as a rather late [WO 4] class in the Acker \& Neiner (2003) scheme. The nebula of Pe 1-1 was recently analysed with an actually deeper high resolution spectra by García-Rojas et al. (2012).

The object He 2-86 has been classified by Acker \& Neiner (2003) as [WC 4]. They registered broad stellar C IV 5805 and He II 4686 features and C III at $\lambda 4649$. While the former two are 
clearly visible in our spectra (see in Fig. C.3), the latter seems to be a compound of much narrower, and, therefore, probably nebular recombination lines. Taking the width of the C IV line of $22 \AA$ (Acker \& Neiner 2003, derived a similar value) into account, this object should be classified as [WC5-6].

The spectrum of He 2-125 presented in Fig. C.2 clearly shows two stellar emission lines of carbon: C III at $\lambda 5695$ and C II at $\lambda 7235$. The intensity ratio of the two lines is about 1.6, which is half of what is predicted for [WC 11] objects, according to the classification criteria. However, it fits well the definition of VL type PNe, since the central star is surrounded by a very low ionisation nebula, with only a trace of [O III] $\lambda 5007$ line detectable in the spectra. This can be seen in Fig. 3, presenting it in its whole wavelength range.

Weidmann \& Gamen (2011a) who use their own spectra, have classified He 2-107 as [WC 10-11] object. In our spectra, the ratio of C III at $\lambda 5695$ to C II at $\lambda 7235$ is 0.31 , but it cannot be precisely derived by how much the nebular emission contributes to the latter line. This object is also of relatively low ionisation, and although the [O III] lines are present, the intensity of $\lambda 5007$ is at only $76 \%$ of $\mathrm{H} \beta$. We, therefore, rate this object to the VL-type PNe with emission-line CSs.

The objects He 2-131 and $\mathrm{He}$ 2-108 are well studied emission-line objects with CSs models available in literature (Hultzsch et al. 2007; Pauldrach et al. 2004; Kudritzki et al. 1997). The object He 2-108 was recently analysed by Pottasch et al. (2011) with apparently lacking good optical spectra. We feel both PNe are worth to be included in the sample for at least illustrative purposes how they would be processed and classified with the kind of spectra we collected.

He 2-131 and He 2-108 were first classified as WELs objects in Tylenda et al. (1993). However, both objects display not narrow CIV $\lambda 5801 / 12$ emissions but a C III $\lambda 5695$, and C II $\lambda 7235$, and He II $\lambda 4685$ line that is also identified as stellar in our low resolution spectra. The additional interesting property of He 2-131 is that there are traces of C IV $\lambda 5801 / 12$ in absorption. The central star of He 2-131 is surrounded by a low ionisation nebula with [O III] $\lambda 5007$ at the level of only $10 \%$ of $\mathrm{H} \beta$, whereas the star is presumably hotter and, therefore, the intensity of [O III] 5007 is almost two times larger than $\mathrm{H} \beta$ in the case of He 2-108. We would classify them both, however, as VL type.

\subsection{Mimics of emission-line stars}

The WELs type PNe are probably a heterogeneous group of objects that has already been suggested by Tylenda et al. (1993). Recently, it has been proposed by Corradi et al. (2011) that the stellar emission lines of $\mathrm{C}$ and $\mathrm{N}$ attributed in WELs to the enhanced mass loss may originate from the irradiated zone in close binary systems. Miszalski et al. (2011) argue this is actually the case of NGC 6326, which they observed both photometrically and spectroscopically. In the bottom panel of Fig. C.3, we present our low resolution spectra of NGC 6326. Faint but clearly visible emission lines of CIV at $\lambda 5801 / 12$ would normally be identified as stellar and clearly would allow us to classify this object as a typical WEL. The C II $\lambda 7325$ and, in particular, the complex of $\mathrm{C}$ and $\mathrm{N}$ lines near $4650 \AA$ are clearly of nebular origin, since they appear as emitted from a spatially extended region in our 2D spectra. Could the C IV $\lambda 5801 / 12$ lines also have the nebular origin in some PNe?

The central star of NGC 5979 has been classified by Weidmann \& Gamen (2011b) using the low resolution spectra they acquired as a WEL object. In Fig. 6, we present our fully
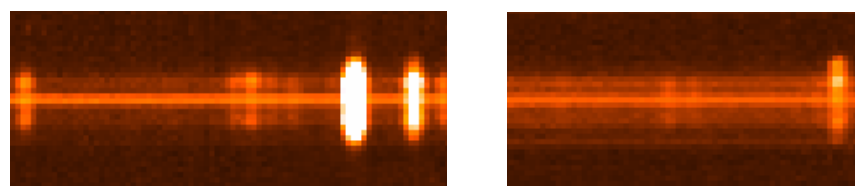

Fig. 6. Spectrum of NGC 5979 around $4640 \AA$ (left) and $5800 \AA$ (right).
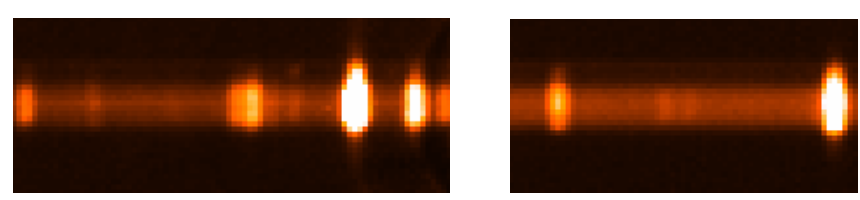

Fig. 7. Spectrum of NGC 3918 around $4640 \AA$ (left) and $5800 \AA$ (right).

reduced 2D spectrum of this PN. In the right panel, we show the part of the spectrum around $5805 \AA$, and in the left panel, the region centred on $4640 \AA$. The lines of N III, C III, and C IV ions are clearly detectable at the expected wavelengths. They all are, however, emitted from the spatially extended region and are, therefore, not of the stellar but nebular origin. The stellar continuum emission can also be recognised in the centre of the images. It is broadened in the spatial direction by the seeing but obviously much narrower than the emission lines. If analysed using only the final summed 1D spectrum, this object would perfectly mimic WEL type spectra.

In Fig. 7, we show the same regions of spectrum for the NGC 3918. In the case of this object, the stellar continuum is detectable only in the blue part. The emission lines of CIV at 5801/12 and the combination of lines around $4650 \AA$ are again clearly not of stellar origin. In the case of the presumed C IV line identified at $4658 \AA$, it can be noticed that the emission has two separate spatial components.

The objects NGC 3918 and NGC 5979 are high ionisation PNe. From our line measurements, we derived the ratio of selective to total $\mathrm{He}^{++} / \mathrm{He}$ abundance to be 0.38 and 0.81 , respectively. In Fig. 3, we presented the full spectrum of NGC 5979, where lines of highly ionised ions can be identified. The effective temperature of NGC 5979 calculated with Zanstra He method is $T_{\star}=100 \mathrm{kK}$, and the luminosity is $\log L_{\star}=3.68 L_{\odot}$. In the case of NGC 3918, those parameters can be derived as $148 \mathrm{kK}$ and $3.52 L_{\odot}$. Apparently, some carbon in both these PNe are ionised up to $\mathrm{C}^{4+}$ in the large part of the nebula and can give rise to lines that are otherwise expected to be observed from stellar atmospheres.

\subsection{Occurrence rate and evolutionary status}

It was noticed by Górny et al. (2001) that there is an important difference in the distribution of spectral classes among [WR] PNe located in the bulge as compared to the PNe in the Galactic disk. An apparent underpopulation of [WR] CSs in the [WC5]-[WC7] range for disk objects was observed. In the bulge, on the contrary, [WR] CSs were found to be mostly of the intermediate spectral types suggesting that the Wolf-Rayet phenomenon depends on the characteristics of the investigated stellar population giving rise to the observed PNe. The new observations of bulge PNe by Górny et al. (2004, 2009) did not solve the problem since the comparable search surveys for the Galactic disk were not available. Instead, a potential new class of emission-line objects (VL) had to be introduce (Górny et al. 2009). 


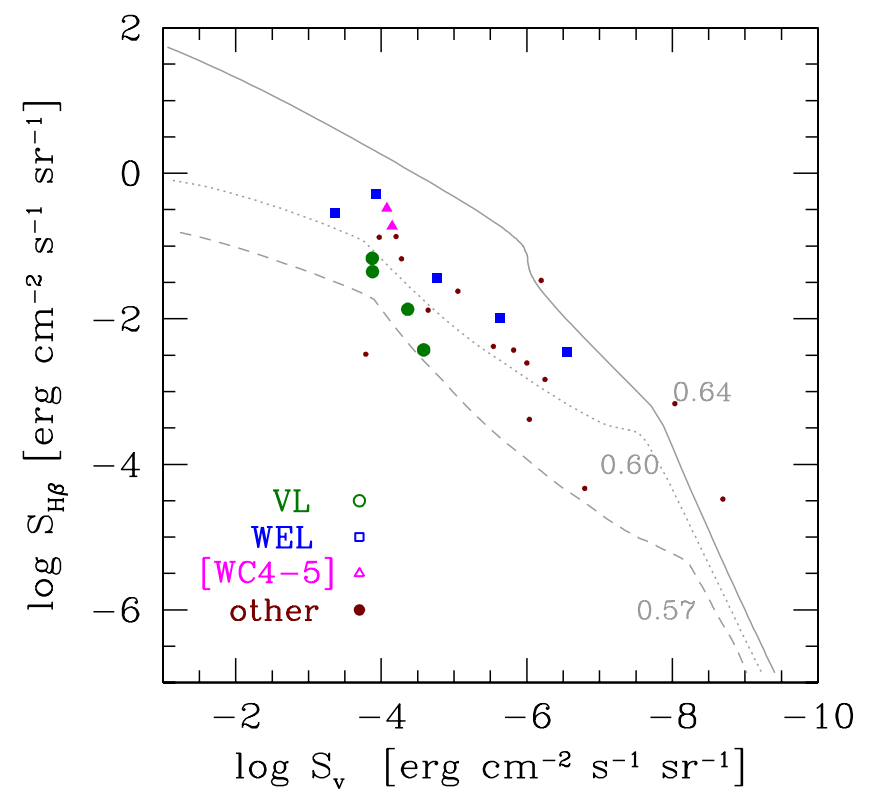

Fig. 8. Nebular surface brightness $S_{\mathrm{H} \beta}$ versus parameter $S_{V}$ as defined in an analogous way using stellar $V$ flux. Data presented for different types of disk PNe from the observed sample: magenta triangles - [WR] PNe, blue squares - WEL PNe, and green circles VL PNe ([WC 11]-like spectra). Small symbols mark normal PNe without emission-line CSs detected. The lines present model calculations for central stars of $0.57,0.60$, and $0.64 M_{\odot}$, adopting a simple nebular model (see text).

Recently, Depew et al. (2011) published a list of newly discovered [WR] PNe that contains some possible intermediate [WC] class objects in the Galactic disk ${ }^{4}$. Additionally, we found or reclassified three intermediate [WC] spectral-class objects in our disk sample (see Table B.2). The first important result from the present work is therefore that the difference in spectral class distribution, although still present, may be not that pronounced. Possibly more such objects could be found in a deeper dedicated search. The second piece of information is that the VL objects are also present in the Galactic disk and not confined only to the inner parts of the Milky Way and its bulge in particular.

In Fig. 8, we present the locations of PNe from the observed sample in the $S_{\mathrm{H} \beta}$ versus $S_{V}$ plot, where $S_{\mathrm{H} \beta}$ is the nebular surface brightness in $\mathrm{H} \beta$ and $S_{V}$ is defined in an analogous way but using the stellar flux in the visual $V$ band (see in Górny et al. 1997). The evolutionary tracks shown in Fig. 8 have been calculated with a simple model of PNe by assuming total nebular mass $M_{\text {neb }}=0.20 M_{\odot}$, a filling factor $\epsilon=0.75$ and an expansion velocity $V_{\exp }=20 \mathrm{~km} \mathrm{~s}^{-1}$ for central stars of $0.57,0.60$, and $0.64 M_{\odot}$ evolving in agreement with Blöcker (1995) models.

It can be seen in Fig. 8 that the locations of VL PNe clearly differ from those of [WR] and WEL objects. In particular, VLPNe cannot be evolutionary predecessors of either of the two other groups, as first noted by Górny et al. (2009). Because $S_{\mathrm{H} \beta}$ and $S_{V}$ are distance independent, one can directly compare locations of PNe analysed in this work with Fig. 11 of Górny et al. (2009), which present bulge and inner-disk emission-line CSs that they discovered. Analogous locations are occupied in the case of any of the three groups in both plots. We therefore

\footnotetext{
4 Originally, Depew et al. (2011) used different classification schemes of [WC] and [WO] subclasses, whereas we continue to use the classical [WC] scheme that range from [WC11] to [WC2].
}

can confirm the conclusion of Górny et al. (2009) that [WR], VL, and WELs form three independent types of emission-line CSs phenomenon and that it is also true for the PNe in the Galactic disk.

The rate of occurrence of the different types of $\mathrm{PNe}$ with emission-line CSs is, of course, of a large importance if one wants to discuss the possible evolutionary paths of their creation. At the same time, it is very difficult to be established, as the number of objects that are discovered in a given sample is unavoidably subject to serious bias. The bias originates from the observational details, selection effects when choosing targets, and obvious physical constraining factors, such as the distance to the given population.

A natural sample to compare with the present one would be the 44 Galactic bulge PNe observed by Górny et al. (2004). Both groups have been actually observed with the same instrument and almost identical setup, but there are also differences. The Galactic bulge PNe are further away and smaller, which should work against efficient discovery of emission-line CSs in the bulge sample due to the stronger contamination effect from the nebulae. On the other hand, the Górny et al. (2004) sample was preselected by choosing objects with infrared IRAS colours typical for [WR] PNe (Górny et al. 2001). This could have an important consequence since no such preselection was active in the present sample. Nevertheless, taking the numbers of objects into account discovered from original new observations in both studies (i.e., comparing only with sample G of Górny et al. 2004, see Col. 3 in their Table 4) one findss that seven WELs and two [WR] were discovered in the bulge by Gorny et al. (2004), as compared to three WEL, two [WR] and one new VL in the present sample. Clearly, no final conclusions about the rate of occurrence of emission-line phenomenon in both environments can be reached in this way.

The precise answer to the question of what exactly is the rate of occurrence of each type of emission-line phenomenon in different environments requires constructing a more complete samples in both regions of the Milky Way. Possible selection effects need to be carefully considered but is outside the scope of the present data paper.

\section{Chemical abundances and plasma parameters}

We start this section with the description of the method we used. Then we analyse the calculated plasma parameters and present the derived chemical abundances. We finalise the result by comparing them to the abundances of the Galactic bulge and inner-disk PNe populations that were analysed recently.

\subsection{Method}

We use the code ABELION that was developed by G. Stasińska, which is based on the classical empirical method to derive the plasma parameters and nebular chemical abundances. The version of the code is identical with that used by Górny et al. (2009) and Chiappini et al. (2009). We first derive the electron densities from the [S II] $\lambda 6731 / 6716$ ratio and electron temperatures $T_{\mathrm{e}}\left(\mathrm{O}\right.$ III) from the [O III] $\lambda 4363 / 5007$ and/or $T_{\mathrm{e}}(\mathrm{N}$ II $)$ from [ $\mathrm{N}$ II] $\lambda 5755 / 6583$ ratios. We used them to refine the inferred reddening corrections, as described above. Later, we use $T_{\mathrm{e}}(\mathrm{N}$ II) to derive abundances of ions with low ionisation potential and $T_{\mathrm{e}}(\mathrm{O}$ III) for hydrogen and lines from other ions with intermediate and high ionisation potentials. If $T_{\mathrm{e}}(\mathrm{N}$ II) was very uncertain (three cases) we used the $T_{\mathrm{e}}(\mathrm{O}$ III) for all the ions instead. If the observational data did not allow for the estimation 
of the electron temperature, the object was rejected from further considerations (five cases).

As discussed in detail in Górny et al. (2009), the $\mathrm{O}^{+}$ionic abundances derived from $\lambda 3727$ line as compared to $\lambda 7325$ differ frequently. The latter can be affected by recombination from $\mathrm{O}^{++}$ions, but this does not solve the problem, as checked by Górny et al. (2009). In Fig. C.4, we compare the $\mathrm{O}^{+}$ionic abundances derived from $\lambda 7325$ to $\mathrm{O}^{+}$from $\lambda 3727$ by showing their ratio as a function of electron density. It can be noted that the median difference for the presented observations is $0.17 \mathrm{dex}$, and we use this value to correct $\lambda 7325$ measurements, as proposed by Górny et al. (2009). In Fig. C.5, we plot the same ratios as a function of electron temperature $T_{\mathrm{e}}(\mathrm{N}$ II). A weak correlation can be seen in the sense that the discrepancy between $\lambda 7325$ and $\lambda 3727$ also becomes larger for PNe with larger $T_{\mathrm{e}}(\mathrm{N}$ II). We, however, attempted no fitting to this correlation when correcting the $\lambda 7325$ line. The final $\mathrm{O}^{+}$ionic abundance is a mean of the two values weighted by their reversed uncertainties.

After the ionic abundances are computed, the elemental abundances are obtained using the ionisation correction factors (ICFs), as in Górny et al. (2009) and based mainly on the scheme of ICFs from Kingsburgh \& Barlow (1994). The uncertainties in abundance ratios and other derived parameters were obtained by propagating uncertainties in the observed emission line intensities using Monte-Carlo simulations by assuming that the principle line intensity errors are of at least $5 \%$, as explained above.

In Table B.3, we give the derived plasma diagnostics and ionic and elemental abundances for 48 objects ordered by PN G numbers. For each object, there are three rows of data. The first row gives the values of parameters computed from the nominal values of the observed lines and their ratios. The second and third row give the upper and lower limits of these parameters, respectively. Column 1 of Table B. 3 gives the PN G number and Col. 2 gives the usual name of the object; Col. 3 gives the electron density deduced from [S II] $\lambda 6731 / 6716$, Cols. 4 and 5 give the electron temperature deduced from [N II] $\lambda 5755 / 6583$ and [O III] $\lambda 4363 / 5007$, respectively. If the value of $T_{\mathrm{e}}(\mathrm{N}$ II) is in parenthesis, $T_{\mathrm{e}}(\mathrm{O}$ III) was chosen for all ions. Column 6 gives the $\mathrm{He} / \mathrm{H}$ ratio and Cols. 7 to 12 the $\mathrm{N} / \mathrm{H}, \mathrm{O} / \mathrm{H}, \mathrm{Ne} / \mathrm{H}, \mathrm{S} / \mathrm{H}$, $\mathrm{Ar} / \mathrm{H}, \mathrm{Cl} / \mathrm{H}$ ratios, respectively. To avoid dealing with values that are too uncertain, we removed from further consideration any plasma parameter or abundance ratio for which the error (at twosigma level) is larger than 0.3 dex. We marked these values with a colon in Table B.3.

\subsection{Plasma parameters}

In this section, we present the plasma parameters derived for our observed disk PNe from Vela-Norma direction and compare it to the Galactic bulge and inner-disk samples of Chiappini et al. (2009) that were computed with exactly the same code and assumptions. The inner-disk sample is less well defined and includes PNe that are observed in the direction of the Galactic centre but do not pertain to the bulge, according to the standard criteria. They can be located at Galactocentric distances estimated ${ }^{5}$ as less than $2 \mathrm{kpc}$ up to almost $7 \mathrm{kpc}$ but the median Galactocentric distance is about $3 \mathrm{kpc}$. In Fig. 9, we plot $T_{\mathrm{e}}\left(\mathrm{O}\right.$ III) versus $T_{\mathrm{e}}(\mathrm{N}$ II). First, it can be noted that all disk PNe that we show here seem to have $T_{\mathrm{e}}$ larger than $10^{4} \mathrm{~K}$. Among the bulge and inner-disk samples, there is a considerable number of objects with temperatures below that value. From Fig. 9,

\footnotetext{
5 These estimates are based on distances from Cahn et al. (1992).
}

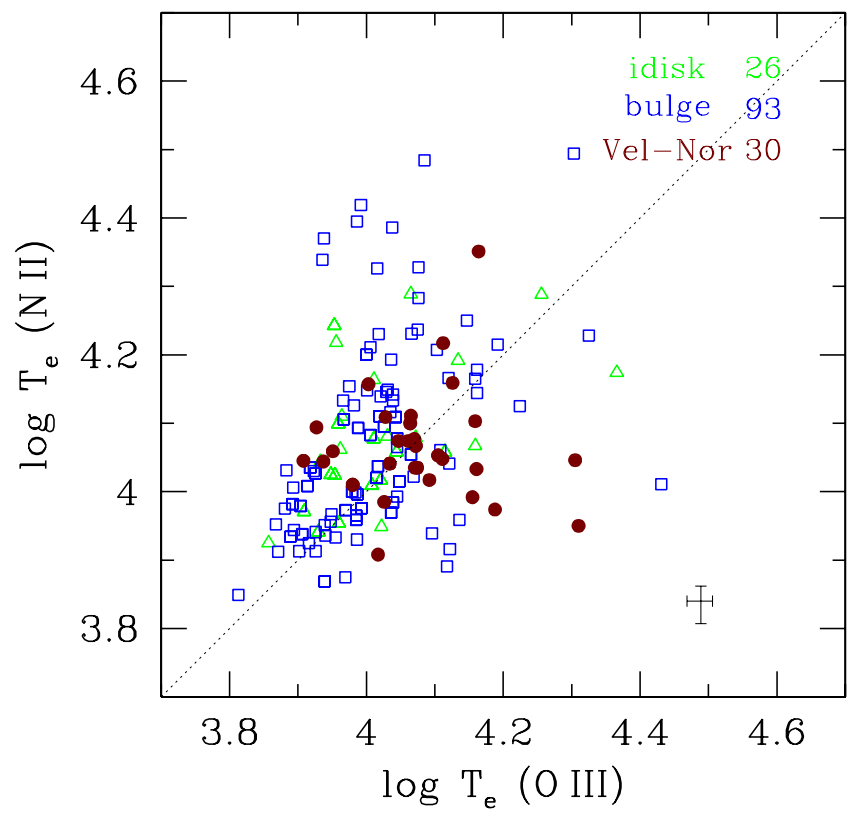

Fig. 9. Electron temperature derived from [O III] $\lambda 4363 / 5007$ versus electron temperature from [N II] $\lambda 5755 / 6583$. Dark dots mark the Galactic disk PNe observed in this work (Vela-Norma); blue open squares - Galactic bulge PNe from Chiappini et al. (2009); green open triangles - Galactic inner-disk PNe from the same reference. The numbers in the top right give the numbers of objects presented in the plot for each sample.

the correlation between $T_{\mathrm{e}}(\mathrm{O}$ III $)$ and $T_{\mathrm{e}}(\mathrm{N}$ II $)$ seems to be at the same level for disk $\mathrm{PNe}$ as for the other two groups but there are two $\mathrm{PNe}$ in this sample that have $T_{\mathrm{e}}(\mathrm{O}$ III $) \gg T_{\mathrm{e}}(\mathrm{N}$ II $)$. In the bulge PNe sample, on the contrary, there is a group with $T_{\mathrm{e}}(\mathrm{N}$ II $) \gg T_{\mathrm{e}}(\mathrm{O}$ III $)$. Calculating a median value of $\log T_{\mathrm{e}}(\mathrm{O}$ III $)$ for the disk PNe (39 objects with useful data) we checked that it is 4.09 and 0.06 dex larger than for the bulge PNe. The tests indicate the difference is statistically significant ${ }^{6}$ at more than $99 \%$ confidence level.

Analysing the distributions of the electron density derived from [S II] $\lambda 6731 / 6716$ ratio for the three samples of $\mathrm{PNe}$, we found no statistically significant differences, although our disk sample from Vela-Norma direction seems to have more members with smaller densities. The median $\log N_{\mathrm{e}}=3.26$ for the objects presented here are 0.07 and 0.20 dex smaller than for the Galactic bulge and inner-disk PNe, respectively (Chiappini et al. 2009). This qualitatively agrees with the ionisation level of these nebulae that we checked measuring the relative ionic $\mathrm{He}^{++}$to total $\mathrm{He}$ abundance. The median $\mathrm{He}^{++} / \mathrm{He}$ for the Galactic disk $\mathrm{PNe}$ investigated here is 0.11 . A similar value have been derived for the Galactic inner-disk sample, whereas very few observed $\mathrm{PNe}$ have any $\mathrm{He}^{++}$ions at all for the bulge PNe.

Summarising, we would tentatively describe the disk PNe from the sample analysed here as more evolved, of higher electron temperature, and also of presumably higher ionisation level than the PNe in the other two samples. This is what could be expected, since it is generally more difficult to observe evolved $\mathrm{PNe}$ at larger distances like the bulge or inner-disk regions.

6 We used Kolmogorov-Smirnov and Wilcoxson tests for all the distributions analysed in this work. 
S. K. Górny: Spectroscopy of southern Galactic disk planetary nebulae

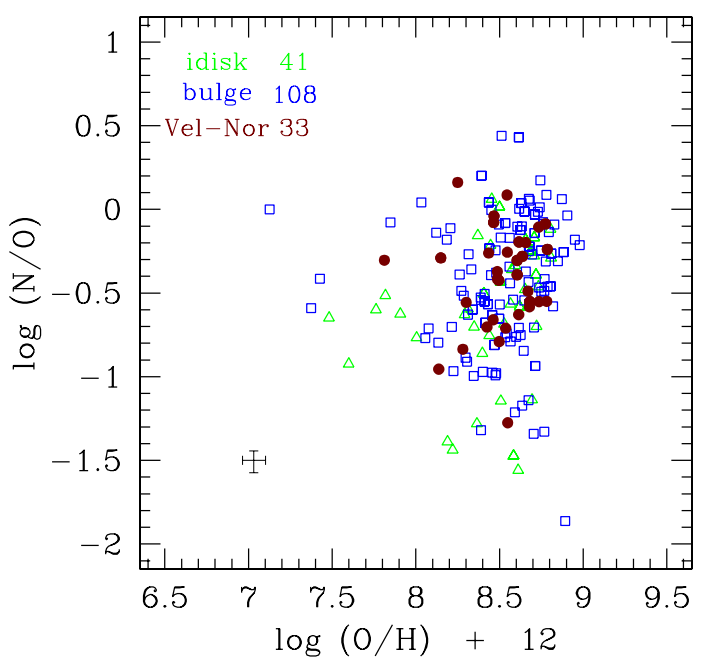

Fig. 10. Nebular abundance ratios $\mathrm{N} / \mathrm{O}$ versus $\mathrm{O} / \mathrm{H}$ for the three analysed Galactic PNe samples. The notation of symbols as in Fig. 9.

\subsection{Chemical abundances}

One of the advantages of studding chemical abundances of PNe is that some of them bring information on the nucleosynthesis processes occurring in the interiors of their progenitor stars (e.g. nitrogen), whereas others are assumed to remain unchanged during the life of the star and inform about the primordial chemical composition of the matter that the parent star was born from.

In Fig. 10 we show the relation of $\mathrm{O} / \mathrm{H}$ versus $\mathrm{N} / \mathrm{O}$ for the $\mathrm{PNe}$ included in the sample investigated here as compared to Galactic bulge and inner-disk samples of Chiappini et al. (2009). Similar behaviour can be seen in this plot for the three groups of PNe. There are also very few outliers. The object with the lowest $\mathrm{O} / \mathrm{H}$ abundance in the disk $\mathrm{PNe}$ group in this plot is He 2-131 that we discussed already in Sect. $3.2^{7}$. We derive median $\log \mathrm{O} / \mathrm{H}=-3.46$ and median $\log \mathrm{N} / \mathrm{O}=-0.37$ for the disk PNe sample analysed here.

In Fig. 11, we plot $\mathrm{He} / \mathrm{H}$ versus $\mathrm{N} / \mathrm{H}$ for the analysed $\mathrm{PNe}$ of the three Galactic locations. The median value $\log \mathrm{He} / \mathrm{H}=11.07$ for our disk PNe sample seems very similar to the other two samples (see Table 2 of Chiappini et al. 2009). Nevertheless, analysing them with the statistical tests, there is only $1-2 \%$ chance that our disk sample and bulge sample of Chiappini et al. (2009) originate in the same parent distribution. This is probably due to the group of objects with $\log \mathrm{He} / \mathrm{H}>11.2$ that can be noted in the bulge PNe sample. Surprisingly, according to the standard view on the chemical evolution of the AGB stars, this could mean there is a group of PNe with higher mass central stars that is observed in the bulge but missing in our disk sample. This is, however, not confirmed by statistical test for neither $\mathrm{N} / \mathrm{H}$ nor N/O distributions, although a very convincing correlation of $\mathrm{He} / \mathrm{H}$ with $\mathrm{N} / \mathrm{H}$ can be seen in Fig. 11.

Figure 12 presents the comparison of Ne/Ar abundance ratios for the three samples of PNe. In this case, a gradual increase of $\mathrm{Ne} / \mathrm{Ar}$ can be observed from disk sample with the smallest ratio through bulge $\mathrm{PNe}$ and towards the inner-disk sample. The difference between our disk sample and the inner-disk PNe is confirmed at about $99 \%$ significance level. We noticed no

\footnotetext{
7 The low $\mathrm{O}$ abundance we calculate is the result of the high $T_{\mathrm{e}}(\mathrm{O}$ III $)$ $\approx 20400 \mathrm{~K}$ that we derive from a very faint [O III] $\lambda 4363$ line, as compared to $T_{\mathrm{e}}(\mathrm{N}$ II $) \approx 8900 \mathrm{~K}$. If the true $T_{\mathrm{e}}$ is close to the latter value and the preference would be given to $\mathrm{O}^{+}$from $\lambda 7325$, then $\mathrm{O} / \mathrm{H}=$ $1.86 \times 10^{-4}$ would be derived.
}

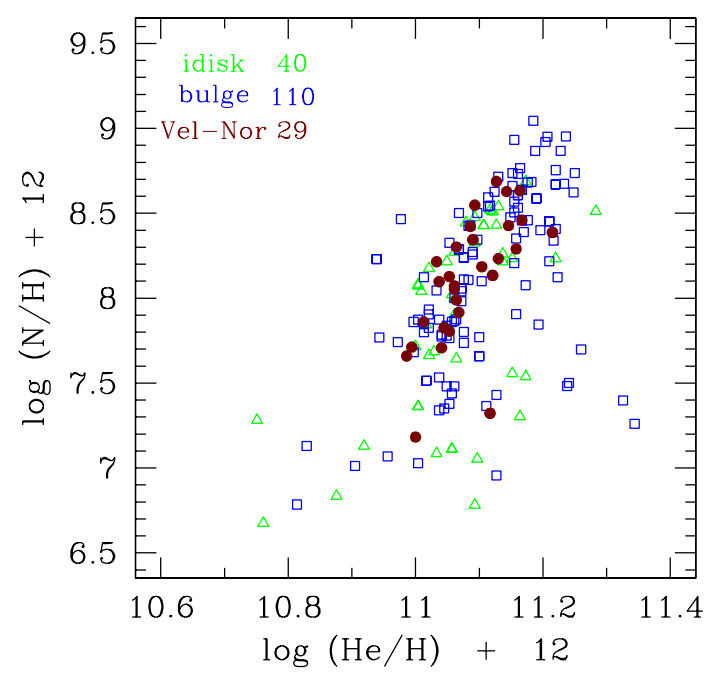

Fig. 11. Nebular abundance ratios $\mathrm{He} / \mathrm{H}$ versus $\mathrm{N} / \mathrm{H}$ for the three analysed Galactic PNe samples. The notation of symbols as in Fig. 9.

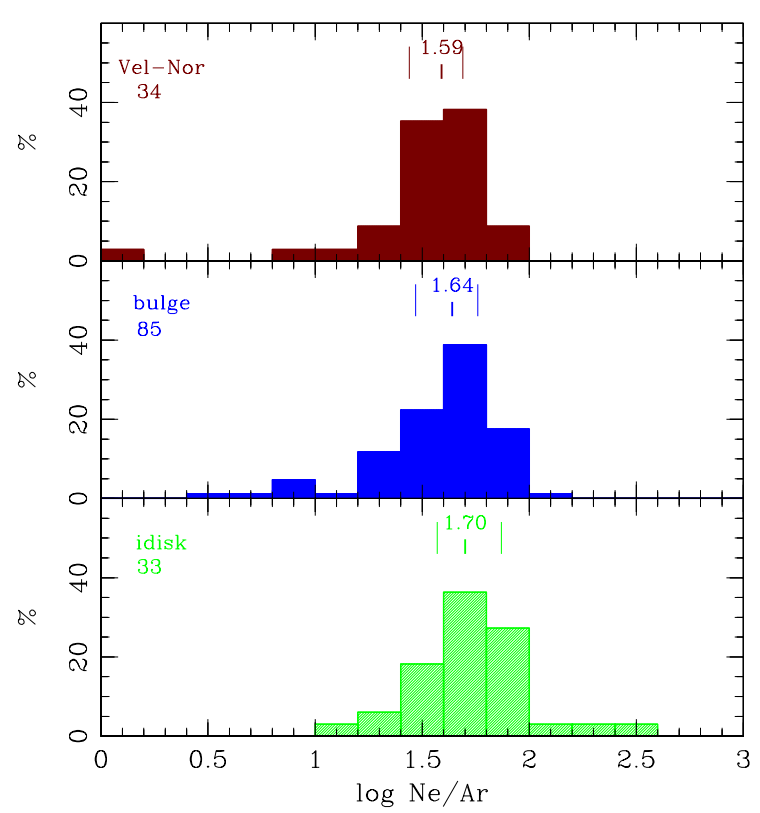

Fig. 12. Distributions of the nebular $\mathrm{Ne} / \mathrm{Ar}$ abundance ratio for the three analysed Galactic samples: disk PNe from Vela-Norma direction (top), bulge PNe (middle), and inner-disk PNe (bottom). The median values, the 25 and 75 percentiles are marked with three short vertical lines above each histogram. Numbers of objects used are shown in the lefthand parts of the panels below sample names.

statistically significant differences in distributions of any other abundance ratios comparing the three PNe samples.

Although the group of PNe we observed is not numerous enough and, as we mentioned above, a large and properly selected samples should be used to study gradients of chemical abundances in the Milky Way, we present the derived $\mathrm{O} / \mathrm{H}$ abundances versus the Galactocentric distances of these objects in the Fig. 13. This is mostly done to demonstrate the usability of the data we collected for this and other purposes. We used the distances of Cahn et al. (1992) and found them for 19 of our disk PNe. As in previous cases, we analysed only objects with an $\mathrm{O} / \mathrm{H}$ ratio errors estimated to be smaller than 0.3 dex. As seen in Fig. 13, the observed PNe are located from about 5 to $10 \mathrm{kpc}$ 


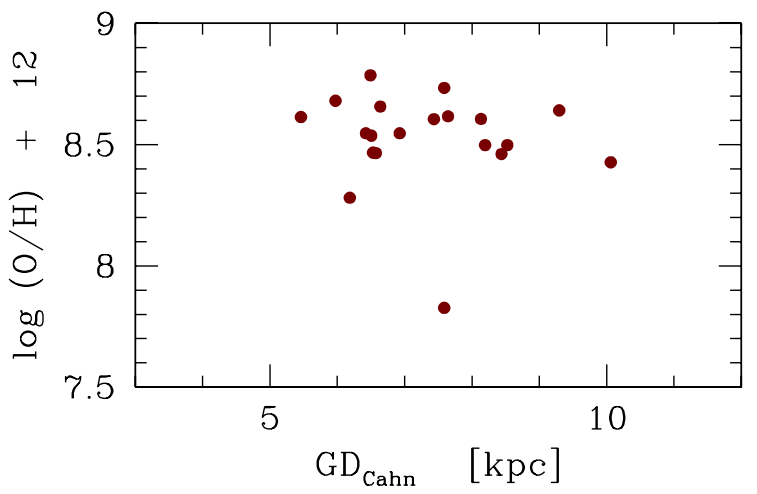

Fig. 13. Nebular abundance ratio $\mathrm{O} / \mathrm{H}$ versus Galactocentric distance for PNe observed in this work.

from the Galactic centre. Even though the presented sample of disk PNe is small, their locations in Fig. 13 clearly support the idea of flattening the chemical gradient in the internal parts of the Milky Way.

\section{Summary}

We presented low resolution optical spectroscopic observations for a sample of $53 \mathrm{PNe}$ located in the southern sky between Vela and Norma constellations and pertaining to the Galactic disk. We used the spectra to analyse the chemical composition of PNe and search for new emission-line central stars. Our main results are as follows:

1. We derived chemical abundances of 48 observed PNe for the first time for most of them or allowed abundances of additional, previously unobserved elements to be measured.

2. We compared the nebular chemical abundances in our sample with the results of Chiappini et al. (2009) for Galactic bulge and inner-disk PNe populations. We found no statistically meaningful differences in abundance distributions, except for $\mathrm{He} / \mathrm{H}$, that seems more abundant in the bulge $\mathrm{PNe}$ as compared to our disk sample and $\mathrm{Ne} / \mathrm{Ar}$ with larger ratios found in the inner-disk PNe population.

3. The oxygen abundances derived for the analysed sample favour flattening of the $\mathrm{O} / \mathrm{H}$ gradient within the inner parts of the Galactic disk.

4. We performed extensive search for central stars with emission-lines and found three new WEL, two [WR] and one VL type object. Re-analysing the spectra of previously classified objects additional three members of the VL group have been proposed.

5. We identify NGC 3918 and NGC 5979 as the possible mimics of WEL objects with C IV 5801/12 emitted from highly ionised nebulae.

6. We confirmed for the first time that the VL type PNe are also located outside the inner parts of the Milky Way. We identified three examples of [WR]-type central stars with intermediate spectral class [WC5]-[WC6] pertaining to the Galactic disk.

7. We argue WELs, [WR], and VL objects are three evolutionary unrelated types of emission-line phenomenon in central stars of PNe.

Acknowledgements. Part of this work was supported from grant N203511838 of the Science and High Education Ministry of Poland. I wish to thank M. Hajduk who assisted during observations in June 2005 and A. D. García-Hernández for his help in selecting targets in 2011.

\section{References}

Acker, A., \& Neiner, C. 2003, A\&A, 403, 659

Acker, A., Marcout, J., Ochsenbein, F., et al. 1992, The Strasbourg-ESO Catalogue of Galactic Planetary Nebulae, Parts I, II

Blöcker, T. 1995, A\&A, 299, 755

Cahn, J. H., Kaler, J. B., \& Stanghellini, L. 1992, A\&AS, 94, 399

Cavichia, O., Costa, R. D. D., \& Maciel, W. J. 2010, Rev. Mex. Astron. Astrofis., 46, 159

Chiappini, C., Górny, S. K., Stasińska, G., \& Barbuy, B. 2009, A\&A, 494, 591

Corradi, R. L. M., Sabin, L., Miszalski, B., et al. 2011, MNRAS, 410, 1349

Cuisinier, F., Acker, A., \& Koeppen, J. 1996, A\&A, 307, 215

de Freitas Pacheco, J. A., Maciel, W. J., Costa, R. D. D., \& Barbuy, B. 1991, A\&A, 250, 159

de Freitas Pacheco, J. A., Maciel, W. J., \& Costa, R. D. D. 1992, A\&A, 261, 579

Depew, K., Parker, Q. A., Miszalski, B., et al. 2011, MNRAS, 414, 2812

Dopita, M. A., \& Hua, C. T. 1997, ApJS, 108, 515

García-Rojas, J., Peña, M., Morisset, C., Mesa-Delgado, A., \& Ruiz, M. T. 2012, A\&A, 538, A54

Górny, S. K. 2006, in Planetary Nebulae in our Galaxy and Beyond, eds. M. J. Barlow, \& R. H. Méndez, IAU Symp., 234, 409

Górny, S. K., Stasińska, G., \& Tylenda, R. 1997, A\&A, 318, 256

Górny, S. K., Stasińska, G., Szczerba, R., \& Tylenda, R. 2001, A\&A, 377, 1007

Górny, S. K., Stasińska, G., Escudero, A. V., \& Costa, R. D. D. 2004, A\&A, 427, 231

Górny, S. K., Chiappini, C., Stasińska, G., \& Cuisinier, F. 2009, A\&A, 500, 1089

Henry, R. B. C., Kwitter, K. B., Jaskot, A. E., et al. 2010, ApJ, 724, 748

Herwig, F. 2005, ARA\&A, 43, 435

Hultzsch, P. J. N., Puls, J., Méndez, R. H., et al. 2007, A\&A, 467, 1253

Iben, Jr., I. 1995, Phys. Rep., 250, 2

Kingsburgh, R. L., \& Barlow, M. J. 1994, MNRAS, 271, 257

Kudritzki, R. P., Mendez, R. H., Puls, J., \& McCarthy, J. K. 1997, in Planetary Nebulae, eds. H. J. Habing, \& H. J. G. L. M. Lamers, IAU Symp., 180, 64

Kwitter, K. B., Henry, R. B. C., \& Milingo, J. B. 2003, PASP, 115, 80

Lee, T.-H., Stanghellini, L., Ferrario, L., \& Wickramasinghe, D. 2007, AJ, 133, 987

Milingo, J. B., Kwitter, K. B., Henry, R. B. C., \& Cohen, R. E. 2002, ApJS, 138, 279

Milingo, J. B., Kwitter, K. B., Henry, R. B. C., \& Souza, S. P. 2010, ApJ, 711, 619

Miszalski, B., Parker, Q. A., Acker, A., et al. 2008, MNRAS, 384, 525

Miszalski, B., Jones, D., Rodríguez-Gil, P., et al. 2011, A\&A, 531, A158

Parker, Q. A., \& Frew, D. J. 2011, in Asymmetric Planetary Nebulae 5 Conference

Parker, Q. A., Acker, A., Frew, D. J., et al. 2006, MNRAS, 373, 79

Pauldrach, A. W. A., Hoffmann, T. L., \& Méndez, R. H. 2004, A\&A, 419, 1111

Pottasch, S. R., Surendiranath, R., \& Bernard-Salas, J. 2011, A\&A, 531, A23

Seaton, M. J. 1979, MNRAS, 187, 73P

Stasińska, G., \& Tylenda, R. 1994, A\&A, 289, 225

Tylenda, R., Acker, A., \& Stenholm, B. 1993, A\&AS, 102, 595

Weidmann, W. A., \& Gamen, R. 2011a, A\&A, 531, A172

Weidmann, W. A., \& Gamen, R. 2011b, A\&A, 526, A6 
S. K. Górny: Spectroscopy of southern Galactic disk planetary nebulae
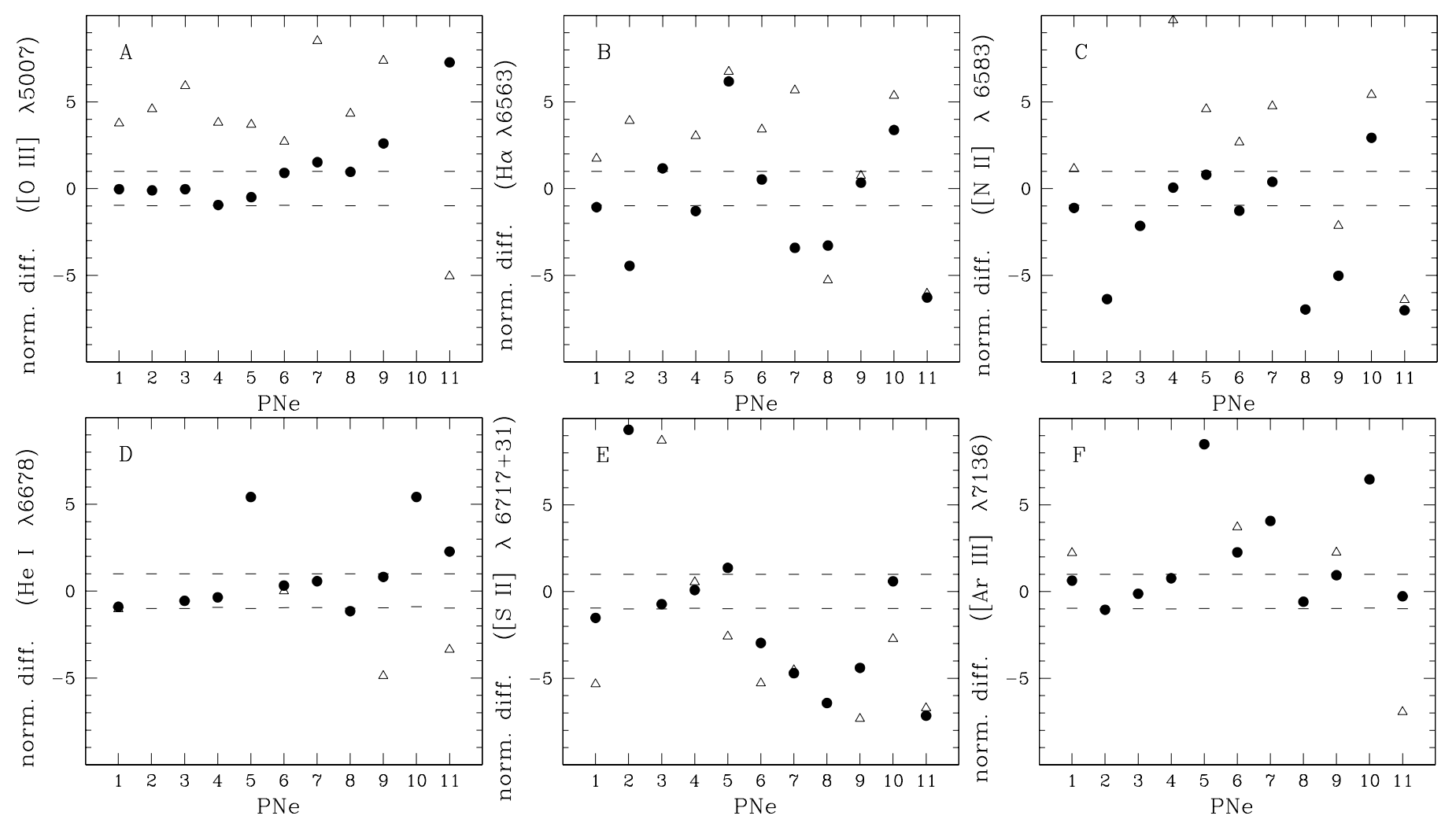

Fig. A.1. Comparison of our line intensities with measurements of Dopita \& Hua (1997) for 11 PNe in common that are listed in Table A.1. The difference for each PNe (identified on horizontal axis) between our measurement and of Dopita \& Hua (1997) is marked with a black dot using a normalised scale (vertical axis). The normalisation was done with the original errors from Dopita \& Hua (1997). If the normalised absolute difference is less than 1 (dashed lines) our measurements agree within the uncertainty given by the latter authors. Open triangles present an analogous comparison for data from Acker et al. (1992) compared to Dopita \& Hua (1997) for the same PNe and are given for reference.

\section{Appendix A: Comparison with emission-line flux standards}

In this section, we compare our line measurements with data published by Dopita \& Hua (1997). We have 11 PNe in common with their list of southern emission-line flux standards. They are listed in Table A.1. In Fig. A.1, we present the comparison for the lines of [O III] $\lambda 5007, \mathrm{H} \alpha$, [N II] $\lambda 6583, \mathrm{He}$ I $\lambda 6678$, [S II] $\lambda 6717+31$, and [Ar III] $\lambda 7136$. The differences have been normalised separately for each PNe and each line to the error of the line intensity as given by Dopita \& Hua (1997).

Because our observations are not absolutely flux calibrated, we first had to recalculate values of Dopita \& Hua (1997) to the same scale $(\mathrm{H} \beta=100)$ as in our Table B.1. Therefore, the deviations shown in Fig. A.1 are influenced not only by the uncertainty of the given line but also to some degree by the errors of $\mathrm{H} \beta$ in both our and Dopita \& Hua (1997) measurements. For the $11 \mathrm{PNe}$ in common with our observations and presented in Fig. A.1, the error of the $\mathrm{H} \beta$ flux $^{8}$ in Dopita \& Hua (1997) varies between $1 \%$ and $2 \%$.

The dashed lines in Fig. A.1 represent the normalised error limits of Dopita \& Hua (1997) measurements. Our results are shown with black-filled circles. The triangles in Fig. A.1 represent line measurements from the Strasbourg-ESO catalogue of Acker et al. (1992) and are shown for reference. The latter have been derived from the Catalogue's spectroscopic survey and are of considerably lower sensitivity than our spectra.

\footnotetext{
8 In practise, the errors in $\mathrm{H} \beta$ have minor influence on our further calculations since they cancel when ratios of lines are computed, except through the $\mathrm{H} \alpha / \mathrm{H} \beta$ ratio used to deredden the observations.
}

The panel A of Fig. A.1 presents the comparison of our measurement and that of Dopita \& Hua (1997) of the [O III] $\lambda 5007$ line. In almost perfect agreement, it can be seen that most of our points are confined within the error bars given by Dopita \& Hua (1997).

The situation is different in panelB that presents the comparison of $\mathrm{H} \alpha$ measurements. Although there is no systematic deviation between our data and Dopita \& Hua (1997), the scatter is larger than in the previous plot. It cannot be blamed on the measurement of $\mathrm{H} \beta$ line, which is sometimes 10 times fainter then the $\mathrm{H} \alpha$ line, since it would then have comparable impact in the first panel. We checked that the internal errors of Dopita measurements for $\mathrm{H} \alpha / \mathrm{H} \beta$ line ratio are largest for objects Nos. 1, 6, and 9 (see Table A.1) and reach 4.0, 4.5, and 3.2\%, respectively. It can be noted that our measurements actually fall within the normalised errors in these cases. One possibility is therefore that the errors of Dopita \& Hua (1997) are underestimated for other PNe. The discrepancy of $\mathrm{H} \alpha / \mathrm{H} \beta$ ratios between different authors are not uncommon. In this case, we can see that they are mostly influenced by $\mathrm{H} \alpha$ measurements itself.

In panel $\mathrm{C}$ of Fig. A.1, we show a comparison for the close [N II] $\lambda 6583$ line. The same objects Nos. 1, 6, and five others show satisfactory agreement with Dopita \& Hua (1997). The objects that deviate most are Nos. 2, 8, and 11. Object 2 is a high excitation nebula with [N II] lines very weak, and the error of this measurement could be larger than calculated by Dopita \& Hua (1997). In the case of Nos. 8 and 11, another explanation can be 
Table A.1. List of PNe in common with Dopita \& Hua (1997).

\begin{tabular}{rll}
\hline \hline No. & PNG & Name \\
\hline 1 & $285.4+01.5$ & Pe 1-1 \\
2 & $289.8+07.7$ & He 2- 63 \\
3 & $286.0-06.5$ & He 2- 41 \\
4 & $295.3-09.3$ & He 2- 62 \\
5 & $296.3-03.0$ & He 2- 73 \\
6 & $300.7-02.0$ & He 2- 86 \\
7 & $309.0+00.8$ & He 2-96 \\
8 & $320.9+02.0$ & He 2-117 \\
9 & $323.9+02.4$ & He 2-123 \\
10 & $324.2+02.5$ & He 2-125 \\
11 & $327.1-01.8$ & He 2-140 \\
\hline
\end{tabular}

invoked. Those two PNe are low ionisation objects with [N II] dominating the spectra. Dopita \& Hua (1997) used slitless spectroscopic observations and measured the cumulative flux from the nebula. Since we used a narrow slit positioned on the central star, we could have missed some of the [N II] radiation from the external parts of the nebula ${ }^{9}$. This difference in observing technique will have smaller influence on ions of higher ionisation potentials, like [O III], since they are naturally concentrated towards the centre of the nebula.
In panelD of Fig. A.1, we compare the He I $\lambda 6678$ line. Despite that it is usually much fainter, we find a better agreement with the data of Dopita \& Hua (1997). This again advocates in favour of the errors of some $\mathrm{H} \alpha$ and [N II] measurements being underestimated by these authors. However, some influence in which we frequently had to use short snapshot spectra to measure such lines cannot be excluded.

In panels $\mathrm{E}$ and $\mathrm{F}$ of Fig. A.1, we compare our results with Dopita \& Hua (1997) for the lines of another two ions. In the case of [S II] doublet $\lambda 6717+31$, a similar picture to [N II] is seen strengthening our arguments presented above. For [Ar III] $\lambda 7136$, we found a generally satisfactory agreement. It is worth to note that no measurable influence by second order contamination effects is noticeable in our data. It would systematically underestimate measurements of red lines, like [Ar III] $\lambda 7136$, which is not observed.

In summary, the analysis presented above show that there are no systematic deviations in our line measurements compared to Dopita \& Hua (1997). It also demonstrates that the discrepancies in measured line intensities between different authors can be a complex function of many factors (wavelength, blending, location of emission zone within the nebula, etc.), and the values do not always converge with increasing line strength.

\footnotetext{
9 This underestimation have, however, a minor effect on our results, since N/O abundance ratio is derived by comparison to [O II] lines that origin from a similar region in the nebula.
} 
S. K. Górny: Spectroscopy of southern Galactic disk planetary nebulae

Appendix B: Supplementary tables

Table B.1. Main nebular lines on the scale $\mathrm{H} \beta=100$.

\begin{tabular}{|c|c|c|c|c|c|c|c|c|c|}
\hline \multirow{2}{*}{$\begin{array}{l}\text { PNG } \\
\text { name } \\
\mathrm{C}(\mathrm{H} \beta)\end{array}$} & \multirow[b]{3}{*}[\mathrm{O}\mathrm{II]}]{} & \multicolumn{2}{|c|}{$\begin{array}{c}268.4+02.4 \\
\text { PB } 5\end{array}$} & \multicolumn{2}{|c|}{$269.7-03.6$} & \multicolumn{2}{|c|}{ 279.6-03.1 } & \multicolumn{2}{|c|}{$283.8+02.2$} \\
\hline & & \multicolumn{2}{|r|}{1.82} & & 1.41 & & 0.87 & & 0.84 \\
\hline 3727 & & 12.1: & $32.52: \mathrm{c}$ & 158.4 & $252.20 \mathrm{c}$ & 54.8 & 137.91 & 11.2 & $18.37 ; \mathrm{c}$ \\
\hline 3869 & [Ne III] & 49.9 & $118.48 \mathrm{c}$ & 73.0 & $110.57 \mathrm{c}$ & 66.2 & 145.11 & 58.2 & $89.73 \mathrm{c}$ \\
\hline 4068 & {$[\mathrm{~S}$ II $]$} & 6.5: & $12.96: \mathrm{c}$ & 8.7: & $12.23: \mathrm{c}$ & & & $\mathrm{p}$ & $\mathrm{p}$ \\
\hline 4102 & H I & 13.5 & $26.13 \mathrm{c}$ & 17.5 & $24.27 \mathrm{c}$ & 15.2 & 26.20 & 19.0 & $26.46 \mathrm{c}$ \\
\hline 4340 & H I & 28.6 & $47.17 \mathrm{c}$ & 36.9 & $48.24 \mathrm{c}$ & 35.0 & 47.26 & 37.3 & $47.90 \mathrm{c}$ \\
\hline 4363 & [O III] & 13.8 & 22.39 & 11.0 & 14.26 & 16.4 & 24.12 & 15.3 & 19.46 \\
\hline 4471 & $\mathrm{He} \mathrm{I}$ & 4.0 & 5.82 & 4.0 & 4.89 & 3.0: & 4.05: & 1.5 & 1.81 \\
\hline 4686 & He II & 36.0 & 42.36 & 25.5 & 27.83 & 50.9 & 58.20 & 74.5 & 80.79 \\
\hline 4711 & [Ar IV] & 3.9 & 3.04 & 5.2 & 4.96 & 4.8 & 4.80 & 9.7 & 10.14 \\
\hline 4725 & [Ne IV] & 1.2 & 1.36 & 1.8: & 1.93: & & & 0.9: & $0.96:$ \\
\hline 4740 & [Ar IV] & 5.8 & 6.50 & 3.2: & 3.40: & 4.0 & 4.39 & 8.3 & 8.78 \\
\hline 4861 & H I & 100.0 & 100.00 & 100.0 & 100.00 & 100.0 & 100.00 & 100.0 & 100.00 \\
\hline 4959 & [O III] & 510.3 & 462.21 & 477.2 & 442.06 & 467.3 & 445.65 & 420.6 & 401.79 \\
\hline 5007 & [O III] & 1644.5 & 1422.24 & 1462.0 & 1306.84 & 1442.4 & 1345.42 & 1279.4 & 1196.34 \\
\hline 5200 & {$[\mathrm{~N} \mathrm{I}]$} & 0.7 & 0.51 & 6.3: & 4.94: & 1.5: & 1.29: & & \\
\hline 5515 & [Cl III] & ? & $?$ & 2.4; & 1.53 & 1.4; & 1.06; & 1.1: & $0.84:$ \\
\hline 5537 & [Cl III] & 1.4 & 0.77 & 1.4: & 0.88: & 1.1 & 0.82 & 0.8: & 0.61: \\
\hline 5755 & {$[\mathrm{~N} \mathrm{II}]$} & 9.5 & 4.25 & 13.0 & 6.98 & 1.6: & 1.09: & & \\
\hline 5876 & $\mathrm{He} \mathrm{I}$ & 32.7 & 13.17 & 29.1 & 14.41 & 12.9 & 8.34 & 8.9 & 5.85 \\
\hline 6300 & {$[\mathrm{O} \mathrm{I}]$} & 37.8 & 11.42 & 56.9 & 22.56 & 10.4 & 5.86 & ? & $?$ \\
\hline 6312 & [S III] & 10.5 & 3.15 & 8.2 & 3.23 & 5.4 & 3.03 & 3.2 & 1.83 \\
\hline 6548 & [N II] & 118.1 & 30.63 & 338.4 & 119.27 & 39.5 & 20.68 & 3.3 & 1.77 \\
\hline 6563 & $\mathrm{HI}$ & 1092.2 & 280.79 & 808.4 & 283.00 & 535.8 & 279.40 & 524.9 & 280.14 \\
\hline 6583 & {$[\mathrm{~N}$ II] } & 352.4 & 89.51 & 1091.7 & 378.63 & 123.4 & 63.98 & 8.0 & 4.25 \\
\hline 6678 & He I & 13.6 & 3.28 & 11.2 & 3.73 & 5.1 & 2.58 & 3.9 & 2.02 \\
\hline 6716 & [S II] & 9.1 & 2.15 & 74.1 & 24.31 & 13.3 & 6.66 & 1.1 & 0.56 \\
\hline 6730 & [S II] & 19.9 & 4.67 & 118.5 & 38.67 & 13.6 & 6.79 & 1.5 & 0.77 \\
\hline 7006 & [Ar V] & 11.8 & 2.43 & 1.3 & 0.38 & 2.0 & 0.94 & 3.7 & 1.78 \\
\hline 7136 & [Ar III] & 94.9 & 18.39 & 95.4 & 26.85 & 35.7 & 16.26 & 22.8 & 10.68 \\
\hline 7325 & [O II] & 133.7 & 23.69 & 92.1 & 24.18 & 12.6 & 5.50 & 2.5 & 1.12 \\
\hline PNG & & & 8-04.2 & & 01.5 & & 6.5 & & 07.7 \\
\hline name & & & 2- 39 & & & & & & \\
\hline $\mathrm{C}(\mathrm{H} \beta)$ & & & 0.44 & & 1.72 & & 0.47 & & 0.13 \\
\hline 3727 & [O II] & 157.5 & $261.58 \mathrm{c}$ & 26.1 & $71.42 \mathrm{c}$ & 36.63 & 48.17 & 14.80: & $18.37: \mathrm{c}$ \\
\hline 3869 & [Ne III] & 97.9 & $151.98 \mathrm{c}$ & 31.8 & $76.76 \mathrm{c}$ & 51.12 & 64.97 & 56.85 & $69.40 \mathrm{c}$ \\
\hline 4068 & {$[\mathrm{~S} \mathrm{II}]$} & & & 2.5 & $5.06 ; \mathrm{c}$ & 1.11; & 1.34; & & \\
\hline 4102 & $\mathrm{HI}$ & 18.9 & $26.19 \mathrm{c}$ & 13.4 & $26.30 \mathrm{c}$ & 20.75 & 24.93 & 21.95 & $26.07 \mathrm{c}$ \\
\hline 4340 & H I & 38.0 & $47.24 \mathrm{c}$ & 29.0 & 48.26 & 42.18 & 48.45 & 40.64 & $47.09 \mathrm{c}$ \\
\hline 4363 & [O III] $]$ & 18.2 & 22.88 & 4.7 & 7.67 & 7.64 & 8.73 & 11.26 & 12.67 \\
\hline 4471 & $\mathrm{He} \mathrm{I}$ & & & 4.0 & 5.84 & 4.75 & 5.27 & & \\
\hline 4686 & He II & 71.4 & 77.33 & & & & & 43.80 & 45.67 \\
\hline 4711 & [Ar IV] & 7.1: & $7.60:$ & 1.0: & $0.35:$ & 1.25 & 0.49 & 2.37 & 2.46 \\
\hline 4725 & [Ne IV] & & & & & & & & \\
\hline 4740 & [Ar IV] & 10.9 & 11.52 & & & 0.94 & 0.97 & 3.08 & 3.17 \\
\hline 4861 & H I & 100.0 & 100.00 & 100.0 & 100.00 & 100.00 & 100.00 & 100.00 & 100.00 \\
\hline 4959 & [O III] & 456.0 & 445.17 & 349.3 & 318.24 & 287.99 & 280.78 & 339.79 & 337.45 \\
\hline 5007 & [O III] & 1362.1 & 1314.91 & 1082.5 & 944.27 & 862.42 & 830.94 & 1030.56 & 1020.17 \\
\hline 5200 & {$[\mathrm{~N} \mathrm{I}]$} & 4.2: & 3.89: & 1.3: & 0.97: & 0.67 : & 0.62 : & & \\
\hline 5515 & [Cl III] & & & $0.7:$ & 0.41: & 0.38 & 0.33 & & \\
\hline 5537 & [Cl III] $]$ & & & 1.3 & 0.74 & 0.66 & 0.57 & & \\
\hline 5755 & {$[\mathrm{~N} \mathrm{II}]$} & 2.8: & 2.30: & 7.2 & 3.38 & 1.45 & 1.18 & & \\
\hline 5876 & $\mathrm{He} \mathrm{I}$ & 7.1: & 5.69: & 40.5 & 17.22 & 18.79 & 14.89 & 8.76 & 8.22 \\
\hline 6300 & {$[\mathrm{O} \mathrm{I}]$} & 15.3 & 11.44 & 29.1 & 9.44 & 4.64 & 3.42 & 1.18 & 1.09 \\
\hline 6312 & [S III] & 3.6: & 2.69: & 6.7 & 2.16 & 1.67 & 1.23 & 1.22 & 1.12 \\
\hline 6548 & [N II] & 76.5 & 55.12 & 130.8 & 36.74 & 19.32 & 13.67 & 5.53 & 5.03 \\
\hline 6563 & H I & 388.9 & 279.62 & 1023.4 & 285.09 & 401.24 & 283.37 & 310.11 & 282.06 \\
\hline 6583 & [N II] & 235.3 & 168.69 & 418.9 & 115.38 & 55.71 & 39.22 & 14.44 & 13.12 \\
\hline 6678 & $\mathrm{He} \mathrm{I}$ & 3.7 & 2.62 & 17.1 & 4.49 & 5.40 & 3.75 & 3.89 & 3.52 \\
\hline 6716 & [S II] & 21.2 & 14.94 & 10.4 & 2.68 & 1.14 & 0.79 & 2.03: & 1.84: \\
\hline 6730 & [S II] & 23.1 & 16.25 & 20.2 & 5.17 & 2.23 & 1.54 & 2.47: & 2.23: \\
\hline 7006 & [Ar V] & 2.0 & 1.36 & 1.1 & 0.25 & & & & \\
\hline 7136 & [Ar III] & 34.3 & 23.03 & 103.8 & 22.17 & 14.16 & 9.30 & 8.54 & 7.62 \\
\hline 7325 & {$[\mathrm{O}$ II] } & 14.0 & 9.20 & 133.8 & 26.26 & 16.06 & 10.31 & 4.12 & 3.65 \\
\hline
\end{tabular}

Notes. The two columns for each object give measured (left) and dereddened (right) intensities, respectively. Meaning of the symbols: (:) refers to line error at $20 \%$; (;) is a line error at $40 \%$; (p) is a line present but not measurable; (?) defines uncertain identyfication; (c) is a additional reddening correction applied. 
Table B.1. continued.

\begin{tabular}{|c|c|c|c|c|c|c|c|c|c|}
\hline \multirow{3}{*}{$\begin{array}{l}\mathrm{PNG} \\
\text { name } \\
\mathrm{C}(\mathrm{H} \beta)\end{array}$} & \multirow[b]{4}{*}{ [O II] } & \multicolumn{2}{|c|}{$291.4+19.2$} & \multicolumn{2}{|c|}{$292.8+01.1$} & \multicolumn{2}{|c|}{$\overline{293.1-00.0}$} & \multicolumn{2}{|c|}{$293.6+01.2$} \\
\hline & & \multicolumn{2}{|c|}{ ESO 320-2 } & \multicolumn{2}{|c|}{ He 2- 67} & \multicolumn{2}{|c|}{ BMPJ1128-6 } & \multicolumn{2}{|c|}{ He 2- 70} \\
\hline & & & 0.33 & & 0.81 & & 2.16 & & 0.92 \\
\hline 3727 & & & & 44.6 & $61.45 \mathrm{c}$ & & & 244.7: & 419.46:c \\
\hline 3869 & {$[\mathrm{Ne}$ III] } & 20.9: & $13.10: \mathrm{c}$ & 85.2 & $114.90 \mathrm{c}$ & 77.1; & 98.64; c & 146.3: & 234.49:c \\
\hline 4068 & [S II] & & & 5.4 & $7.05 \mathrm{c}$ & & & & \\
\hline 4102 & H I & 31.0: & $26.36: c$ & 19.9 & $25.83 \mathrm{c}$ & & & & \\
\hline 4340 & H I & 44.4 & $47.46 \mathrm{c}$ & 37.2 & 47.28 & 35.8 & 47.32; c & 35.9 & $47.15 \mathrm{c}$ \\
\hline 4363 & [O III] & 10.6; & 9.71 & 5.2 & 6.55 & 28.2 & 37.08 & 26.8: & 34.84: \\
\hline 4471 & $\mathrm{He} \mathrm{I}$ & & & 4.7 & 5.62 & & & & \\
\hline 4686 & He II & 107.9 & 104.86 & 18.9 & 20.43 & 49.9: & 55.15: & 76.7 & 83.78 \\
\hline 4711 & [Ar IV] & 20.0: & 19.52: & 3.6 & 3.22 & & & 15.2: & 16.40: \\
\hline 4725 & {$[\mathrm{Ne} I \mathrm{IV}]$} & & & & & & & & \\
\hline 4740 & [Ar IV] & 17.8 & 17.46; & 3.9 & 4.12 & & & 13.9: & 14.79: \\
\hline 4861 & $\mathrm{H} \mathrm{I}$ & 100.0 & 100.00 & 100.0 & 100.00 & 100.0 & 100.00 & 100.0 & 100.00 \\
\hline 4959 & [O III] & 120.4 & 118.30 & 407.3 & 389.82 & 509.9 & 453.53 & 356.9 & 339.54 \\
\hline 5007 & [O III] & 358.6 & 349.44 & 1242.6 & 1165.17 & 1605.8 & 1352.23 & 1100.3 & 1022.69 \\
\hline 5200 & {$[\mathrm{~N} \mathrm{I}]$} & & & 2.0 & 1.74 & & & 39.5 & 33.72 \\
\hline 5515 & [Cl III] & 6.5: & 5.86: & 1.0 & 0.77 & & & & \\
\hline 5537 & [Cl III] & & & 1.6 & 1.23 & & & & \\
\hline 5755 & {$[\mathrm{~N} \mathrm{III}]$} & & & 5.4 & 3.78 & 12.7 & 4.90; & 40.9 & 27.27 \\
\hline 5876 & $\mathrm{He} \mathrm{I}$ & & & 25.1 & 16.78 & 35.2 & 12.00 & 38.6: & 24.42: \\
\hline 6300 & [O I] & & & 14.5 & 8.53 & 34.2 & 8.29 & 83.3 & 45.58 \\
\hline 6312 & [S III] & & & 6.0 & 3.52 & 17.4 & 4.18 & 16.8: & 9.16: \\
\hline 6548 & [N II] & & & 133.8 & 73.57 & 128.0 & 25.91 & 948.5 & 480.59 \\
\hline 6563 & H I & 351.7 & 276.09 & 524.7 & 287.41 & 1389.6 & 278.37 & 544.0 & 274.43 \\
\hline 6583 & {$[\mathrm{~N} \mathrm{II}]$} & & & 420.0 & 228.83 & 391.5 & 77.31 & 3024.5 & 1516.50 \\
\hline 6678 & $\mathrm{He} \mathrm{I}$ & & & 8.6 & 4.58 & 12.5 & 2.32 & $\mathrm{p}$ & $\mathrm{p}$ \\
\hline 6716 & [S II $]$ & & & 21.4 & 11.29 & 8.4: & 1.52: & 209.4 & 101.27 \\
\hline 6730 & [S II] & & & 36.6 & 19.26 & 23.1 & 4.15 & 180.8 & 87.12 \\
\hline 7006 & {$[\mathrm{Ar} \mathrm{V}]$} & 9.1; & 6.87 & & & 36.3 & 5.58 & & \\
\hline 7136 & [Ar III] & $\mathrm{p}$ & $\mathrm{p}$ & 64.2 & 31.03 & 153.2 & 21.97 & 102.8 & 44.98 \\
\hline 7325 & [O II] $]$ & & & 20.3 & 9.43 & 174.9 & 18.54 & 55.5: & 23.21: \\
\hline PNG & & & $6+04.7$ & & $9-04.3$ & 295 & -09.3 & 296 & $3-03.0$ \\
\hline name & & $\mathrm{NC}$ & 3918 & & 2- 68 & & $2-62$ & & $2-73$ \\
\hline $\mathrm{C}(\mathrm{H} \beta)$ & & & 0.27 & & 0.33 & & 0.33 & & 1.4 \\
\hline 3727 & [O II] & 58.7: & 61.84:c & 126.7 & $153.71 \mathrm{c}$ & 26.7 & $38.90 \mathrm{c}$ & 20.8 & $58.69 \mathrm{c}$ \\
\hline 3869 & {$[\mathrm{Ne} \mathrm{III]}]$} & 100.7 & $106.75 \mathrm{c}$ & 2.8 & $3.32 \mathrm{c}$ & 61.7 & $85.03 \mathrm{c}$ & 56.4 & $139.07 \mathrm{c}$ \\
\hline 4068 & [S II] & 2.1: & 2.24:c & 3.0: & $3.43: \mathrm{c}$ & $2.5:$ & $3.18: c$ & 3.0 & $6.10 \mathrm{c}$ \\
\hline 4102 & H I & 24.4 & $26.09 \mathrm{c}$ & 22.9 & $26.07 \mathrm{c}$ & 20.8 & $26.10 \mathrm{c}$ & 13.2 & $26.01 \mathrm{c}$ \\
\hline 4340 & H I & 43.0 & $46.65 \mathrm{c}$ & 42.6 & 46.98 & 41.1 & $47.14 \mathrm{c}$ & 29.0 & $47.01 \mathrm{c}$ \\
\hline 4363 & [O III] & 19.4 & 20.98 & 1.1: & 1.21: & 9.8 & 11.49 & 9.8 & 15.92 \\
\hline 4471 & $\mathrm{He} \mathrm{I}$ & 3.2 & 3.40 & 3.7 & 3.98 & 4.4 & 4.98 & 3.4 & 4.96 \\
\hline 4686 & He II & 47.1 & 48.36 & 0.3: & 0.31: & & & 21.0 & 24.78 \\
\hline 4711 & [Ar IV] & 7.9: & 7.56: & 0.6 & & 1.1: & $0.36:$ & 4.7 & 4.71 \\
\hline 4725 & [Ne IV] & 1.8 & 1.84 & & & & & 1.7 & 1.94; \\
\hline 4740 & [Ar IV] & 8.5: & 8.66: & & & 1.1: & 1.14: & 8.1: & 9.09: \\
\hline 4861 & H I & 100.0 & 100.00 & 100.0 & 100.00 & 100.0 & 100.00 & 100.0 & 100.00 \\
\hline 4959 & [O III] & 537.1 & 529.16 & 48.6 & 47.74 & 279.9 & 274.99 & 553.7 & 513.23 \\
\hline 5007 & [O III] & 1613.1 & 1578.26 & 150.0 & 146.12 & 848.0 & 826.27 & 1723.9 & 1542.26 \\
\hline 5200 & {$[\mathrm{~N} \mathrm{I}]$} & 1.0 & 0.95 & 0.6 & 0.57 & 0.7 & 0.66 & 1.1 & 0.86 \\
\hline 5515 & [Cl III] & 0.6 & 0.55 & 0.2 & 0.18 & 0.4 & 0.36 & 0.9 & 0.58 \\
\hline 5537 & [Cl III] & 0.9 & 0.82 & 0.3 & 0.27 & 0.5 & 0.45 & 1.4 & 0.88 \\
\hline 5755 & {$[\mathrm{~N} \mathrm{II}]$} & 2.0 & 1.77 & 4.0 & 3.46 & 2.4 & 2.08 & 5.7 & 3.08 \\
\hline 5876 & $\mathrm{He} \mathrm{I}$ & 11.8 & 10.29 & 13.7 & 11.62 & 18.9 & 16.06 & 30.8 & 15.34 \\
\hline 6300 & [O I] & 6.5 & 5.43 & 4.1 & 3.30 & 4.0 & 3.23 & 17.2 & 6.87 \\
\hline 6312 & [S III] & 3.3 & 2.75 & 1.1 & 0.88 & 2.5 & 2.02 & 8.7 & 3.45 \\
\hline 6548 & {$[\mathrm{~N}$ II $]$} & 32.2 & 26.28 & 68.5 & 53.68 & 25.7 & 20.19 & 107.7 & 38.26 \\
\hline 6563 & H I & 345.5 & 281.66 & 364.5 & 285.18 & 358.7 & 281.35 & 803.2 & 283.45 \\
\hline 6583 & [N II] & 101.2 & 82.35 & 212.6 & 165.98 & 62.9 & 49.23 & 321.7 & 112.48 \\
\hline 6678 & He I & 4.0 & 3.23 & 3.8 & 2.94 & 4.9 & 3.80 & 11.7 & 3.93 \\
\hline 6716 & [S II] & 3.5 & 2.82 & 2.1 & 1.62 & 1.9 & 1.47 & 14.0 & 4.63 \\
\hline 6730 & [S II] & 6.3 & 5.07 & 4.5 & 3.46 & 3.5 & 2.70 & 26.2 & 8.62 \\
\hline 7006 & {$[\mathrm{Ar} \mathrm{V}]$} & 2.9 & 2.29 & 0.3 & 0.23 & & & 2.9 & 0.86 \\
\hline 7136 & [Ar III] & 25.3 & 19.77 & 9.1 & 6.77 & 14.3 & 10.66 & 93.1 & 26.46 \\
\hline 7325 & [O II] & 11.3 & 8.71 & 42.1 & 30.80 & 16.0 & 11.74 & 45.4 & 12.04 \\
\hline
\end{tabular}


S. K. Górny: Spectroscopy of southern Galactic disk planetary nebulae

Table B.1. continued.

\begin{tabular}{|c|c|c|c|c|c|c|c|c|c|}
\hline \multirow{2}{*}{$\begin{array}{l}\text { PNG } \\
\text { name } \\
\mathrm{C}(\mathrm{H} \beta)\end{array}$} & \multirow[b]{3}{*}{ [O II] } & \multicolumn{2}{|c|}{$\begin{array}{c}297.4+03.7 \\
\text { He } 2-78\end{array}$} & \multicolumn{2}{|c|}{$\overline{299.0+18.4}$} & \multicolumn{2}{|c|}{$299.5+02.4$} & \multicolumn{2}{|c|}{ 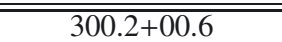 } \\
\hline & & & 0.89 & & 0.13 & & 0.92 & & 2.42 \\
\hline 3727 & & 138.9 & $234.70 \mathrm{c}$ & 170.7 & $221.26 \mathrm{c}$ & 293.7 & $457.07 \mathrm{c}$ & 29.2: & 56.49:c \\
\hline 3869 & [Ne III] & & & 75.1 & $94.48 \mathrm{c}$ & 55.5 & $81.64 \mathrm{c}$ & & \\
\hline 4068 & [S II $]$ & & & & & & & & \\
\hline 4102 & $\mathrm{H} \mathrm{I}$ & 17.1: & $24.30: \mathrm{c}$ & 21.7 & $25.97 \mathrm{c}$ & 19.3 & $25.86 \mathrm{c}$ & 12.5 & $25.65 \mathrm{c}$ \\
\hline 4340 & H I & 37.8 & 49.29 & 41.2 & $46.96 \mathrm{c}$ & 37.5 & $46.82 \mathrm{c}$ & 23.3 & $47.74 \mathrm{c}$ \\
\hline 4363 & [O III] & & & 7.5: & 8.48: & & & & \\
\hline 4471 & $\mathrm{He} \mathrm{I}$ & 3.4: & 4.14: & 4.4; & 4.85 & & & 5.2 & 8.87 \\
\hline 4686 & He II & & & 14.5 & 15.15 & 17.4 & 18.72 & & \\
\hline 4711 & [Ar IV] & & & & & & & & \\
\hline 4725 & [Ne IV] & & & & & & & & \\
\hline 4740 & [Ar IV] & & & & & & & & \\
\hline 4861 & H I & 100.0 & 100.00 & 100.0 & 100.00 & 100.0 & 100.00 & 100.0 & 100.00 \\
\hline 4959 & [O III] & 12.9 & 12.29 & 314.4 & 312.23 & 259.4 & 246.79 & 26.2 & 22.98 \\
\hline 5007 & [O III] & 35.0 & 32.59 & 944.5 & 934.96 & 797.3 & 741.09 & 82.3 & 67.89 \\
\hline 5200 & {$[\mathrm{~N} \mathrm{I}]$} & & & & & 15.6 & 13.32 & & \\
\hline 5515 & [Cl III] & & & & & & & & \\
\hline 5537 & [Cl III] & & & 1.6; & 1.53; & & & & \\
\hline 5755 & {$[\mathrm{~N} \mathrm{II}]$} & 2.2 & 1.48; & 3.0: & 2.84: & 6.8: & 4.54: & 8.7 & 3.00 \\
\hline 5876 & $\mathrm{He} \mathrm{I}$ & 11.6 & 7.43 & 14.2: & 13.33: & 23.7 & 15.00 & 48.4 & 14.50 \\
\hline 6300 & [O I] & 2.3; & 1.28; & 5.6 ; & 5.15 & 83.4 & 45.65 & 9.7: & 1.98: \\
\hline 6312 & [S III] & & & & & 4.8; & 2.62 & 6.5: & 1.32: \\
\hline 6548 & [N II] & 105.7 & 54.54 & 50.3 & 45.77 & 210.5 & 106.70 & 609.8 & 101.92 \\
\hline 6563 & H I & 568.2 & 291.93 & 312.5 & 284.20 & 567.9 & 286.59 & 1763.7 & 291.40 \\
\hline 6583 & [N II] & 346.5 & 176.97 & 152.1 & 138.21 & 660.4 & 331.25 & 1941.6 & 315.70 \\
\hline 6678 & $\mathrm{He} \mathrm{I}$ & 5.7 & 2.84 & 4.8: & 4.35: & 9.2 & 4.50 & 29.9 & 4.54 \\
\hline 6716 & [S II] & 8.1 & 3.99 & 25.6 & 23.15 & 117.4 & 56.80 & 34.3 & 5.07 \\
\hline 6730 & [S II] & 14.8 & 7.27 & 20.0 & 18.07 & 96.3 & 46.42 & 66.5 & 9.74 \\
\hline 7006 & [Ar V] & & & & & & & & \\
\hline 7136 & [Ar III] & 11.7 & 5.23 & 18.3 & 16.32 & 40.1 & 17.55 & 114.8 & 13.04 \\
\hline 7325 & [O II] & 25.8 & 11.04 & 7.6; & 6.73; & 37.5 & 15.69 & 81.7 & 8.24 \\
\hline$\overline{\mathrm{PNG}}$ & & & $4-00.9$ & & $5-01.1$ & 300 & -02.0 & 300 & $3-03.4$ \\
\hline name & & & $2-84$ & & $2-85$ & & -86 & ES & 095-1 \\
\hline $\mathrm{C}(\mathrm{H} \beta)$ & & & 1.27 & & 1.76 & & 2.00 & & 0.67 \\
\hline 3727 & [O II] & 91.8 & $161.37 \mathrm{c}$ & 18.5: & 49.45:c & 7.8 & $37.40 \mathrm{c}$ & 134.1: & $161.27: \mathrm{c}$ \\
\hline 3869 & [Ne III] & 76.2 & $125.10 \mathrm{c}$ & 46.4 & $108.72 \mathrm{c}$ & 21.7 & $83.58 \mathrm{c}$ & 91.2: & $107.46: \mathrm{c}$ \\
\hline 4068 & [S II] & & & & & 1.6: & 4.48:c & & \\
\hline 4102 & H I & 16.8 & $24.61 \mathrm{c}$ & 13.8 & $26.02 \mathrm{c}$ & 9.7 & $25.73 \mathrm{c}$ & & \\
\hline 4340 & H I & 35.6 & $47.95 \mathrm{c}$ & 29.7 & $47.03 \mathrm{c}$ & 24.9 & $46.64 \mathrm{c}$ & 42.3 & $47.13 \mathrm{c}$ \\
\hline 4363 & [O III] & 8.4 & 11.19 & 9.3 & 14.81 & 1.7: & 3.42: & 18.8; & 20.88 \\
\hline 4471 & $\mathrm{He} \mathrm{I}$ & 5.1: & 6.37: & 2.2: & 3.15: & 4.3 & 7.41 & & \\
\hline 4686 & He II & 25.9 & 28.52 & 40.2 & 47.00 & ? & $?$ & & \\
\hline 4711 & [Ar IV] & 6.5: & 6.29: & 9.6 & 10.56 & 1.2: & 0.54: & & \\
\hline 4725 & [Ne IV] & & & & & & & & \\
\hline 4740 & [Ar IV] & 5.3: & 5.67: & 8.2 & 9.15 & 1.5: & 1.77: & & \\
\hline 4861 & $\mathrm{H} \mathrm{I}$ & 100.0 & 100.00 & 100.0 & 100.00 & 100.0 & 100.00 & 100.0 & 100.00 \\
\hline 4959 & [O III] & 402.0 & 375.18 & 505.5 & 459.55 & 311.3 & 279.26 & 533.6 & 514.64 \\
\hline 5007 & [O III] & 1241.5 & 1121.92 & 1570.6 & 1365.70 & 989.1 & 843.42 & 1622.4 & 1538.56 \\
\hline 5200 & {$[\mathrm{~N} \mathrm{I}]$} & 16.8 & 13.49 & & & 1.0 & 0.71 & & \\
\hline 5515 & [Cl III] & & & 1.5 & 0.86 & 0.9 & 0.48 & & \\
\hline 5537 & [Cl III] & & & 1.9: & 1.07: & 1.7 & 0.88 & & \\
\hline 5755 & {$[\mathrm{~N} \mathrm{II}]$} & 19.8 & 11.30 & 3.4 & 1.57 & 7.1 & 2.94 & & \\
\hline 5876 & $\mathrm{He} \mathrm{I}$ & 31.3 & 16.60 & 27.1 & 11.29 & 55.5 & 20.46 & & \\
\hline 6300 & [O I] & 54.7 & 23.73 & 15.7 & 4.96 & 13.6 & 3.66 & 15.1 & 9.75 \\
\hline 6312 & [S III] & 13.7 & 5.91 & 9.6 & 3.01 & 9.4 & 2.51 & 14.5 & 9.34 \\
\hline 6548 & {$[\mathrm{~N} \mathrm{II}]$} & 439.6 & 171.48 & 86.9 & 23.70 & 175.5 & 39.91 & 40.0 & 24.43 \\
\hline 6563 & H I & 731.4 & 283.57 & 1046.7 & 283.06 & 1285.7 & 289.60 & 462.3 & 281.41 \\
\hline 6583 & [N II] & 1395.2 & 536.40 & 266.4 & 71.21 & 538.4 & 119.68 & 131.2 & 79.51 \\
\hline 6678 & $\mathrm{He} \mathrm{I}$ & 14.1 & 5.23 & 12.2 & 3.10 & 25.4 & 5.33 & & \\
\hline 6716 & [S II] & 128.0 & 46.81 & 22.0 & 5.49 & 11.6 & 2.38 & 31.2 & 18.42 \\
\hline 6730 & [S II] & 149.0 & 54.21 & 36.9 & 9.14 & 24.2 & 4.93 & 29.5 & 17.37 \\
\hline 7006 & {$[\mathrm{Ar} \mathrm{V}]$} & 5.7: & 1.89: & 10.4 & 2.27 & & & & \\
\hline 7136 & [Ar III] & 100.5 & 32.00 & 107.5 & 22.15 & 203.8 & 33.67 & 52.8 & 28.99 \\
\hline 7325 & [O II] & 48.9 & 14.62 & 32.3 & 6.10 & 55.5 & 8.31 & & \\
\hline
\end{tabular}


Table B.1. continued.

\begin{tabular}{|c|c|c|c|c|c|c|c|c|c|}
\hline \multirow{3}{*}{$\begin{array}{l}\mathrm{PNG} \\
\text { name } \\
\mathrm{C}(\mathrm{H} \beta)\end{array}$} & & \multicolumn{2}{|c|}{$\overline{302.2+02.5}$} & \multicolumn{2}{|c|}{$\overline{305.1+01.4}$} & \multicolumn{2}{|c|}{$307.3+05.0$} & \multicolumn{2}{|c|}{$308.2+07.7$} \\
\hline & & Wray & $16-120$ & $\mathrm{He}$ & $2-90$ & Wray & $16-128$ & $\mathrm{Me}$ & Ve $1-3$ \\
\hline & & & 1.22 & & 1.23 & & 0.96 & & 0.49 \\
\hline 3727 & [O II] & & & 12.8 & $25.07 \mathrm{c}$ & & & & \\
\hline 3869 & [Ne III] & 76.0 & $10.89 ; \mathrm{c}$ & 2.5 & $4.44 \mathrm{c}$ & 20.5 & $35.26 \mathrm{c}$ & 55.9 & $82.56 \mathrm{c}$ \\
\hline 4068 & [S II] & & & 1.4 & $2.16 \mathrm{c}$ & & & & \\
\hline 4102 & H I & & & 17.6 & $26.57 \mathrm{c}$ & 17.6 & $26.33 \mathrm{c}$ & 19.6 & $26.35 \mathrm{c}$ \\
\hline 4340 & H I & 63.5 & $46.92 ; \mathrm{c}$ & 36.1 & $47.72 \mathrm{c}$ & 35.8 & 47.63 & 38.4 & $47.46 \mathrm{c}$ \\
\hline 4363 & [O III] & & & 5.3 & 7.19 & 8.6 & 11.32 & 15.1 & 18.61 \\
\hline 4471 & $\mathrm{He} \mathrm{I}$ & & & 5.0 & 6.33 & 4.6 & 5.69 & & \\
\hline 4686 & He II & 87.8 & 82.61 & & & 101.6 & 111.45 & 102.5 & 110.15 \\
\hline 4711 & [Ar IV] & & & 0.8 & & 14.0 & 14.22 & 14.1 & 15.00 \\
\hline 4725 & [Ne IV] & & & & & 2.5 & 2.69 & & \\
\hline 4740 & [Ar IV] & & & & & 10.4 & 11.10 & 11.4 & 11.99 \\
\hline 4861 & H I & 100.0 & 100.00 & 100.0 & 100.00 & 100.0 & 100.00 & 100.0 & 100.00 \\
\hline 4959 & [O III] & 354.2 & 331.59 & 52.2 & 48.82 & 154.5 & 146.64 & 231.4 & 225.39 \\
\hline 5007 & [O III] & 1070.6 & 971.85 & 162.6 & 147.40 & 475.9 & 440.80 & 702.9 & 676.26 \\
\hline 5200 & {$[\mathrm{~N} \mathrm{I}]$} & & & 3.9 & 3.15 & & & & \\
\hline 5515 & [Cl III] & & & $0.4:$ & 0.27 : & & & & \\
\hline 5537 & [Cl III] & & & 0.6 & 0.40 & 0.7 & 0.51 & & \\
\hline 5755 & [N II] & & & 11.4 & 6.62 & & & & \\
\hline 5876 & He I & & & 25.2 & 13.63 & 1.4 & 0.87 & & \\
\hline 6300 & [O I] & & & 1.8 & 0.80 & & & & \\
\hline 6312 & [S III] & & & 10.4 & 4.61 & $3.5:$ & 1.85: & 3.4: & $2.47:$ \\
\hline 6548 & [N II] & & & 38.7 & 15.55 & & & & \\
\hline 6563 & $\mathrm{H} \mathrm{I}$ & 704.5 & 284.90 & 680.8 & 271.90 & 566.5 & 276.66 & 396.4 & 276.17 \\
\hline 6583 & [N II] & 49.0 & 19.66 & 96.9 & 38.39 & 3.5 & 1.70 & & \\
\hline 6678 & He I & & & 8.7 & 3.33 & 2.8 & 1.32 & & \\
\hline 6716 & [S II] & & & 0.6 & 0.23 & 1.0 & 0.47 & & \\
\hline 6730 & [S II] & & & 1.3 & 0.49 & 0.7 & 0.33; & & \\
\hline 7006 & [Ar V] & & & & & 13.4 & 5.82 & 5.1: & $3.35:$ \\
\hline 7136 & [Ar III] & 49.2 & 16.48 & 40.7 & 13.43 & 13.3 & 5.60 & 12.6 & 8.14 \\
\hline 7325 & [O II] & & & 84.8 & 26.34 & & & & \\
\hline PNG & & 309. & +00.8 & 309. & -02.9 & 310.2 & +01.3 & 310 & $7-02.9$ \\
\hline name & & $\mathrm{He}$ & 2- 96 & $\mathrm{Ma}$ & $1-2$ & & 4 & & $2-103$ \\
\hline $\mathrm{C}(\mathrm{H} \beta)$ & & & 1.78 & & 1.27 & & 3.25 & & 1.05 \\
\hline 3727 & [O II] & 17.0: & 73.21:c & 91.04: & 122.57:c & & & 233.9 & $433.55 \mathrm{c}$ \\
\hline 3869 & [Ne III] & 20.3: & 71.46:c & 78.21: & 102.73:c & & & 68.1: & 116.88:c \\
\hline 4068 & [S II] & 2.2 & $5.77 ; \mathrm{c}$ & & & & & & \\
\hline 4102 & H I & 10.3 & $25.71 \mathrm{c}$ & & & & & 19.1: & 28.88:c \\
\hline 4340 & H I & 25.8 & $46.60 \mathrm{c}$ & 38.68 & $47.03 \mathrm{c}$ & & & 38.4 & 52.47 \\
\hline 4363 & [O III] & 1.6 & 3.08 & 13.11; & 15.85 & & & 7.2; & 9.72 \\
\hline 4471 & $\mathrm{He} \mathrm{I}$ & 3.7 & 6.16 & & & & & & \\
\hline 4686 & He II & & & 14.91 & 15.91 & 70.7: & 96.61: & 4.5 & 4.98 \\
\hline 4711 & [Ar IV] & 2.0 & 1.72; & & & & & & \\
\hline 4725 & [Ne IV] & & & & & & & & \\
\hline 4740 & [Ar IV] & & & & & & & & \\
\hline 4861 & $\mathrm{H} \mathrm{I}$ & 100.0 & 100.00 & 100.00 & 100.00 & 100.0: & 100.00: & 100.0 & 100.00 \\
\hline 4959 & [O III] & 307.1 & 278.78 & 543.11 & 507.01 & 534.6 & 448.22 & 282.9 & 267.20 \\
\hline 5007 & [O III] & 972.0 & 843.37 & 1648.96 & 1490.70 & 1728.9 & 1335.03 & 872.2 & 802.13 \\
\hline 5200 & {$[\mathrm{~N} \mathrm{I}]$} & 1.1 & 0.81 & & & & & 5.0 & 4.17 \\
\hline 5515 & [Cl III] & 0.9: & 0.51: & & & & & & \\
\hline 5537 & [Cl III] & 2.0: & 1.11: & & & & & & \\
\hline 5755 & [N II] & 4.5 & 2.05 & 13.49: & 7.71: & & & $6.7:$ & 4.21: \\
\hline 5876 & $\mathrm{He} \mathrm{I}$ & 47.8 & 19.65 & 31.42 & 16.70 & 47.9: & 9.49: & 27.1 & 16.04 \\
\hline 6300 & [O I] & 17.2 & 5.34 & 54.53 & 23.74 & 27.6 & 3.28 & 55.3 & 27.73 \\
\hline 6312 & [S III] & 7.6 & 2.34 & 4.72 & 2.04; & 76.3 & 8.93; & 18.2 & 9.08 \\
\hline 6548 & [N II] & & & 292.55 & 114.52 & 184.1 & 16.65 & 193.9 & 89.02 \\
\hline 6563 & $\mathrm{H} \mathrm{I}$ & 1095.0 & 290.19 & 727.74 & 283.16 & 3217.8 & 286.55 & 617.8 & 282.21 \\
\hline 6583 & [N II] & 273.0 & 71.50 & 908.68 & 350.61 & 524.0 & 45.67 & 600.5 & 272.41 \\
\hline 6678 & He I & 20.4 & 5.08 & 10.28 & 3.83 & 37.4 & 2.97; & 9.8: & 4.31: \\
\hline 6716 & [S II] & 8.5 & 2.08 & 24.43 & 8.97 & 68.2 & 5.23 & 65.7 & 28.59 \\
\hline 6730 & [S II] & 17.2 & 4.17 & 34.81 & 12.71 & 79.9 & 6.05 & 59.9 & 25.96 \\
\hline 7006 & {$[\mathrm{Ar} \mathrm{V}]$} & & & & & 79.3: & 4.75: & & \\
\hline 7136 & [Ar III] & 110.7 & 22.26 & 86.42 & 27.63 & 419.3 & 22.58 & 39.0 & 15.14 \\
\hline 7325 & [O II] & 93.5 & 17.22 & 65.09 & 19.55 & 111.1: & 4.19: & 29.1 & 10.72 \\
\hline
\end{tabular}


S. K. Górny: Spectroscopy of southern Galactic disk planetary nebulae

Table B.1. continued.

\begin{tabular}{|c|c|c|c|c|c|c|c|c|c|}
\hline \multirow{4}{*}{$\begin{array}{l}\mathrm{PNG} \\
\text { name } \\
\mathrm{C}(\mathrm{H} \beta)\end{array}$} & & \multicolumn{2}{|c|}{$311.4+02.8$} & \multicolumn{2}{|c|}{$312.6-01.8$} & \multicolumn{2}{|c|}{$314.4+02.2$} & \multicolumn{2}{|c|}{$315.1-13.0$} \\
\hline & & \multicolumn{2}{|c|}{ He $2-102$} & \multicolumn{2}{|c|}{ He 2-107 } & \multicolumn{2}{|c|}{ PM 1- 81} & \multicolumn{2}{|c|}{ He $2-131$} \\
\hline & & & 1.03 & & 1.31 & & 4.69 & & 0.09 \\
\hline & [O II] & 6.6 & $11.20 \mathrm{c}$ & 50.7 & $132.37 \mathrm{c}$ & & & 75.5 & $93.26 \mathrm{c}$ \\
\hline 3869 & {$[\mathrm{Ne} \mathrm{III}]$} & 50.9 & $81.58 \mathrm{c}$ & & & & & & \\
\hline 4068 & [S II] & 2.3; & $3.40 ; \mathrm{c}$ & & & & & 4.5 & $5.17 \mathrm{c}$ \\
\hline 4102 & H I & 17.8 & $25.94 \mathrm{c}$ & 14.1 & $25.51 \mathrm{c}$ & & & 23.2 & $26.45 \mathrm{c}$ \\
\hline 4340 & H I & 34.4 & 46.74 & 31.1 & 45.84 & & & 43.9 & $47.57 \mathrm{c}$ \\
\hline 4363 & [O III] & 6.2 & 8.33 & & & & & $0.3:$ & 0.33: \\
\hline 4471 & $\mathrm{He} \mathrm{I}$ & 3.9 & 4.90 & 5.4 & 7.21 & & & 1.6 & 1.72 \\
\hline 4686 & He II & 37.1 & 40.97 & 2.0: & 2.27: & & & 0.3 & 0.31 \\
\hline 4711 & [Ar IV] & 4.5 & 4.33 & & & & & 0.3 & \\
\hline 4725 & [Ne IV] & & & & & & & & \\
\hline 4740 & [Ar IV] & 4.6 & 4.93 & & & & & & \\
\hline 4861 & H I & 100.0 & 100.00 & 100.0 & 100.00 & 100.0; & 100.00; & 100.0 & 100.00 \\
\hline 4959 & [O III] & 354.3 & 334.98 & 21.2 & 19.75 & 1381.2 & 1070.59 & 3.1 & 3.08 \\
\hline 5007 & [O III] & 1086.8 & 1000.98 & 66.7 & 60.11 & 4431.6 & 3049.74 & 9.5 & 9.43 \\
\hline 5200 & {$[\mathrm{~N} \mathrm{I}]$} & & & & & & & 0.6 & 0.59 \\
\hline 5515 & [Cl III] & 0.9: & 0.65 : & & & & & $0.1:$ & 0.10 : \\
\hline 5537 & [Cl III] & $0.5:$ & 0.36 : & & & & & $0.2:$ & 0.19 : \\
\hline 5755 & [N II] & & & 2.1: & 1.18: & 101.1; & 12.75; & 3.0 & 2.88 \\
\hline 5876 & $\mathrm{He} \mathrm{I}$ & 22.3 & 13.32 & 39.4 & 20.54 & 325.8 & 31.38 & 5.7 & 5.44 \\
\hline 6300 & [O I] & & & & & 342.5 & 15.73 & 2.4 & 2.26 \\
\hline 6312 & [S III] & 2.3 & 1.16 & 1.5: & 0.63: & 122.4: & 5.51: & 0.8 & 0.75 \\
\hline 6548 & [N II] & 3.4 & 1.58 & 182.5 & 69.38 & 1696.0 & 52.59 & 89.2 & 83.26 \\
\hline 6563 & H I & 614.8 & 284.81 & 780.1 & 294.71 & 8893.1 & 269.62 & 294.0 & 274.30 \\
\hline 6583 & [N II] & 8.7 & 4.00 & 577.4 & 216.25 & 5559.3 & 163.39 & 275.7 & 257.07 \\
\hline 6678 & He I & 8.4 & 3.75 & 15.6 & 5.63 & 185.3: & 4.77: & 1.6 & 1.49 \\
\hline 6716 & [S II $]$ & 1.5 & 0.66 & 7.5 & 2.67 & 199.1: & 4.86: & & \\
\hline 6730 & [S II] & 1.9 & 0.84 & 12.6 & 4.46 & 253.4: & 6.08: & & \\
\hline 7006 & {$[\mathrm{Ar} \mathrm{V}]$} & & & & & & & 0.2 & 0.18 \\
\hline 7136 & [Ar III] & 26.4 & 10.42 & 45.7 & 14.10 & 1512.9 & 22.17 & 3.5 & 3.22 \\
\hline 7325 & [O II] & 6.8 & 2.55 & 9.6 & 2.78 & 1837.4 & 17.58 & 10.5 & 9.61 \\
\hline $\mathrm{PNG}$ & & & $4+05.2$ & 315 & +05.5 & 316 & +08.4 & 318 & $3-02.5$ \\
\hline name & & & $2-109$ & & Tr 8 & $\mathrm{He}$ & -108 & & $2-116$ \\
\hline $\mathrm{C}(\mathrm{H} \beta)$ & & & 0.89 & & 0.40 & & 0.51 & & 1.08 \\
\hline 3727 & [O II] & 269.5 & $529.16 \mathrm{c}$ & & & 82.7 & $151.31 \mathrm{c}$ & 162.8 & $306.97 \mathrm{c}$ \\
\hline 3869 & {$[\mathrm{Ne}$ III $]$} & 71.2 & $128.02 \mathrm{c}$ & 284.3; & 349.68; & 3.0: & 5.04:c & 52.1 & $90.77 \mathrm{c}$ \\
\hline 4068 & [S II] & $\mathrm{p}$ & $\mathrm{p}$ & & & 0.5 ; & $0.74 ; \mathrm{c}$ & & \\
\hline 4102 & H I & 16.7 & $25.95 \mathrm{c}$ & & & 17.8 & $25.91 \mathrm{c}$ & 17.1: & $26.15: c$ \\
\hline 4340 & H I & 34.3 & $46.93 \mathrm{c}$ & & & 37.1 & $46.88 \mathrm{c}$ & 33.0 & 45.48 \\
\hline 4363 & [O III] & 6.6 & 9.04 & & & 1.0 & 1.30 & & \\
\hline 4471 & $\mathrm{He} \mathrm{I}$ & 5.0: & 6.38: & & & 5.1: & 6.27: & & \\
\hline 4686 & He II & 13.1 & 14.58 & 104.8 & 108.94 & 3.4 & 3.73 & 17.5 & 19.42 \\
\hline 4711 & [Ar IV] & 0.8 & 0.15 & & & 0.7 & 0.06 & & \\
\hline 4725 & [Ne IV] & & & & & & & & \\
\hline 4740 & [Ar IV] & & & & & & & & \\
\hline 4861 & H I & 100.0 & 100.00 & 100.0; & 100.00; & 100.0 & 100.00 & 100.0 & 100.00 \\
\hline 4959 & [O III] & 382.6 & 364.64 & 405.8 & 397.02 & 60.6 & 58.95 & 215.6 & 203.31 \\
\hline 5007 & [O III] & 1166.8 & 1087.32 & 1256.3 & 1216.63 & 184.1 & 176.81 & 650.6 & 596.94 \\
\hline 5200 & {$[\mathrm{~N} \mathrm{I}]$} & 6.2 & 5.32 & & & & & $\mathrm{p}$ & $\mathrm{p}$ \\
\hline 5515 & [Cl III] & $\mathrm{p}$ & $\mathrm{p}$ & & & 0.5 : & 0.43: & & \\
\hline 5537 & [Cl III] & $\mathrm{p}$ & $\mathrm{p}$ & & & 0.4: & $0.34:$ & & \\
\hline 5755 & {$[\mathrm{~N} \mathrm{II}]$} & 7.4 & 5.01 & & & 0.7 & 0.56 & 10.1 & 6.27 \\
\hline 5876 & $\mathrm{He} \mathrm{I}$ & 25.1 & 16.14 & & & 21.6 & 16.77 & 29.2 & 17.03 \\
\hline 6300 & [O I] & 64.6 & 36.11 & & & & & 10.4: & 5.12: \\
\hline 6312 & [S III] & 1.9: & 1.06: & & & 1.1 & 0.79 & $\mathrm{p}$ & $\mathrm{p}$ \\
\hline 6548 & [N II] & 176.3 & 91.51 & & & 32.0 & 21.98 & 301.1 & 135.29 \\
\hline 6563 & H I & 551.0 & 284.80 & 388.4 & 287.68 & 416.8 & 285.61 & 639.4 & 285.81 \\
\hline 6583 & [N II] & 548.4 & 281.80 & 97.6: & 72.10: & 102.1 & 69.73 & 940.9 & 417.57 \\
\hline 6678 & $\mathrm{He} \mathrm{I}$ & 8.4 & 4.21 & & & 7.2 & 4.85 & 11.9 & 5.12 \\
\hline 6716 & [S II] & 37.1 & 18.41 & 28.5: & 20.72: & 3.0 & 2.01 & 128.3 & 54.57 \\
\hline 6730 & [S II] & 39.2 & 19.38 & 15.5: & 11.25: & 3.6 & 2.41 & 107.0 & 45.32 \\
\hline 7006 & [Ar V] & & & & & & & & \\
\hline 7136 & [Ar III] & 37.5 & 16.90 & 54.4: & 37.85: & 24.3 & 15.39 & 63.4 & 23.97 \\
\hline 7325 & [O II $]$ & 41.9 & 18.07 & & & 4.5 & 2.78 & 28.1 & 10.07 \\
\hline
\end{tabular}


Table B.1. continued.

\begin{tabular}{|c|c|c|c|c|c|c|c|c|c|}
\hline \multirow{3}{*}{$\begin{array}{l}\mathrm{PNG} \\
\text { name } \\
\mathrm{C}(\mathrm{H} \beta)\end{array}$} & & \multicolumn{2}{|c|}{$319.2+06.8$} & \multicolumn{2}{|c|}{$320.9+02.0$} & \multicolumn{2}{|c|}{$321.3+02.8$} & \multicolumn{2}{|c|}{$321.8+01.9$} \\
\hline & & \multicolumn{2}{|c|}{ He 2-112 } & \multicolumn{2}{|c|}{ He 2-117 } & \multicolumn{2}{|c|}{ He 2-115 } & \multicolumn{2}{|c|}{ He 2-120 } \\
\hline & & & 1.19 & & 2.70 & & 2.21 & & 1.21 \\
\hline 3727 & [O II] & 51.1 & $121.86 \mathrm{c}$ & 7.5 & $32.60 \mathrm{c}$ & 16.5 & $67.93 \mathrm{c}$ & 123.9 & 252.22 \\
\hline 3869 & [Ne III] & 78.4 & $165.14 \mathrm{c}$ & 14.7 & $52.57 \mathrm{c}$ & 8.4 & $29.01 \mathrm{c}$ & 41.8; & 77.88 ; \\
\hline 4068 & [S II] & 4.3: & 7.58:c & 2.2 & $5.98 ; \mathrm{c}$ & & & & \\
\hline 4102 & H I & 15.3 & $26.19 \mathrm{c}$ & 9.9 & $25.66 \mathrm{c}$ & & & 13.3; & 21.41; \\
\hline 4340 & H I & 33.5 & 47.70 & 23.2 & $46.54 \mathrm{c}$ & 22.9 & $46.68 \mathrm{c}$ & 35.1 & 50.29 \\
\hline 4363 & [O III] & 21.4 & 30.06 & 1.1 & 2.22 & 1.3 & 2.58 & $\mathrm{p}$ & $\mathrm{p}$ \\
\hline 4471 & $\mathrm{He} \mathrm{I}$ & 3.8 & 4.94 & 4.2 & 7.22 & 3.3 & 5.61 & & \\
\hline 4686 & He II & 41.2 & 46.20 & & & 1.9 & 2.40 & 17.1 & 19.21 \\
\hline 4711 & [Ar IV] & 7.2 & 7.18 & $\mathrm{p}$ & $\mathrm{p}$ & 1.1 & 0.53 & & \\
\hline 4725 & [Ne IV] & 1.9 & 2.08 & & & & & & \\
\hline 4740 & [Ar IV] & 4.6 & 4.98 & $\mathrm{p}$ & $\mathrm{p}$ & 1.0 & 1.18 & & \\
\hline 4861 & H I & 100.0 & 100.00 & $100.0^{1}$ & 100.00 & 100.0 & 100.00 & 100.0 & 100.00 \\
\hline 4959 & [O III] & 598.7 & 561.24 & 282.8 & 244.25 & 208.5 & 184.92 & 260.1 & 243.55 \\
\hline 5007 & [O III] & 1852.0 & 1684.52 & 894.9 & 721.78 & 666.1 & 558.55 & 800.2 & 726.61 \\
\hline 5200 & {$[\mathrm{~N} \mathrm{I}]$} & 3.4 & 2.77 & 1.4; & 0.88 & & & 7.5 & 6.09 \\
\hline 5515 & [Cl III] & 1.5 & 1.03 & 1.2 & 0.51 & 1.3 & 0.64 & & \\
\hline 5537 & [Cl III] & 1.7 & 1.15 & 2.8 & 1.15 & 1.0 & 0.48 & & \\
\hline 5755 & [N II] & 12.6 & 7.45 & 11.0 & 3.36 & 5.7 & 2.15 & 9.1 & 5.33 \\
\hline 5876 & He I & 26.8 & 14.80 & 85.7 & 22.30 & 51.4 & 17.06 & 32.4 & 17.71 \\
\hline 6300 & [O I] & 21.2 & 9.70 & 27.8 & 4.72 & 15.2 & 3.56 & 42.7 & 19.28 \\
\hline 6312 & [S III] & 11.3 & 5.15 & 12.6 & 2.12 & 6.4 & 1.48 & 4.5; & 2.02; \\
\hline 6548 & [N II] & 229.8 & 95.22 & 365.9 & 49.60 & 123.8 & 24.09 & 321.3 & 131.06 \\
\hline 6563 & $\mathrm{H} \mathrm{I}$ & 678.3 & 279.47 & 2175.9 & 291.19 & 1500.5 & 288.91 & 707.8 & 287.06 \\
\hline 6583 & [N II] & 727.0 & 297.18 & 1134.4 & 149.12 & 384.4 & 72.94 & 1016.5 & 408.96 \\
\hline 6678 & He I & 10.1 & 3.99 & 43.9 & 5.34 & 23.6 & 4.20 & 14.5 & 5.64 \\
\hline 6716 & [S II] & 33.1 & 12.91 & 30.7 & 3.63 & 5.8 & 1.01 & 109.5 & 42.00 \\
\hline 6730 & [S II] & 48.4 & 18.79 & 61.6 & 7.20 & 12.5 & 2.16 & 100.2 & 38.25 \\
\hline 7006 & [Ar V] & 5.8 & 2.07 & & & $1.1 ?$ & $0.16 ?$ & & \\
\hline 7136 & [Ar III] & 71.6 & 24.53 & 332.4 & 29.28 & 120.9 & 16.53 & 75.6 & 25.41 \\
\hline 7325 & [O II] & 52.1 & 16.84 & 108.8 & 8.39 & 187.7 & 23.01 & 27.5 & 8.71; \\
\hline$\overline{P N G}$ & & & $.5-05.2$ & 323 & +02.4 & 324. & +02.5 & 324 & -01.1 \\
\hline name & & & C 5979 & $\mathrm{He}$ & -123 & $\mathrm{He}$ & -125 & $\mathrm{He}$ & -133 \\
\hline $\mathrm{C}(\mathrm{H} \beta)$ & & & 0.25 & & 1.62 & & 1.71 & & 3.59 \\
\hline 3727 & [O II] & 7.7 & $9.17 \mathrm{c}$ & 19.1 & $57.86 \mathrm{c}$ & 17.4: & 67.97:c & & \\
\hline 3869 & [Ne III] & 54.5 & $63.74 \mathrm{c}$ & 3.7 & $9.62 \mathrm{c}$ & & & 23.8: & 150.36: \\
\hline 4068 & [S II] & 1.9 & $2.16 \mathrm{c}$ & & & & & & \\
\hline 4102 & $\mathrm{H} \mathrm{I}$ & 23.1 & $26.20 \mathrm{c}$ & 12.7 & $25.61 \mathrm{c}$ & 11.1 & $25.37 \mathrm{c}$ & 5.1 ; & 20.91; \\
\hline 4340 & H I & 42.7 & $47.27 \mathrm{c}$ & 29.2 & $47.26 \mathrm{c}$ & 27.5 & 45.61 & 18.2 & 52.81 \\
\hline 4363 & [O III] & 15.8 & 17.28 & & & & & 2.9 & 8.08; \\
\hline 4471 & $\mathrm{He} \mathrm{I}$ & 0.8: & 0.86: & 5.7 & 8.16 & 1.0; & 1.46; & $\mathrm{p}$ & $\mathrm{p}$ \\
\hline 4686 & He II & 101.2 & 104.34 & & & & & & \\
\hline 4711 & [Ar IV] & 15.7 & 15.99 & 0.4 & & & & $\mathrm{p}$ & $\mathrm{p}$ \\
\hline 4725 & {$[\mathrm{Ne}$ IV] } & 3.7: & 3.79: & & & & & & \\
\hline 4740 & [Ar IV] & 13.5 & 13.79 & & & & & $\mathrm{p}$ & $\mathrm{p}$ \\
\hline 4861 & H I & 100.0 & 100.00 & 100.0 & 100.00 & 100.0 & 100.00 & $100.0^{1}$ & $100.00^{1}$ \\
\hline 4959 & [O III] & 319.0 & 314.65 & 66.1 & 60.53 & & & 467.9 & 385.08 \\
\hline 5007 & [O III] & 965.3 & 946.07 & 209.0 & 183.67 & 3.3 & 2.88 & 1574.8 & 1183.33 \\
\hline 5200 & {$[\mathrm{~N} \mathrm{I}]$} & & & 1.2 & 0.91 & 1.5; & 1.12; & & \\
\hline 5515 & [Cl III] & 0.6 : & $0.55:$ & 0.8 & 0.48 & & & $\mathrm{p}$ & $\mathrm{p}$ \\
\hline 5537 & [Cl III] & 0.6 : & 0.55: & 1.0 & 0.59 & & & 3.9: & 1.20: \\
\hline 5755 & [N II] & 0.2 & 0.18 & 3.4 & 1.66 & 1.9: & 0.90: & 22.2 & 4.56 \\
\hline 5876 & He I & 3.1 & 2.73 & 52.8 & 23.52 & 9.8 & 4.19 & 124.8 & 20.85 \\
\hline 6300 & [O I] & & & 3.3: & 1.14: & 4.2 & 1.37 & 70.5 & 6.68 \\
\hline 6312 & [S III] & 2.5 & 2.12 & 2.3: & 0.79: & 0.9 : & 0.29: & 27.1 & 2.53 \\
\hline 6548 & [N II] & 1.7 & 1.41 & 251.6 & 75.73 & 277.1 & 78.47 & 573.8 & 40.28 \\
\hline 6563 & $\mathrm{H} \mathrm{I}$ & 337.1 & 279.26 & 979.1 & 292.42 & 1061.5 & 298.14 & 4148.7 & 286.27 \\
\hline 6583 & [N II] & 3.9 & 3.23 & 774.3 & 228.79 & 860.4 & 238.95 & 1823.7 & 122.89 \\
\hline 6678 & He I & 2.1: & 1.72: & 21.1 & 5.95 & 4.6 & 1.22 & 77.8 & 4.73 \\
\hline 6716 & [S II] & 0.8 & 0.66 & 19.5 & 5.41 & 36.6 & 9.50 & 53.8 & 3.15 \\
\hline 6730 & [S II] & 0.8 & 0.65 & 31.2 & 8.59 & 68.0 & 17.54 & 109.4 & 6.31 \\
\hline 7006 & {$[\mathrm{Ar} \mathrm{V}]$} & 4.3 & 3.45 & & & & & & \\
\hline 7136 & [Ar III] & 15.5 & 12.35 & 50.6 & 11.75 & 7.9 & 1.70 & 641.2 & 25.38 \\
\hline 7325 & [O II] & 1.1 & 0.87 & 10.0 & 2.14 & 7.5: & 1.49: & 354.0 & 9.65 \\
\hline
\end{tabular}


S. K. Górny: Spectroscopy of southern Galactic disk planetary nebulae

Table B.1. continued.

\begin{tabular}{|c|c|c|c|c|c|c|c|c|c|}
\hline \multirow{2}{*}{\multicolumn{2}{|c|}{$\begin{array}{l}\mathrm{PNG} \\
\text { name }\end{array}$}} & \multirow{2}{*}{\multicolumn{2}{|c|}{$\begin{array}{c}327.1-01.8 \\
\text { He 2-140 }\end{array}$}} & \multicolumn{2}{|c|}{$327.8-01.6$} & \multicolumn{2}{|c|}{ 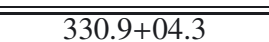 } & \multicolumn{2}{|c|}{$\overline{3336.9+08.3}$} \\
\hline & & & & & $2-143$ & Wray & 6-189 & StV & 4- 10 \\
\hline $\mathrm{C}(\mathrm{H} \beta)$ & & & 1.94 & & 0.74 & & 1.15 & & 0.95 \\
\hline 3727 & [O II] & 44.5: & 138.94:c & 97.4 & $150.06 \mathrm{c}$ & & & & \\
\hline 3869 & [Ne III] & & & 104.9 & $153.14 \mathrm{c}$ & $\mathrm{p}$ & $\mathrm{p}$ & 34.0 & $96.11 \mathrm{c}$ \\
\hline 4068 & [S II] & & & 3.8: & 5.14:c & & & & \\
\hline 4102 & $\mathrm{H} \mathrm{I}$ & 14.5; & 31.09; c & 19.9 & $26.58 \mathrm{c}$ & & & 12.8 & $26.10 \mathrm{c}$ \\
\hline 4340 & H I & 29.2: & 51.94: & 38.3 & $47.66 \mathrm{c}$ & $\mathrm{p}$ & $\mathrm{p}$ & 33.4 & $47.13 \mathrm{c}$ \\
\hline 4363 & [O III] & & & 20.2 & 24.93 & $\mathrm{p}$ & $\mathrm{p}$ & 6.6 & 10.95 \\
\hline 4471 & $\mathrm{He} \mathrm{I}$ & & & 2.5: & 2.94: & & & 3.8 & 5.66 \\
\hline 4686 & $\mathrm{He}$ II & & & 80.8 & 86.73 & & & & \\
\hline 4711 & [Ar IV] & & & 8.9 & 9.07 & & & 1.6; & 0.11 \\
\hline 4725 & {$[\mathrm{Ne}$ IV] } & & & & & & & & \\
\hline 4740 & [Ar IV] & & & 7.6 & 7.99 & & & 2.8; & 3.18 \\
\hline 4861 & H I & 100.0 & 100.00 & 100.0 & 100.00 & 100.0 & 100.00 & 100.0 & 100.00 \\
\hline 4959 & [O III] & 17.1 & 15.39 & 637.6 & 612.61 & 468.3 & 439.94 & 293.6 & 278.87 \\
\hline 5007 & [O III] & 56.7 & 48.58 & 1937.3 & 1826.93 & 1350.2 & 1231.95 & 878.4 & 814.49 \\
\hline 5200 & {$[\mathrm{~N} \mathrm{I}]$} & & & 1.6; & $1.41 ;$ & & & & \\
\hline 5515 & [Cl III] & & & 2.6 & 2.06 & & & & \\
\hline 5537 & [Cl III] & & & 2.1 & 1.65 & & & & \\
\hline 5755 & {$[\mathrm{~N} \mathrm{II}]$} & 8.9: & 3.78: & 4.4 & 3.18 & & & & \\
\hline 5876 & $\mathrm{He} \mathrm{I}$ & & & 9.7 & 6.72 & 33.1: & 18.65: & 23.3 & 14.52 \\
\hline 6300 & [O I] & 10.1 & 2.83 & 7.4 & 4.56 & & & 0.9 : & 0.48: \\
\hline 6312 & [S III] & 4.4; & 1.22; & 12.1 & 7.44 & & & 1.8 & 0.96 \\
\hline 6548 & {$[\mathrm{~N}$ II] } & 420.6 & 100.03 & 97.6 & 56.58 & & & & \\
\hline 6563 & H I & 1233.8 & 290.72 & 487.1 & 281.38 & 662.5 & 281.07 & 570.7 & 281.52 \\
\hline 6583 & {$[\mathrm{~N} \mathrm{II}]$} & 1316.6 & 306.27 & 300.4 & 172.69 & 24.2: & 10.19: & 5.2 & 2.55 \\
\hline 6678 & $\mathrm{He} \mathrm{I}$ & 16.2 & 3.57 & 4.3 & 2.42 & & & 8.3 & 3.96 \\
\hline 6716 & [S II] & 23.0 & 4.96 & 40.3 & 22.50 & & & & \\
\hline 6730 & [S II] & 48.3 & 10.33 & 43.3 & 24.11 & & & & \\
\hline 7006 & [Ar V] & & & 2.9 & 1.53 & & & & \\
\hline 7136 & [Ar III] & 59.4 & 10.36 & 69.2 & 35.66 & 17.4 & 6.18 & 16.1 & 6.86 \\
\hline 7325 & [O II] & 62.4 & 9.89 & 12.5 & 6.21 & & & 2.8: & 0.94: \\
\hline$\overline{P N G}$ & & & $1-08.3$ & & & & & & \\
\hline name & & NC & 6326 & & & & & & \\
\hline $\mathrm{C}(\mathrm{H} \beta)$ & & & 0.11 & & & & & & \\
\hline 3727 & [O II] & 40.5 & 43.24 & & & & & & \\
\hline 3869 & {$[\mathrm{Ne} \mathrm{III}]$} & 102.2 & 108.23 & & & & & & \\
\hline 4068 & [S II] & 2.1 & 2.20 & & & & & & \\
\hline 4102 & H I & 25.2 & 26.33 & & & & & & \\
\hline 4340 & H I & 45.0 & 46.52 & & & & & & \\
\hline 4363 & [O III] & 13.7 & 14.14 & & & & & & \\
\hline 4471 & He I & 3.4 & 3.48 & & & & & & \\
\hline 4686 & He II & 51.4 & 51.95 & & & & & & \\
\hline 4711 & [Ar IV] & 6.6 & 6.23 & & & & & & \\
\hline 4725 & [Ne IV] & 0.7 & 0.71 & & & & & & \\
\hline 4740 & [Ar IV] & 5.2: & 5.24: & & & & & & \\
\hline 4861 & H I & 100.0 & 100.00 & & & & & & \\
\hline 4959 & [O III] & 446.3 & 443.60 & & & & & & \\
\hline 5007 & [O III] & 1342.5 & 1330.61 & & & & & & \\
\hline 5200 & {$[\mathrm{~N} \mathrm{I}]$} & $0.4:$ & 0.39: & & & & & & \\
\hline 5515 & [Cl III] & 0.7 & 0.68 & & & & & & \\
\hline 5537 & [Cl III] & 0.6 & 0.58 & & & & & & \\
\hline 5755 & {$[\mathrm{~N} \mathrm{II}]$} & 0.5 & 0.48 & & & & & & \\
\hline 5876 & $\mathrm{He} \mathrm{I}$ & 10.4 & 9.84 & & & & & & \\
\hline 6300 & [O I] & 2.5 & 2.32 & & & & & & \\
\hline 6312 & [S III] & 2.4 & 2.23 & & & & & & \\
\hline 6548 & {$[\mathrm{~N} \mathrm{II}]$} & 10.0 & 9.21 & & & & & & \\
\hline 6563 & H I & 307.7 & 283.14 & & & & & & \\
\hline 6583 & [N II] & 29.8 & 27.40 & & & & & & \\
\hline 6678 & $\mathrm{He} \mathrm{I}$ & 3.5 & 3.21 & & & & & & \\
\hline 6716 & [S II] & 5.1 & 4.67 & & & & & & \\
\hline 6730 & [S II] & 5.9 & 5.40 & & & & & & \\
\hline 7006 & {$[\mathrm{Ar} \mathrm{V}]$} & 1.0 & 0.91 & & & & & & \\
\hline 7136 & [Ar III] & 14.1 & 12.75 & & & & & & \\
\hline 7325 & [O II] & 3.4 & 3.06 & & & & & & \\
\hline
\end{tabular}


Table B.2. New, reobserved, and mis-classified PNe with emission-line central stars.

\begin{tabular}{lccc}
\hline \hline Name & FWHM & \multicolumn{2}{c}{ Classification } \\
& & t.w. & WG \\
\hline New WELs: & & WEL & - \\
PB 5 & & WEL? & - \\
My 60 & & WEL & - \\
He 2-115 & & & \\
New [WR]: & $43 \AA$ & [WC 4] & - \\
He 2- 67 & $25 \AA$ & [WC 5-6] & - \\
He 2-117 & & VL & - \\
He 2-125 & & & \\
Reobserved: & $45 \AA$ & [WC 4-5] & [WO 4] \\
Pe 1- 1 & & undetect. & WEL \\
He 2- 63 & $22 \AA$ & [WC 5-6] & [WC 4] \\
He 2- 86 & & VL & [WC10-11] \\
He 2-107 & & VL & WEL \\
He 2-131 & & VL & WEL \\
He 2-108 & & WEL & WEL? \\
He 2-123 & & & \\
Misclassified/mimics: & & WEL? & \\
NGC 6326 & & not stellar & WEL \\
NGC 5979 & & not stellar & - \\
NGC 3918 & &
\end{tabular}

Notes. Column 3 gives the width of C IV $\lambda 5805$ stellar emission feature if is broader than instrumental profile. Columns 4 and 5 give stellar classification of this work and from Weidmann \& Gamen (2011). 
Table B.3. Plasma parameters and abundances.

\begin{tabular}{|c|c|c|c|c|c|c|c|c|c|c|c|}
\hline PN G & Main name & $n_{\mathrm{e}}(\mathrm{S}$ II $)$ & $T_{\mathrm{e}}(\mathrm{N}$ II $)$ & $T_{\mathrm{e}}(\mathrm{O}$ III & $\mathrm{He} / \mathrm{H}$ & $\mathrm{N} / \mathrm{H}$ & $\mathrm{O} / \mathrm{H}$ & $\mathrm{Ne} / \mathrm{H}$ & $\mathrm{S} / \mathrm{H}$ & $\mathrm{Ar} / \mathrm{H}$ & $\mathrm{Cl} / \mathrm{H}$ \\
\hline \multirow{3}{*}{$268.4+02.4$} & PB 5 & $1.82 \mathrm{E}+04:$ & (14413) & 13362 & $1.13 \mathrm{E}-01$ & $1.34 \mathrm{E}-04$ & $3.06 \mathrm{E}-04$ & $6.48 \mathrm{E}-05$ & $4.39 \mathrm{E}-06$ & $1.77 \mathrm{E}-06$ & $4.80 \mathrm{E}-07$ \\
\hline & & $4.43 \mathrm{E}+04$ & (16435) & 13737 & $1.20 \mathrm{E}-01$ & $1.80 \mathrm{E}-04$ & $3.76 \mathrm{E}-04$ & $7.84 \mathrm{E}-05$ & 5.79E-06 & $2.03 \mathrm{E}-06$ & $6.47 \mathrm{E}-07$ \\
\hline & & $1.12 \mathrm{E}+04$ & ( 8523) & 12629 & $1.08 \mathrm{E}-01$ & $1.19 \mathrm{E}-04$ & $2.76 \mathrm{E}-04$ & $5.67 \mathrm{E}-05$ & 3.91E-06 & $1.64 \mathrm{E}-06$ & $3.62 \mathrm{E}-07$ \\
\hline \multirow{3}{*}{ 269.7-03.6 } & PB 3 & $2.50 \mathrm{E}+03$ & 10829 & 11849 & $1.23 \mathrm{E}-01$ & $2.21 \mathrm{E}-04$ & $4.38 \mathrm{E}-04$ & $1.02 \mathrm{E}-04$ & $6.39 \mathrm{E}-06$ & $2.51 \mathrm{E}-06$ & 3.57E-07: \\
\hline & & $3.08 \mathrm{E}+03$ & 11190 & 12267 & $1.28 \mathrm{E}-01$ & $2.52 \mathrm{E}-04$ & $4.88 \mathrm{E}-04$ & 1.19E-04 & 7.23E-06 & $2.77 \mathrm{E}-06$ & $4.70 \mathrm{E}-07$ \\
\hline & & $2.11 \mathrm{E}+03$ & 10446 & 11541 & $1.16 \mathrm{E}-01$ & $1.89 \mathrm{E}-04$ & $3.92 \mathrm{E}-04$ & $9.02 \mathrm{E}-05$ & $5.57 \mathrm{E}-06$ & $2.24 \mathrm{E}-06$ & $2.60 \mathrm{E}-07$ \\
\hline \multirow[t]{3}{*}{$279.6-03.1$} & He 2- 36 & $5.50 \mathrm{E}+02$ & 10793 & 14481 & $1.13 \mathrm{E}-01$ & $6.38 \mathrm{E}-05$ & $2.89 \mathrm{E}-04$ & 7.77E-05 & $2.87 \mathrm{E}-06$ & $1.25 \mathrm{E}-06$ & 5.81E-07: \\
\hline & & $6.42 \mathrm{E}+02$ & 12013 & 14743 & $1.18 \mathrm{E}-01$ & 9.13E-05 & $3.59 \mathrm{E}-04$ & $9.24 \mathrm{E}-05$ & $3.74 \mathrm{E}-06$ & $1.44 \mathrm{E}-06$ & $9.59 \mathrm{E}-07$ \\
\hline & & $4.33 \mathrm{E}+02$ & 9822 & 13657 & $1.08 \mathrm{E}-01$ & $5.31 \mathrm{E}-05$ & $2.66 \mathrm{E}-04$ & $6.56 \mathrm{E}-05$ & $2.57 \mathrm{E}-06$ & $1.17 \mathrm{E}-06$ & $3.63 \mathrm{E}-07$ \\
\hline \multirow[t]{3}{*}{$283.8+02.2$} & My 60 & 1.51E+03: & & 13868 & $1.10 \mathrm{E}-01$ & 5.11E-05 & $3.15 \mathrm{E}-04$ & $6.02 \mathrm{E}-05$ & 4.33E-06 & $1.68 \mathrm{E}-06$ & 8.33E-06 \\
\hline & & $2.45 \mathrm{E}+03$ & & 14412 & $1.16 \mathrm{E}-01$ & $6.40 \mathrm{E}-05$ & $3.80 \mathrm{E}-04$ & $6.92 \mathrm{E}-05$ & $5.10 \mathrm{E}-06$ & $1.86 \mathrm{E}-06$ & $1.04 \mathrm{E}-05$ \\
\hline & & $1.05 \mathrm{E}+03$ & & 13324 & $1.03 \mathrm{E}-01$ & 4.17E-05 & $2.62 \mathrm{E}-04$ & $5.24 \mathrm{E}-05$ & $3.66 \mathrm{E}-06$ & $1.48 \mathrm{E}-06$ & $6.34 \mathrm{E}-06$ \\
\hline \multirow[t]{3}{*}{$283.8-04.2$} & He 2-39 & $7.04 \mathrm{E}+02$ & 9821 & 14289 & $1.09 \mathrm{E}-01$ & $1.25 \mathrm{E}-04$ & 4.77E-04 & $1.38 \mathrm{E}-04$ & 2.85E-06 & $2.40 \mathrm{E}-06$ & \\
\hline & & $7.99 \mathrm{E}+02$ & 10751 & 14589 & $1.18 \mathrm{E}-01$ & $1.53 \mathrm{E}-04$ & 6.61E-04 & $2.01 \mathrm{E}-04$ & $3.51 \mathrm{E}-06$ & $3.12 \mathrm{E}-06$ & \\
\hline & & $5.53 \mathrm{E}+02$ & 8774 & 13546 & $9.90 \mathrm{E}-02$ & $1.09 \mathrm{E}-04$ & 4.19E-04 & $1.19 \mathrm{E}-04$ & $2.42 \mathrm{E}-06$ & $1.85 \mathrm{E}-06$ & \\
\hline \multirow{3}{*}{$285.4+01.5$} & Pe 1- 1 & $6.08 \mathrm{E}+03$ & 12859 & 10662 & $1.15 \mathrm{E}-01$ & $1.13 \mathrm{E}-04$ & $3.15 \mathrm{E}-04$ & $7.50 \mathrm{E}-05$ & $5.44 \mathrm{E}-06$ & $2.60 \mathrm{E}-06$ & $1.30 \mathrm{E}-06$ \\
\hline & & $8.96 \mathrm{E}+03$ & 13611 & 10927 & $1.23 \mathrm{E}-01$ & $1.44 \mathrm{E}-04$ & $3.64 \mathrm{E}-04$ & $8.28 \mathrm{E}-05$ & $6.63 \mathrm{E}-06$ & $2.99 \mathrm{E}-06$ & $1.82 \mathrm{E}-06$ \\
\hline & & $4.56 \mathrm{E}+03$ & 12264 & 10301 & $1.08 \mathrm{E}-01$ & $1.04 \mathrm{E}-04$ & $2.81 \mathrm{E}-04$ & $6.65 \mathrm{E}-05$ & 4.87E-06 & $2.38 \mathrm{E}-06$ & 9.03E-07 \\
\hline \multirow[t]{3}{*}{$286.0-06.5$} & He 2- 41 & $6.74 \mathrm{E}+03:$ & (12917) & 11626 & $9.68 \mathrm{E}-02$ & 4.53E-05 & $2.09 \mathrm{E}-04$ & $4.53 \mathrm{E}-05$ & $2.24 \mathrm{E}-06$ & $9.05 \mathrm{E}-07$ & $1.02 \mathrm{E}-06$ \\
\hline & & $1.30 \mathrm{E}+04$ & (13591) & 11976 & $1.02 \mathrm{E}-01$ & $5.12 \mathrm{E}-05$ & $2.48 \mathrm{E}-04$ & $5.37 \mathrm{E}-05$ & $2.55 \mathrm{E}-06$ & $1.03 \mathrm{E}-06$ & $1.21 \mathrm{E}-06$ \\
\hline & & $3.76 \mathrm{E}+03$ & (10618) & 11199 & $9.09 \mathrm{E}-02$ & $3.73 \mathrm{E}-05$ & $1.79 \mathrm{E}-04$ & $4.15 \mathrm{E}-05$ & $1.88 \mathrm{E}-06$ & $8.02 \mathrm{E}-07$ & 7.64E-07 \\
\hline \multirow[t]{3}{*}{$289.8+07.7$} & He 2- 63 & $9.86 \mathrm{E}+02:$ & & 12459 & $9.87 \mathrm{E}-02$ & $5.30 \mathrm{E}-05$ & $2.66 \mathrm{E}-04$ & $4.85 \mathrm{E}-05$ & 2.61E-06 & $9.40 \mathrm{E}-07$ & \\
\hline & & $1.93 \mathrm{E}+03$ & & 12885 & 1.03E-01 & 7.64E-05 & $3.11 \mathrm{E}-04$ & $5.75 \mathrm{E}-05$ & 3.62E-06 & $1.10 \mathrm{E}-06$ & \\
\hline & & $4.38 \mathrm{E}+02$ & & 12078 & $9.16 \mathrm{E}-02$ & $3.46 \mathrm{E}-05$ & $2.31 \mathrm{E}-04$ & 4.67E-05 & $1.70 \mathrm{E}-06$ & $6.73 \mathrm{E}-07$ & \\
\hline \multirow[t]{3}{*}{$291.4+19.2$} & ESO $320-28$ & & & 17898 & $9.38 \mathrm{E}-02$ & & 2.51E-05: & 2.17E-06: & & 1.43E-06: & \\
\hline & & & & 23573 & $1.03 \mathrm{E}-01$ & & $4.65 \mathrm{E}-05$ & $6.30 \mathrm{E}-06$ & & $2.84 \mathrm{E}-06$ & \\
\hline & & & & 13839 & $8.75 \mathrm{E}-02$ & & $1.41 \mathrm{E}-05$ & 1.17E-06 & & $6.83 \mathrm{E}-07$ & \\
\hline \multirow[t]{3}{*}{$292.8+01.1$} & He 2- 67 & $3.07 \mathrm{E}+03$ & 10228 & 9552 & $1.34 \mathrm{E}-01$ & $4.86 \mathrm{E}-04$ & $5.94 \mathrm{E}-04$ & $1.85 \mathrm{E}-04$ & $1.67 \mathrm{E}-05$ & 4.71E-06 & $2.16 \mathrm{E}-06$ \\
\hline & & $3.80 \mathrm{E}+03$ & 10637 & 9774 & $1.41 \mathrm{E}-01$ & $5.60 \mathrm{E}-04$ & $6.95 \mathrm{E}-04$ & $2.26 \mathrm{E}-04$ & $1.98 \mathrm{E}-05$ & $5.23 \mathrm{E}-06$ & $2.77 \mathrm{E}-06$ \\
\hline & & $2.50 \mathrm{E}+03$ & 9825 & 9258 & $1.27 \mathrm{E}-01$ & $3.90 \mathrm{E}-04$ & $5.27 \mathrm{E}-04$ & $1.76 \mathrm{E}-04$ & $1.41 \mathrm{E}-05$ & $4.25 \mathrm{E}-06$ & $1.65 \mathrm{E}-06$ \\
\hline \multirow[t]{3}{*}{ 293.1-00.0 } & BMPJ1128-61 & $1.00 \mathrm{E}+05$ & 9416 & 15416 & $1.10 \mathrm{E}-01$ & 1.15E-04: & 3.33E-04: & 5.25E-05: & 4.75E-06: & 1.26E-06: & \\
\hline & & $1.00 \mathrm{E}+05$ & 12660 & 21593 & $1.28 \mathrm{E}-01$ & 2.68E-04 & $8.59 \mathrm{E}-04$ & $1.58 \mathrm{E}-04$ & $1.06 \mathrm{E}-05$ & $2.27 \mathrm{E}-06$ & \\
\hline & & $2.03 \mathrm{E}+04$ & 7917 & 10081 & $9.74 \mathrm{E}-02$ & $6.97 \mathrm{E}-05$ & $1.49 \mathrm{E}-04$ & & 2.06E-06 & $7.29 \mathrm{E}-07$ & \\
\hline \multirow[t]{3}{*}{$293.6+01.2$} & He 2- 70 & $2.67 \mathrm{E}+02$ & 11118 & 20203 & 2.71E-01: & 2.59E-04 & $1.78 \mathrm{E}-04$ & 9.05E-05: & 4.32E-06: & 1.85E-06: & \\
\hline & & $3.64 \mathrm{E}+02$ & 11571 & 24121 & $3.14 \mathrm{E}-01$ & $2.99 \mathrm{E}-04$ & $2.24 \mathrm{E}-04$ & $1.37 \mathrm{E}-04$ & $5.02 \mathrm{E}-06$ & $2.16 \mathrm{E}-06$ & \\
\hline & & $1.72 \mathrm{E}+02$ & 10777 & 18398 & 2.32E-01 & $1.99 \mathrm{E}-04$ & $1.45 \mathrm{E}-04$ & $6.28 \mathrm{E}-05$ & $3.14 \mathrm{E}-06$ & $1.35 \mathrm{E}-06$ & \\
\hline \multirow[t]{3}{*}{$294.6+04.7$} & NGC 3918 & $4.37 \mathrm{E}+03$ & 11286 & 12728 & $1.08 \mathrm{E}-01$ & $1.64 \mathrm{E}-04$ & $4.04 \mathrm{E}-04$ & $7.24 \mathrm{E}-05$ & $4.55 \mathrm{E}-06$ & $2.48 \mathrm{E}-06$ & $9.27 \mathrm{E}-07$ \\
\hline & & $6.07 \mathrm{E}+03$ & 11744 & 13093 & $1.13 \mathrm{E}-01$ & $1.95 \mathrm{E}-04$ & $4.55 \mathrm{E}-04$ & $8.59 \mathrm{E}-05$ & $5.22 \mathrm{E}-06$ & $2.97 \mathrm{E}-06$ & $1.18 \mathrm{E}-06$ \\
\hline & & $3.52 \mathrm{E}+03$ & 10861 & 12253 & $1.02 \mathrm{E}-01$ & $1.33 \mathrm{E}-04$ & $3.61 \mathrm{E}-04$ & $6.60 \mathrm{E}-05$ & $3.83 \mathrm{E}-06$ & $2.15 \mathrm{E}-06$ & $7.16 \mathrm{E}-07$ \\
\hline \multirow[t]{3}{*}{ 294.9-04.3 } & He 2- 68 & 1.49E+04: & 9666 & 10614 & 7.57E-02: & 4.57E-05: & 2.27E-04: & 1.49E-05: & 1.94E-06: & 8.00E-07: & 1.31E-07: \\
\hline & & $6.42 \mathrm{E}+04$ & 10402 & 11330 & 8.06E-02 & 7.18E-05 & $6.44 \mathrm{E}-04$ & 4.49E-05 & $3.72 \mathrm{E}-06$ & $1.02 \mathrm{E}-06$ & $2.25 \mathrm{E}-07$ \\
\hline & & $8.86 \mathrm{E}+03$ & 8135 & 9485 & 7.01E-02 & $3.79 \mathrm{E}-05$ & $1.68 \mathrm{E}-04$ & $1.09 \mathrm{E}-05$ & $1.56 \mathrm{E}-06$ & $6.75 \mathrm{E}-07$ & 8.94E-08 \\
\hline \multirow[t]{3}{*}{$295.3-09.3$} & He 2- 62 & $4.93 \mathrm{E}+03$ & 16469 & 12945 & $1.03 \mathrm{E}-01$ & $7.38 \mathrm{E}-05$ & $1.41 \mathrm{E}-04$ & $3.81 \mathrm{E}-05$ & $3.18 \mathrm{E}-06$ & $8.37 \mathrm{E}-07$ & $1.00 \mathrm{E}-06$ \\
\hline & & $6.64 \mathrm{E}+03$ & 17364 & 13389 & $1.11 \mathrm{E}-01$ & $8.62 \mathrm{E}-05$ & $1.64 \mathrm{E}-04$ & $4.39 \mathrm{E}-05$ & $3.75 \mathrm{E}-06$ & $9.30 \mathrm{E}-07$ & $1.30 \mathrm{E}-06$ \\
\hline & & $3.85 \mathrm{E}+03$ & 15468 & 12481 & $9.64 \mathrm{E}-02$ & $5.64 \mathrm{E}-05$ & $1.22 \mathrm{E}-04$ & $3.35 \mathrm{E}-05$ & $2.57 \mathrm{E}-06$ & 7.42E-07 & $6.44 \mathrm{E}-07$ \\
\hline
\end{tabular}

Notes. The first row for each PN gives parameters computed from the nominal values of the observational data. The second and third row give the upper and lower limits, respectively, of these parameters. Column (1) gives the PN G number; Col. 2 usual name; Col. (3) electron density deduced from [S II] $\lambda 6731 / 6716$, Cols. 4 and 5 electron temperatures from [N II] $\lambda 5755 / 6583$ and [O III] $\lambda 4363 / 5007$, respectively. The value of $T_{\mathrm{e}}(\mathrm{N}$ II) is in parenthesis if $T_{\mathrm{e}}(\mathrm{O}$ III) was chosen for all ions. Columns 6 to 12 give the $\mathrm{He} / \mathrm{H}, \mathrm{N} / \mathrm{H}, \mathrm{O} / \mathrm{H}, \mathrm{Ne} / \mathrm{H}, \mathrm{S} / \mathrm{H}, \mathrm{Ar} / \mathrm{H}$, and $\mathrm{Cl} / \mathrm{H}$ ratios, respectively. Uncertain values are marked with a colon. 
Table B.3. continued.

\begin{tabular}{|c|c|c|c|c|c|c|c|c|c|c|c|}
\hline PN G & Main name & $n_{\mathrm{e}}(\mathrm{S}$ II $)$ & $T_{\mathrm{e}}(\mathrm{N}$ II $)$ & $T_{\mathrm{e}}(\mathrm{O}$ III $)$ & $\mathrm{He} / \mathrm{H}$ & $\mathrm{N} / \mathrm{H}$ & $\mathrm{O} / \mathrm{H}$ & $\mathrm{Ne} / \mathrm{H}$ & $\mathrm{S} / \mathrm{H}$ & $\mathrm{Ar} / \mathrm{H}$ & $\mathrm{Cl} / \mathrm{H}$ \\
\hline \multirow[t]{3}{*}{$296.3-03.0$} & $\mathrm{He} 2-73$ & $5.05 \mathrm{E}+03$ & 12601 & 11580 & $1.22 \mathrm{E}-01$ & $2.56 \mathrm{E}-04$ & $4.15 \mathrm{E}-04$ & $1.04 \mathrm{E}-04$ & $8.50 \mathrm{E}-06$ & $3.42 \mathrm{E}-06$ & $1.40 \mathrm{E}-06$ \\
\hline & & $7.13 \mathrm{E}+03$ & 13090 & 11942 & $1.28 \mathrm{E}-01$ & $3.09 \mathrm{E}-04$ & 4.74E-04 & 1.17E-04 & $9.78 \mathrm{E}-06$ & $3.85 \mathrm{E}-06$ & $1.50 \mathrm{E}-06$ \\
\hline & & $4.00 \mathrm{E}+03$ & 11929 & 11241 & $1.16 \mathrm{E}-01$ & $2.12 \mathrm{E}-04$ & $3.59 \mathrm{E}-04$ & $9.25 \mathrm{E}-05$ & 7.16E-06 & $3.04 \mathrm{E}-06$ & $1.30 \mathrm{E}-06$ \\
\hline \multirow[t]{3}{*}{$297.4+03.7$} & He 2- 78 & $3.93 \mathrm{E}+03$ & 7847 & & 5.13E-02: & 7.43E-05: & 4.75E-04: & & 5.63E-06: & 1.34E-06: & \\
\hline & & $5.17 \mathrm{E}+03$ & 9025 & & $5.44 \mathrm{E}-02$ & $1.14 \mathrm{E}-04$ & $1.23 \mathrm{E}-03$ & & 8.98E-06 & $2.05 \mathrm{E}-06$ & \\
\hline & & $2.89 \mathrm{E}+03$ & 6680 & & 4.78E-02 & 5.39E-05 & $2.68 \mathrm{E}-04$ & & 4.26E-06 & $1.00 \mathrm{E}-06$ & \\
\hline \multirow[t]{3}{*}{$299.0+18.4$} & K 1- 23 & $1.07 \mathrm{E}+02:$ & 11854 & 11144 & $1.15 \mathrm{E}-01$ & $1.18 \mathrm{E}-04$ & 3.07E-04 & 8.77E-05 & 7.15E-06 & $1.74 \mathrm{E}-06$ & $1.76 \mathrm{E}-06$ \\
\hline & & $1.82 \mathrm{E}+02$ & 13232 & 11899 & $1.33 \mathrm{E}-01$ & $1.67 \mathrm{E}-04$ & 4.10E-04 & $1.23 \mathrm{E}-04$ & 8.93E-06 & $2.15 \mathrm{E}-06$ & $3.17 \mathrm{E}-06$ \\
\hline & & $6.35 \mathrm{E}+01$ & 10822 & 10167 & $8.58 \mathrm{E}-02$ & $8.21 \mathrm{E}-05$ & $2.48 \mathrm{E}-04$ & $7.03 \mathrm{E}-05$ & $5.92 \mathrm{E}-06$ & $1.45 \mathrm{E}-06$ & $1.01 \mathrm{E}-06$ \\
\hline \multirow[t]{3}{*}{$299.5+02.4$} & He 2- 82 & $1.56 \mathrm{E}+02$ & 9922 & & $1.27 \mathrm{E}-01$ & $1.53 \mathrm{E}-04$ & $5.45 \mathrm{E}-04$ & $1.83 \mathrm{E}-04$ & $9.25 \mathrm{E}-06$ & $2.44 \mathrm{E}-06$ & \\
\hline & & $2.24 \mathrm{E}+02$ & 10627 & & $1.35 \mathrm{E}-01$ & $1.87 \mathrm{E}-04$ & 7.66E-04 & $2.47 \mathrm{E}-04$ & $1.33 \mathrm{E}-05$ & $3.06 \mathrm{E}-06$ & \\
\hline & & $1.13 \mathrm{E}+02$ & 9225 & & $1.18 \mathrm{E}-01$ & $1.29 \mathrm{E}-04$ & $3.85 \mathrm{E}-04$ & $1.12 \mathrm{E}-04$ & $6.06 \mathrm{E}-06$ & $1.96 \mathrm{E}-06$ & \\
\hline \multirow[t]{3}{*}{$300.2+00.6$} & He 2- 83 & $5.41 \mathrm{E}+03$ & 8019 & & 9.98E-02: & 1.49E-04 & 2.72E-04 & & 9.28E-06: & 3.13E-06: & \\
\hline & & $7.57 \mathrm{E}+03$ & 8294 & & $1.06 \mathrm{E}-01$ & $1.76 \mathrm{E}-04$ & 3.63E-04 & & $1.24 \mathrm{E}-05$ & $3.68 \mathrm{E}-06$ & \\
\hline & & $4.18 \mathrm{E}+03$ & 7595 & & $9.34 \mathrm{E}-02$ & 1.29E-04 & 2.38E-04 & & 7.19E-06 & $2.79 \mathrm{E}-06$ & \\
\hline \multirow[t]{3}{*}{$300.4-00.9$} & He 2- 84 & $8.06 \mathrm{E}+02$ & 11855 & 11504 & $1.46 \mathrm{E}-01$ & 4.30E-04 & $3.51 \mathrm{E}-04$ & $1.09 \mathrm{E}-04$ & $1.27 \mathrm{E}-05$ & $3.57 \mathrm{E}-06$ & \\
\hline & & $9.53 \mathrm{E}+02$ & 12431 & 12048 & $1.54 \mathrm{E}-01$ & $5.22 \mathrm{E}-04$ & $3.93 \mathrm{E}-04$ & $1.30 \mathrm{E}-04$ & $1.45 \mathrm{E}-05$ & $3.94 \mathrm{E}-06$ & \\
\hline & & $6.71 \mathrm{E}+02$ & 11378 & 11169 & $1.38 \mathrm{E}-01$ & $3.52 \mathrm{E}-04$ & $2.94 \mathrm{E}-04$ & $9.92 \mathrm{E}-05$ & $1.06 \mathrm{E}-05$ & $3.10 \mathrm{E}-06$ & \\
\hline \multirow[t]{3}{*}{$300.5-01.1$} & He 2- 85 & $3.01 \mathrm{E}+03$ & 11663 & 11815 & $1.16 \mathrm{E}-01$ & $2.00 \mathrm{E}-04$ & 4.03E-04 & $8.86 \mathrm{E}-05$ & 7.36E-06 & $3.28 \mathrm{E}-06$ & $1.54 \mathrm{E}-06$ \\
\hline & & $3.80 \mathrm{E}+03$ & 12094 & 12198 & $1.23 \mathrm{E}-01$ & $2.42 \mathrm{E}-04$ & $4.64 \mathrm{E}-04$ & $9.50 \mathrm{E}-05$ & $8.47 \mathrm{E}-06$ & $3.63 \mathrm{E}-06$ & $2.30 \mathrm{E}-06$ \\
\hline & & $2.51 \mathrm{E}+03$ & 11204 & 11406 & $1.09 \mathrm{E}-01$ & $1.62 \mathrm{E}-04$ & $3.55 \mathrm{E}-04$ & $7.56 \mathrm{E}-05$ & $6.17 \mathrm{E}-06$ & $2.94 \mathrm{E}-06$ & $9.97 \mathrm{E}-07$ \\
\hline \multirow[t]{3}{*}{$300.7-02.0$} & He 2- 86 & $9.96 \mathrm{E}+03$ & 11073 & 8659 & $1.39 \mathrm{E}-01$ & 4.25E-04 & 5.42E-04 & $1.82 \mathrm{E}-04$ & 1.96E-05: & $6.54 \mathrm{E}-06$ & 6.36E-06: \\
\hline & & $1.45 \mathrm{E}+04$ & 11741 & 9033 & 1.49E-01 & $5.88 \mathrm{E}-04$ & 7.52E-04 & $2.58 \mathrm{E}-04$ & $3.07 \mathrm{E}-05$ & $8.27 \mathrm{E}-06$ & $1.40 \mathrm{E}-05$ \\
\hline & & $6.77 \mathrm{E}+03$ & 9808 & 8045 & $1.30 \mathrm{E}-01$ & $3.35 \mathrm{E}-04$ & $4.59 \mathrm{E}-04$ & $1.34 \mathrm{E}-04$ & $1.57 \mathrm{E}-05$ & $5.77 \mathrm{E}-06$ & 4.04E-06 \\
\hline \multirow[t]{3}{*}{$300.8-03.4$} & ESO 095-12 & $3.76 \mathrm{E}+02$ & & 12902 & & $9.41 \mathrm{E}-05$ & 2.76E-04: & 5.05E-05: & 1.35E-05: & 2.29E-06: & \\
\hline & & $4.78 \mathrm{E}+02$ & & 14770 & & $1.40 \mathrm{E}-04$ & 4.74E-04 & 9.93E-05 & $2.66 \mathrm{E}-05$ & $3.46 \mathrm{E}-06$ & \\
\hline & & $2.93 \mathrm{E}+02$ & & 10436 & & $6.60 \mathrm{E}-05$ & $1.77 \mathrm{E}-04$ & $2.65 \mathrm{E}-05$ & $8.22 \mathrm{E}-06$ & $1.62 \mathrm{E}-06$ & \\
\hline \multirow[t]{3}{*}{$305.1+01.4$} & He 2- 90 & 1.87E+04: & & 24953 & $5.25 \mathrm{E}-02$ & 3.78E-06: & 8.88E-06: & 5.53E-07: & $6.93 \mathrm{E}-07$ & $3.76 \mathrm{E}-07$ & 3.96E-07: \\
\hline & & $1.00 \mathrm{E}+05$ & & 25828 & $6.09 \mathrm{E}-02$ & 7.98E-06 & $1.39 \mathrm{E}-05$ & $7.40 \mathrm{E}-07$ & $1.01 \mathrm{E}-06$ & 4.74E-07 & $5.84 \mathrm{E}-07$ \\
\hline & & $7.21 \mathrm{E}+03$ & & 21122 & $5.15 \mathrm{E}-02$ & 2.94E-06 & 8.26E-06 & $4.86 \mathrm{E}-07$ & $6.32 \mathrm{E}-07$ & $3.36 \mathrm{E}-07$ & 3.33E-07 \\
\hline \multirow[t]{3}{*}{$307.3+05.0$} & Wray 16-128 & $3.00 \mathrm{E}+01:$ & & 17216 & $1.06 \mathrm{E}-01$ & & 2.07E-04: & 3.84E-05: & & $1.32 \mathrm{E}-06$ & \\
\hline & & $6.48 \mathrm{E}+02$ & & 18192 & $1.13 \mathrm{E}-01$ & & 3.69E-04 & $5.98 \mathrm{E}-05$ & & $1.49 \mathrm{E}-06$ & \\
\hline & & $3.00 \mathrm{E}+01$ & & 16303 & 9.83E-02 & & $1.61 \mathrm{E}-04$ & $3.08 \mathrm{E}-05$ & & $1.14 \mathrm{E}-06$ & \\
\hline \multirow[t]{3}{*}{$308.2+07.7$} & MeWe 1- 3 & & & 17803 & 9.84E-02 & & 4.92E-05 & $1.39 \mathrm{E}-05$ & & $1.16 \mathrm{E}-06$ & \\
\hline & & & & 18652 & 1.04E-01 & & $5.77 \mathrm{E}-05$ & $1.63 \mathrm{E}-05$ & & $1.33 \mathrm{E}-06$ & \\
\hline & & & & 17050 & $9.27 \mathrm{E}-02$ & & 4.18E-05 & $1.19 \mathrm{E}-05$ & & $1.04 \mathrm{E}-06$ & \\
\hline \multirow[t]{3}{*}{$309.0+00.8$} & He 2- 96 & 7.60E+03: & 12410 & 8444 & $1.35 \mathrm{E}-01$ & $1.73 \mathrm{E}-04$ & $6.05 \mathrm{E}-04$ & $1.78 \mathrm{E}-04$ & $1.91 \mathrm{E}-05$ & $4.63 \mathrm{E}-06$ & 1.18E-05: \\
\hline & & $1.22 \mathrm{E}+04$ & 13139 & 8564 & $1.43 \mathrm{E}-01$ & 2.22E-04 & $7.86 \mathrm{E}-04$ & $2.40 \mathrm{E}-04$ & $2.55 \mathrm{E}-05$ & $5.28 \mathrm{E}-06$ & $1.85 \mathrm{E}-05$ \\
\hline & & $5.93 \mathrm{E}+03$ & 11439 & 8068 & $1.27 \mathrm{E}-01$ & $1.41 \mathrm{E}-04$ & 5.71E-04 & $1.43 \mathrm{E}-04$ & $1.68 \mathrm{E}-05$ & 4.33E-06 & 7.46E-06 \\
\hline \multirow[t]{3}{*}{$309.5-02.9$} & MaC 1- 2 & $1.63 \mathrm{E}+03$ & 11936 & 11754 & $1.32 \mathrm{E}-01$ & 3.55E-04: & 3.94E-04: & 7.51E-05: & 4.10E-06: & 2.63E-06: & \\
\hline & & $1.96 \mathrm{E}+03$ & 13156 & 13256 & $1.39 \mathrm{E}-01$ & $6.42 \mathrm{E}-04$ & $7.09 \mathrm{E}-04$ & $1.53 \mathrm{E}-04$ & $8.03 \mathrm{E}-06$ & $4.03 \mathrm{E}-06$ & \\
\hline & & $1.38 \mathrm{E}+03$ & 10827 & 9507 & $1.23 \mathrm{E}-01$ & $2.17 \mathrm{E}-04$ & $2.76 \mathrm{E}-04$ & $4.27 \mathrm{E}-05$ & $1.97 \mathrm{E}-06$ & $1.96 \mathrm{E}-06$ & \\
\hline \multirow[t]{3}{*}{$310.7-02.9$} & He 2-103 & $3.08 \mathrm{E}+02$ & 10404 & 12355 & $1.27 \mathrm{E}-01$ & 8.98E-05: & $2.76 \mathrm{E}-04:$ & $1.08 \mathrm{E}-04:$ & 1.06E-05: & 1.30E-06: & \\
\hline & & $3.60 \mathrm{E}+02$ & 11348 & 13745 & $1.34 \mathrm{E}-01$ & $1.88 \mathrm{E}-04$ & 4.72E-04 & $1.66 \mathrm{E}-04$ & $2.62 \mathrm{E}-05$ & $2.16 \mathrm{E}-06$ & \\
\hline & & $2.24 \mathrm{E}+02$ & 9488 & 9873 & $1.17 \mathrm{E}-01$ & $7.86 \mathrm{E}-05$ & $2.02 \mathrm{E}-04$ & $4.72 \mathrm{E}-05$ & $7.40 \mathrm{E}-06$ & $1.03 \mathrm{E}-06$ & \\
\hline \multirow[t]{3}{*}{$311.4+02.8$} & He 2-102 & $1.06 \mathrm{E}+03$ & & 10812 & $1.31 \mathrm{E}-01$ & 2.10E-05 & $3.52 \mathrm{E}-04$ & 8.33E-05 & 4.30E-06 & $2.02 \mathrm{E}-06$ & 6.10E-06 \\
\hline & & $1.29 \mathrm{E}+03$ & & 11135 & $1.37 \mathrm{E}-01$ & $2.50 \mathrm{E}-05$ & $4.08 \mathrm{E}-04$ & $9.62 \mathrm{E}-05$ & $5.01 \mathrm{E}-06$ & $2.27 \mathrm{E}-06$ & 7.52E-06 \\
\hline & & $8.21 \mathrm{E}+02$ & & 10507 & $1.24 \mathrm{E}-01$ & $1.90 \mathrm{E}-05$ & 3.01E-04 & 7.47E-05 & $3.80 \mathrm{E}-06$ & $1.82 \mathrm{E}-06$ & 4.88E-06 \\
\hline \multirow[t]{3}{*}{$312.6-01.8$} & He 2-107 & $2.49 \mathrm{E}+03$ & 7015 & & 1.42E-01: & $1.51 \mathrm{E}-04$ & 4.69E-04: & & 8.80E-06: & 5.06E-06: & \\
\hline & & $3.09 \mathrm{E}+03$ & 7371 & & $1.51 \mathrm{E}-01$ & $1.92 \mathrm{E}-04$ & 7.18E-04 & & $1.24 \mathrm{E}-05$ & $6.40 \mathrm{E}-06$ & \\
\hline & & $1.98 \mathrm{E}+03$ & 6396 & & $1.32 \mathrm{E}-01$ & $1.26 \mathrm{E}-04$ & $3.20 \mathrm{E}-04$ & & $6.37 \mathrm{E}-06$ & $4.12 \mathrm{E}-06$ & \\
\hline
\end{tabular}


Table B.3. continued.

\begin{tabular}{|c|c|c|c|c|c|c|c|c|c|c|c|}
\hline PN G & Main name & $n_{\mathrm{e}}(\mathrm{S}$ II $)$ & $T_{\mathrm{e}}(\mathrm{N}$ II $)$ & $T_{\mathrm{e}}(\mathrm{O}$ III $)$ & $\mathrm{He} / \mathrm{H}$ & $\mathrm{N} / \mathrm{H}$ & $\mathrm{O} / \mathrm{H}$ & $\mathrm{Ne} / \mathrm{H}$ & $\mathrm{S} / \mathrm{H}$ & $\mathrm{Ar} / \mathrm{H}$ & $\mathrm{Cl} / \mathrm{H}$ \\
\hline \multirow{3}{*}{$315.1-13.0$} & He 2-131 & & 8918 & 20404 & $3.20 \mathrm{E}-02:$ & $3.22 \mathrm{E}-05$ & $6.71 \mathrm{E}-05$ & & 1.64E-07: & 1.18E-07: & \\
\hline & & & 9197 & 24008 & $3.49 \mathrm{E}-02$ & 3.87E-05 & $8.08 \mathrm{E}-05$ & & $2.53 \mathrm{E}-07$ & $1.55 \mathrm{E}-07$ & \\
\hline & & & 8729 & 17216 & $2.86 \mathrm{E}-02$ & $2.57 \mathrm{E}-05$ & $5.22 \mathrm{E}-05$ & & $9.84 \mathrm{E}-08$ & $9.17 \mathrm{E}-08$ & \\
\hline \multirow[t]{3}{*}{$315.4+05.2$} & He 2-109 & $5.57 \mathrm{E}+02$ & 11001 & 10816 & $1.32 \mathrm{E}-01$ & $1.36 \mathrm{E}-04$ & $4.80 \mathrm{E}-04$ & $1.64 \mathrm{E}-04$ & $2.85 \mathrm{E}-06$ & $1.93 \mathrm{E}-06$ & \\
\hline & & $6.53 \mathrm{E}+02$ & 11237 & 11032 & $1.39 \mathrm{E}-01$ & $1.58 \mathrm{E}-04$ & $5.50 \mathrm{E}-04$ & $1.86 \mathrm{E}-04$ & $3.39 \mathrm{E}-06$ & $2.16 \mathrm{E}-06$ & \\
\hline & & $4.72 \mathrm{E}+02$ & 10605 & 10506 & $1.24 \mathrm{E}-01$ & $1.20 \mathrm{E}-04$ & 4.42E-04 & $1.48 \mathrm{E}-04$ & $2.27 \mathrm{E}-06$ & $1.71 \mathrm{E}-06$ & \\
\hline \multirow[t]{3}{*}{$316.1+08.4$} & He 2-108 & $8.71 \mathrm{E}+02$ & 8083 & 10396 & 1.26E-01: & $2.80 \mathrm{E}-05$ & $1.91 \mathrm{E}-04$ & 1.62E-05: & 1.67E-06: & 1.92E-06: & . \\
\hline & & $1.06 \mathrm{E}+03$ & 8463 & 11712 & $1.33 \mathrm{E}-01$ & $3.78 \mathrm{E}-05$ & $2.80 \mathrm{E}-04$ & $2.67 \mathrm{E}-05$ & $3.21 \mathrm{E}-06$ & $2.85 \mathrm{E}-06$ & $1.03 \mathrm{E}-06$ \\
\hline & & $7.45 \mathrm{E}+02$ & 7592 & 9057 & $1.17 \mathrm{E}-01$ & $2.19 \mathrm{E}-05$ & $1.39 \mathrm{E}-04$ & $1.00 \mathrm{E}-05$ & $1.06 \mathrm{E}-06$ & $1.36 \mathrm{E}-06$ & $1.89 \mathrm{E}-07$ \\
\hline \multirow[t]{3}{*}{$318.3-02.5$} & He 2-116 & $1.75 \mathrm{E}+02$ & 10299 & & $1.44 \mathrm{E}-01$ & $1.95 \mathrm{E}-04$ & $3.52 \mathrm{E}-04$ & $1.59 \mathrm{E}-04$ & $1.64 \mathrm{E}-05$ & $3.05 \mathrm{E}-06$ & \\
\hline & & $2.37 \mathrm{E}+02$ & 10641 & & $1.54 \mathrm{E}-01$ & 2.32E-04 & $4.27 \mathrm{E}-04$ & 2.31E-04 & $1.86 \mathrm{E}-05$ & $3.63 \mathrm{E}-06$ & \\
\hline & & $1.17 \mathrm{E}+02$ & 9872 & & $1.35 \mathrm{E}-01$ & $1.76 \mathrm{E}-04$ & $3.17 \mathrm{E}-04$ & $1.19 \mathrm{E}-04$ & $1.54 \mathrm{E}-05$ & $2.74 \mathrm{E}-06$ & \\
\hline \multirow[t]{3}{*}{$319.2+06.8$} & He 2-112 & $1.95 \mathrm{E}+03$ & 12685 & 14422 & $1.40 \mathrm{E}-01$ & 2.67E-04 & 2.93E-04 & $7.20 \mathrm{E}-05$ & 5.29E-06 & 1.74E-06 & $5.26 \mathrm{E}-07$ \\
\hline & & $2.41 \mathrm{E}+03$ & 13103 & 15135 & $1.47 \mathrm{E}-01$ & $3.16 \mathrm{E}-04$ & $3.24 \mathrm{E}-04$ & $7.66 \mathrm{E}-05$ & 5.98E-06 & $1.87 \mathrm{E}-06$ & $6.16 \mathrm{E}-07$ \\
\hline & & $1.60 \mathrm{E}+03$ & 12124 & 14126 & $1.31 \mathrm{E}-01$ & $2.21 \mathrm{E}-04$ & $2.54 \mathrm{E}-04$ & $5.94 \mathrm{E}-05$ & 4.40E-06 & $1.54 \mathrm{E}-06$ & $4.05 \mathrm{E}-07$ \\
\hline \multirow[t]{3}{*}{$320.9+02.0$} & He 2-117 & $6.84 \mathrm{E}+03:$ & 11101 & 8090 & $1.53 \mathrm{E}-01$ & 5.92E-04: & 6.02E-04: & 1.58E-04: & 2.42E-05: & $6.85 \mathrm{E}-06$ & 8.95E-06: \\
\hline & & $1.03 \mathrm{E}+04$ & 11727 & 8978 & 1.64E-01 & $9.02 \mathrm{E}-04$ & 9.99E-04 & $2.70 \mathrm{E}-04$ & 4.78E-05 & 9.91E-06 & $2.66 \mathrm{E}-05$ \\
\hline & & $4.74 \mathrm{E}+03$ & 10264 & 7080 & $1.42 \mathrm{E}-01$ & $3.69 \mathrm{E}-04$ & $3.96 \mathrm{E}-04$ & $8.86 \mathrm{E}-05$ & $1.20 \mathrm{E}-05$ & 4.96E-06 & 3.19E-06 \\
\hline \multirow[t]{3}{*}{$321.3+02.8$} & He $2-115$ & 1.43E+04: & 11453 & 8926 & 1.17 & $8.25 \mathrm{E}-05$ & 3.71E-04: & & 7.15E-06: & -06 & 4.43E-06: \\
\hline & & +04 & 12391 & 9618 & $1.24 \mathrm{E}-01$ & $1.20 \mathrm{E}-04$ & 8.64E-04 & 04 & $1.23 \mathrm{E}-05$ & 4.12E-06 & $1.01 \mathrm{E}-05$ \\
\hline & & $7.90 \mathrm{E}+03$ & 7178 & 7803 & $1.08 \mathrm{E}-01$ & 5.87E-05 & 2.63E-04 & 4.23E-05 & 4.44E-06 & $2.27 \mathrm{E}-06$ & $1.68 \mathrm{E}-06$ \\
\hline \multirow[t]{3}{*}{$321.8+01.9$} & He 2-120 & $2.91 \mathrm{E}+02$ & 9709 & & $1.47 \mathrm{E}-01$ & $2.88 \mathrm{E}-04$ & $4.54 \mathrm{E}-04$ & 1.51E-04: & $8.43 \mathrm{E}-06$ & $3.72 \mathrm{E}-06$ & \\
\hline & & $3.70 \mathrm{E}+02$ & 10064 & & $1.55 \mathrm{E}-01$ & $3.49 \mathrm{E}-04$ & $5.27 \mathrm{E}-04$ & $2.53 \mathrm{E}-04$ & $1.09 \mathrm{E}-05$ & 4.17E-06 & \\
\hline & & $2.20 \mathrm{E}+02$ & 9419 & & $1.39 \mathrm{E}-01$ & $2.17 \mathrm{E}-04$ & 3.81E-04 & $9.30 \mathrm{E}-05$ & $5.92 \mathrm{E}-06$ & $3.25 \mathrm{E}-06$ & \\
\hline \multirow[t]{3}{*}{$322.5-05.2$} & NGC 5979 & $5.09 \mathrm{E}+02:$ & (22456) & 14604 & $1.11 \mathrm{E}-01$ & $6.70 \mathrm{E}-05$ & $3.44 \mathrm{E}-04$ & $5.75 \mathrm{E}-05$ & 5.32E-06 & $2.27 \mathrm{E}-06$ & $9.30 \mathrm{E}-06$ \\
\hline & & $8.49 \mathrm{E}+02$ & (27308) & 15206 & 1.17E-01 & 7.62E-05 & 4.06E-04 & $6.59 \mathrm{E}-05$ & $5.92 \mathrm{E}-06$ & $2.48 \mathrm{E}-06$ & $1.13 \mathrm{E}-05$ \\
\hline & & $2.40 \mathrm{E}+02$ & ( 8121) & 14049 & $1.05 \mathrm{E}-01$ & $5.62 \mathrm{E}-05$ & 2.87E-04 & $5.13 \mathrm{E}-05$ & $4.62 \mathrm{E}-06$ & 2.03E-06 & 6.87E-06 \\
\hline \multirow[t]{3}{*}{$323.9+02.4$} & He $2-123$ & $2.11 \mathrm{E}+03$ & 7687 & & $1.64 \mathrm{E}-01$ & 2.44E-04 & 2.92E-04 & 05 & 7.67E-06 & 3.19E-06 & 1.33E-06: \\
\hline & & $2.51 \mathrm{E}+03$ & 7859 & & 1.74 & $2.83 \mathrm{E}-04$ & 3.31E-04 & & 8.75E-06 & 3.58 & $1.58 \mathrm{E}-06$ \\
\hline & & $1.75 \mathrm{E}+03$ & 7507 & & $1.55 \mathrm{E}-01$ & $2.22 \mathrm{E}-04$ & $2.57 \mathrm{E}-04$ & 4.16E-05 & $6.04 \mathrm{E}-06$ & $2.79 \mathrm{E}-06$ & $1.02 \mathrm{E}-06$ \\
\hline \multirow[t]{3}{*}{$324.2+02.5$} & He 2-125 & $3.83 \mathrm{E}+03:$ & 6158 & & 2.80E-02: & $2.38 \mathrm{E}-04$ & 5.37E-04: & & 1.34E-05: & 9.45E-07: & \\
\hline & & $5.83 \mathrm{E}+03$ & 6492 & & 3.03E-02 & $3.24 \mathrm{E}-04$ & $9.27 \mathrm{E}-04$ & & 2.09E-05 & $1.20 \mathrm{E}-06$ & \\
\hline & & $3.13 \mathrm{E}+03$ & 5763 & & $2.63 \mathrm{E}-02$ & $1.74 \mathrm{E}-04$ & 2.89E-04 & & 8.83E-06 & 7.39E-07 & \\
\hline \multirow[t]{3}{*}{$324.8-01.1$} & He 2-133 & 7.82E+03: & 14361 & 10072 & $1.40 \mathrm{E}-01$ & 4.88E-04: & 4.28E-04: & 1.65E-04: & 1.25E-05: & 3.39E-06 & 4.67E-06: \\
\hline & & $1.32 \mathrm{E}+04$ & 15328 & 11171 & 1.49E-01 & $7.56 \mathrm{E}-04$ & $6.82 \mathrm{E}-04$ & & $2.19 \mathrm{E}-05$ & 4.63E-06 & $1.07 \mathrm{E}-05$ \\
\hline & & $5.42 \mathrm{E}+03$ & 13180 & 8719 & $1.29 \mathrm{E}-01$ & $3.14 \mathrm{E}-04$ & $2.88 \mathrm{E}-04$ & $1.02 \mathrm{E}-04$ & 7.20E-06 & $2.57 \mathrm{E}-06$ & $1.61 \mathrm{E}-06$ \\
\hline \multirow[t]{3}{*}{$327.1-01.8$} & He 2-140 & $1.06 \mathrm{E}+04:$ & 8254 & & & $1.27 \mathrm{E}-04:$ & 2.86E-04: & & 8.14E-06: & 2.29E-06: & \\
\hline & & $3.07 \mathrm{E}+04$ & 8906 & & & $2.65 \mathrm{E}-04$ & $1.08 \mathrm{E}-03$ & & $2.54 \mathrm{E}-05$ & $3.92 \mathrm{E}-06$ & \\
\hline & & $6.60 \mathrm{E}+03$ & 7375 & & & $9.05 \mathrm{E}-05$ & $1.39 \mathrm{E}-04$ & & $4.28 \mathrm{E}-06$ & 1.74E-06 & \\
\hline \multirow[t]{3}{*}{$327.8-01.6$} & He 2-143 & $6.37 \mathrm{E}+02$ & 11164 & 12925 & $1.24 \mathrm{E}-01$ & $3.53 \mathrm{E}-04$ & $6.11 \mathrm{E}-04$ & $1.34 \mathrm{E}-04$ & $1.26 \mathrm{E}-05$ & $3.22 \mathrm{E}-06$ & $1.76 \mathrm{E}-06$ \\
\hline & & $7.70 \mathrm{E}+02$ & 11580 & 13468 & $1.30 \mathrm{E}-01$ & 4.10E-04 & $6.91 \mathrm{E}-04$ & $1.52 \mathrm{E}-04$ & $1.45 \mathrm{E}-05$ & $3.52 \mathrm{E}-06$ & $2.15 \mathrm{E}-06$ \\
\hline & & $5.43 \mathrm{E}+02$ & 10822 & 12544 & $1.17 \mathrm{E}-01$ & $2.83 \mathrm{E}-04$ & $5.28 \mathrm{E}-04$ & $1.18 \mathrm{E}-04$ & $1.03 \mathrm{E}-05$ & $2.87 \mathrm{E}-06$ & $1.28 \mathrm{E}-06$ \\
\hline \multirow[t]{3}{*}{$336.9+08.3$} & StWr 4-10 & & & 12825 & $1.00 \mathrm{E}-01$ & $1.52 \mathrm{E}-05$ & 1.37E-04 & 4.28E-05 & 2.17E-06 & 8.14E-07 & \\
\hline & & & & 13224 & $1.08 \mathrm{E}-01$ & $1.94 \mathrm{E}-05$ & $1.76 \mathrm{E}-04$ & $4.96 \mathrm{E}-05$ & 2.93E-06 & $1.04 \mathrm{E}-06$ & \\
\hline & & & & 11893 & $9.39 \mathrm{E}-02$ & $1.21 \mathrm{E}-05$ & $1.21 \mathrm{E}-04$ & $3.67 \mathrm{E}-05$ & $1.96 \mathrm{E}-06$ & $6.62 \mathrm{E}-07$ & \\
\hline \multirow[t]{3}{*}{$338.1-08.3$} & NGC 6326 & $8.09 \mathrm{E}+02$ & 10845 & 11766 & $1.16 \mathrm{E}-01$ & $9.76 \mathrm{E}-05$ & 4.11E-04 & $9.24 \mathrm{E}-05$ & $5.75 \mathrm{E}-06$ & $1.94 \mathrm{E}-06$ & $1.38 \mathrm{E}-06$ \\
\hline & & $9.61 \mathrm{E}+02$ & 11721 & 12174 & $1.22 \mathrm{E}-01$ & $1.24 \mathrm{E}-04$ & $4.82 \mathrm{E}-04$ & $1.07 \mathrm{E}-04$ & 7.05E-06 & $2.25 \mathrm{E}-06$ & $1.92 \mathrm{E}-06$ \\
\hline & & $6.84 \mathrm{E}+02$ & 9864 & 11392 & $1.11 \mathrm{E}-01$ & $6.99 \mathrm{E}-05$ & $3.66 \mathrm{E}-04$ & $8.18 \mathrm{E}-05$ & 4.53E-06 & $1.73 \mathrm{E}-06$ & 8.83E-07 \\
\hline
\end{tabular}




\section{Appendix C: Supplementary figures}
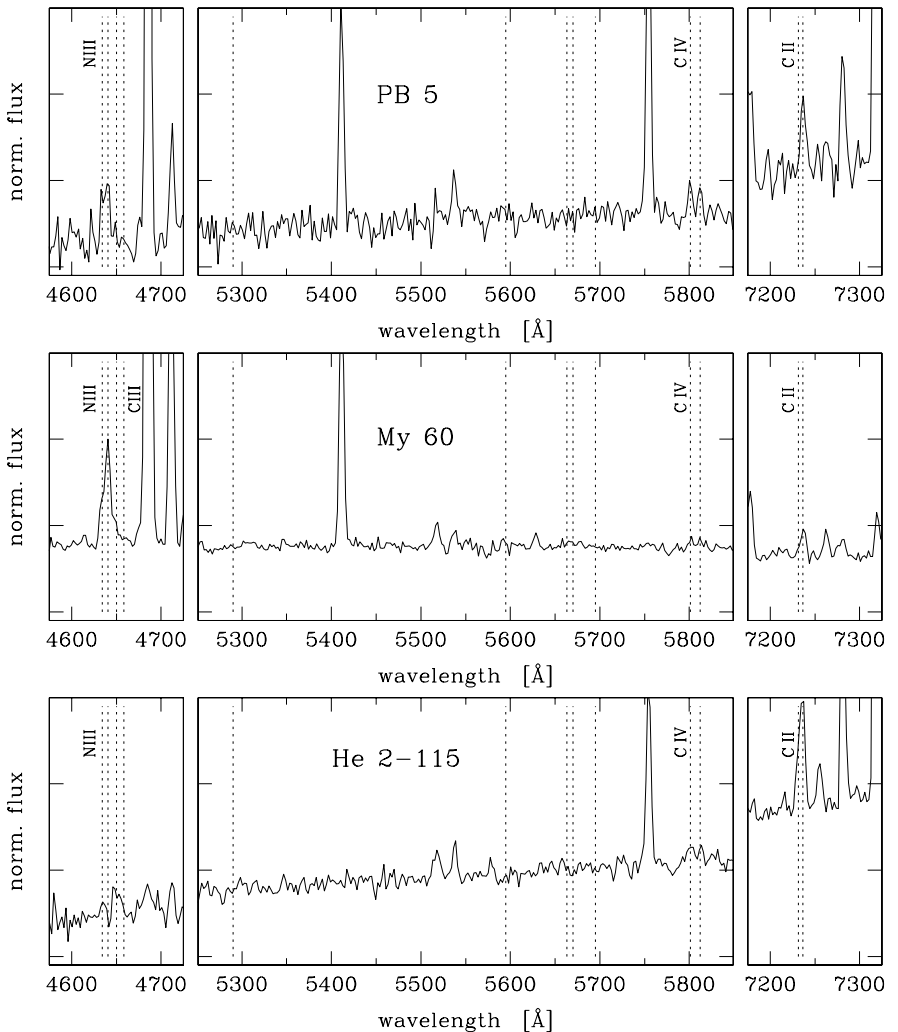

Fig. C.1. Spectra of the new PNe with WELs stars. Dotted lines mark possible locations of stellar emission-lines identified with the ion name if the line was detected.
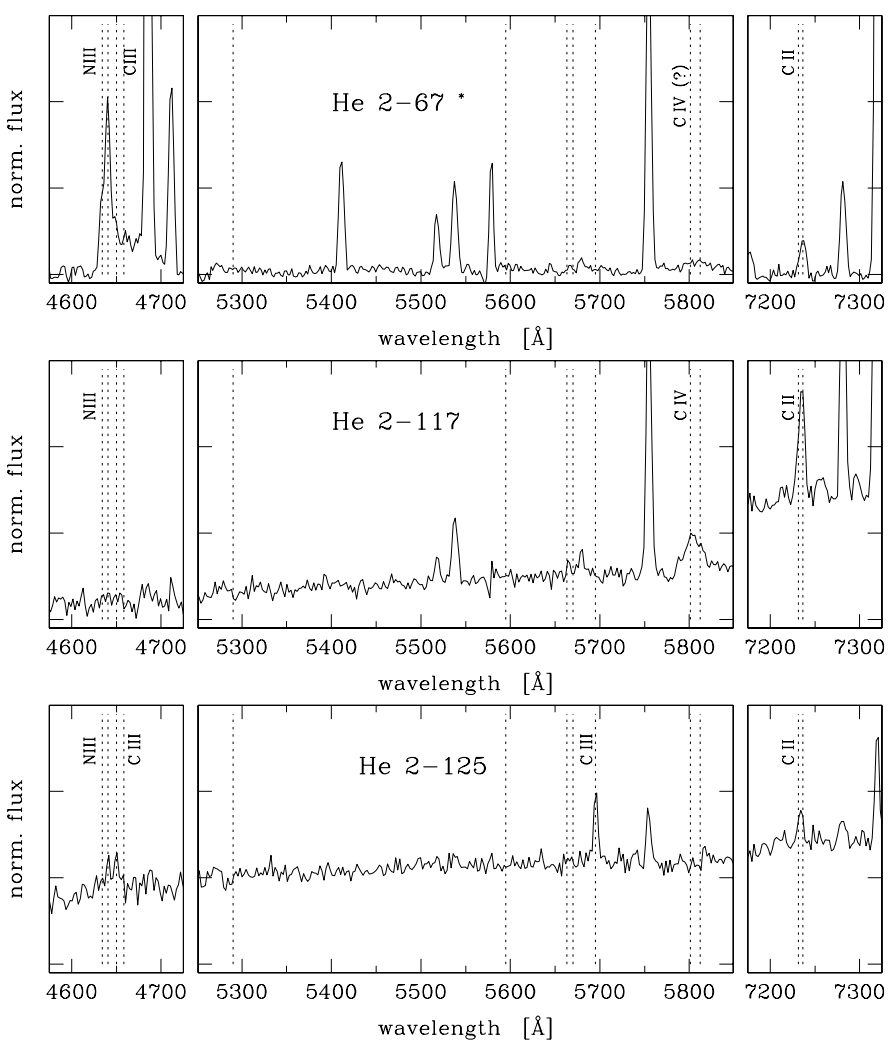

Fig. C.2. Spectra of the possible new PNe with Wolf-Rayet type central stars.
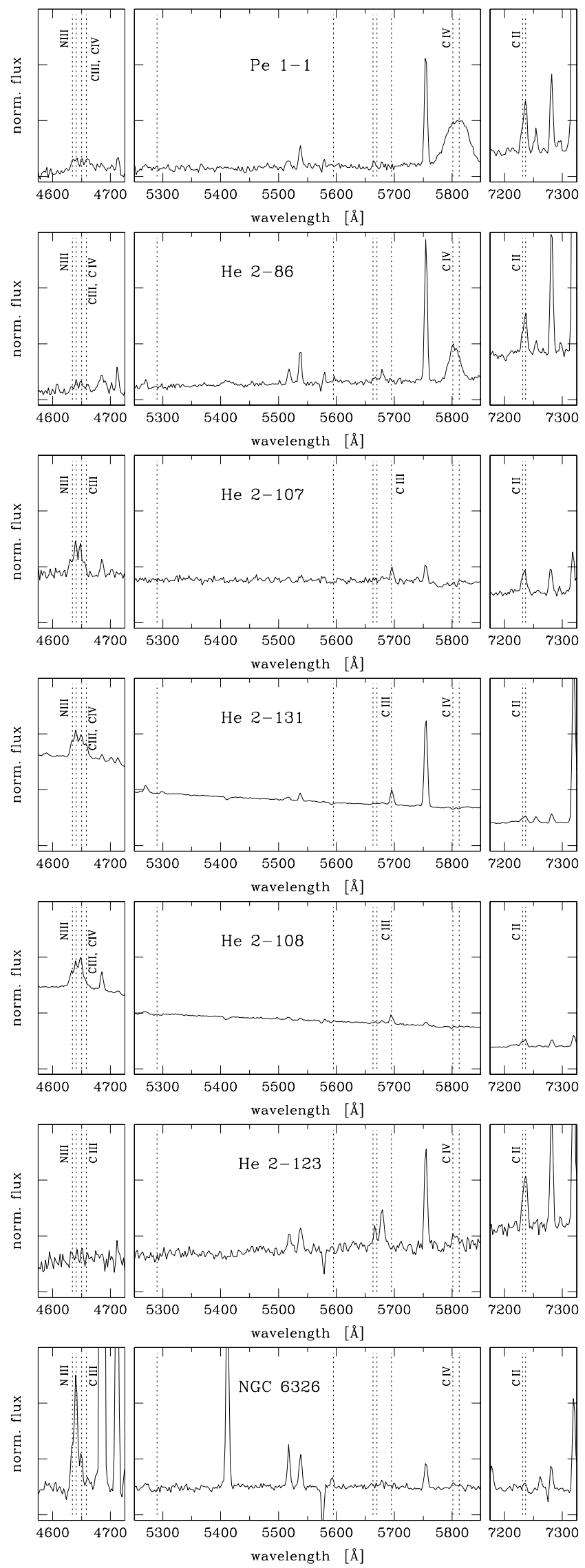

Fig. C.3. Spectra of the reobserved PNe with known and misclassified emission-line central stars. 
S. K. Górny: Spectroscopy of southern Galactic disk planetary nebulae

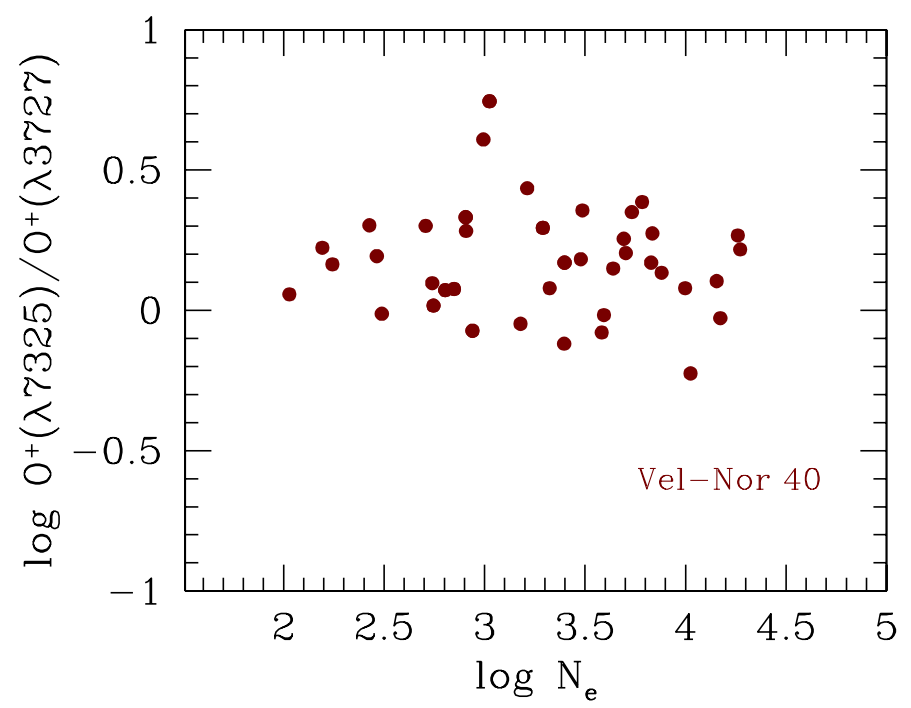

Fig. C.4. Ratio of $\mathrm{O}^{+}$ionic abundances derived from $\lambda 7325$ and $\lambda 3727$ lines as a function of electron density for observed PNe.

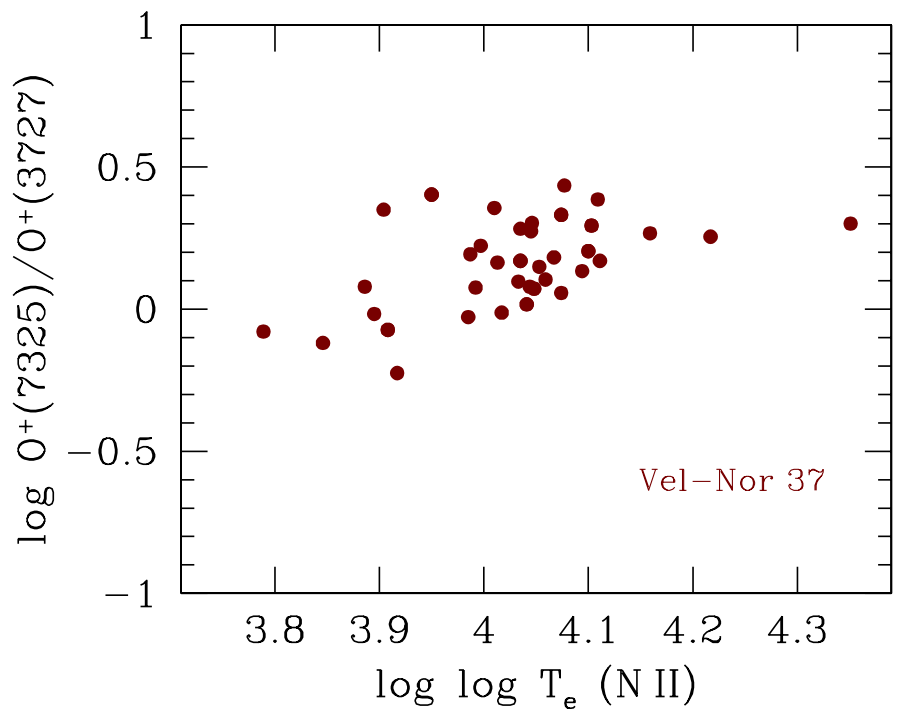

Fig. C.5. Ratio of $\mathrm{O}^{+}$ionic abundances derived from $\lambda 7325$ and $\lambda 3727$ lines as a function of electron temperature $T_{\mathrm{e}}(\mathrm{N}$ II) for observed $\mathrm{PNe}$. 